\title{
DIRECT SIMULATION MONTE CARLO FOR MODELING SPATIALLY HOMOGENEOUS MULTI-COMPONENT AEROSOLS
}

A Dissertation
presented to
the Faculty of the Graduate School
at the University of Missouri-Columbia
In Partial Fulfillment
of the Requirements for the Degree
Doctor of Philosophy in Nuclear Engineering
ISAAC SALDIVAR
Dr. Sudarshan K. Loyalka, Dissertation Supervisor

May 2018 
The undersigned, appointed by the dean of the Graduate School, have examined the dissertation entitled

\title{
DIRECT SIMULATION MONTE CARLO FOR MODELING SPATIALLY HOMOGENEOUS MULTI-COMPONENT AEROSOLS
}

\author{
presented by \\ Isaac Saldivar \\ A candidate for the degree of \\ Doctor OF PHILOSOPHY IN NUCLEAR ENGINEERING
}

and hereby certify that in their opinion it is worthy of acceptance.

Dr. Sudarshan K. Loyalka

Dr. Mark Prelas

Dr. Tushar Ghosh

Dr. Robert V. Tompson

Dr. Dabir S. Viswanath 


\section{ACKNOWLEDGEMENTS}

First and foremost, I would like to express my sincere gratitude to my advisor, Dr. Sudarshan K. Loyalka, for the continuous guidance, support, motivation, and patience throughout my doctoral research and dissertation writing process. I could not have imagined having a better advisor and mentor.

Besides my advisor, I would like to thank the rest of my thesis committee: Dr. Mark Prelas, Dr. Tushar Ghosh, Dr. Robert V. Tompson, and Dr. Dabir S. Viswanath, for taking the time to review my work and provide insightful comments.

I would also like to extend my deepest gratitude to the NSEI support staff, James Bennett and Latricia Vaughn, as well as my classmates for all your support in making my time at MU a success.

I would like to thank my family for their love and support. Particularly, my parents who taught me the importance of character, hard work, and education.

It is directly because of your selfless years of hard work and sacrifices that I had the opportunity to be where I am today.

I would also like to thank Marisol. You are my source of inspiration and the reason I strive to be a better version of myself every day.

Finally, I would like to thank the US Nuclear Regulatory Commission for providing the financial support for my work. 


\section{TABLE OF CONTENTS}

AKNOWLEDGEMENTS................................................................................ ii

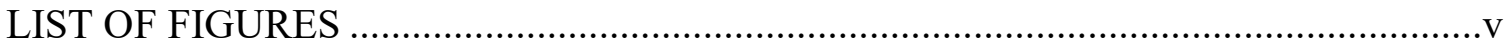

LIST OF TABLES ........................................................................................ viii

LIST OF RELEVANT ABBREVIATIONS.............................................................

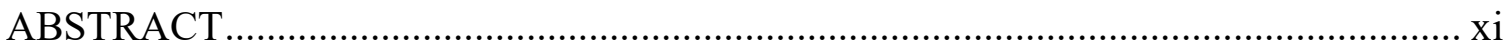

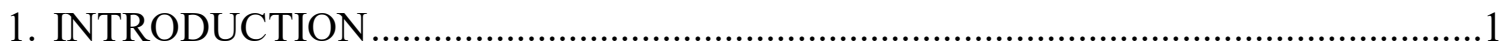

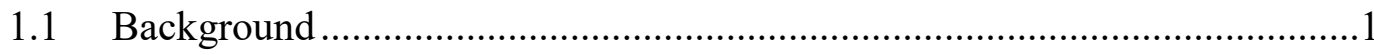

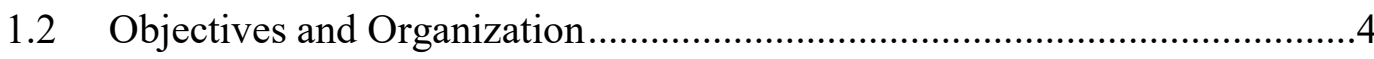

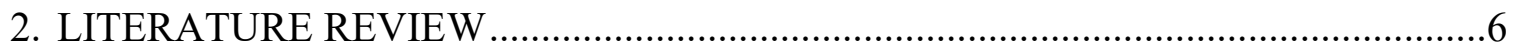

2.1 LACE Program Overview................................................................

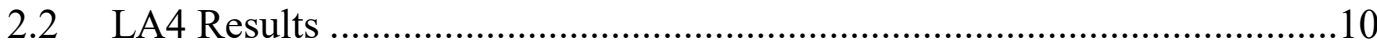

2.3 Simulation Efforts Post LA4 ............................................................ 16

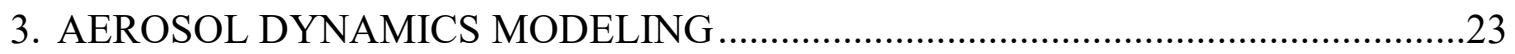

3.1 The General Dynamic Equation.......................................................23

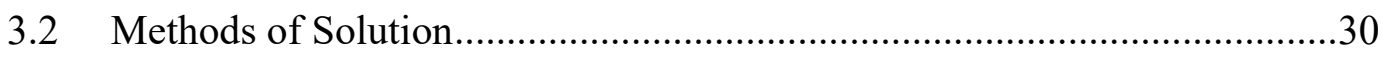

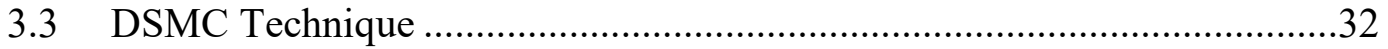

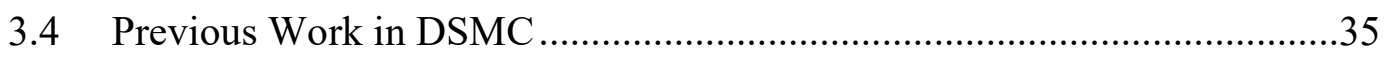

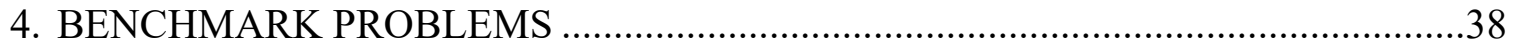

4.1 Benchmark 1: Single-Component Coagulation, Condensation, and

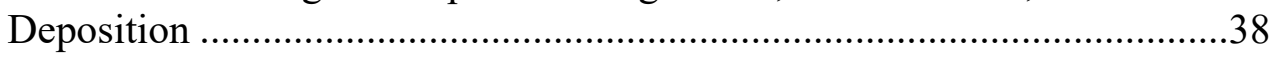

4.2 Benchmark 2: Two-Component Coagulation and Deposition....................47

4.3 Benchmark 3: Two-Component Coagulation and Condensation ................56 
5. CONDENSATION AND MODELS.

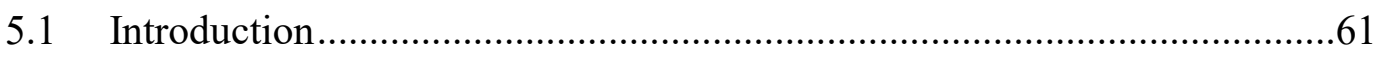

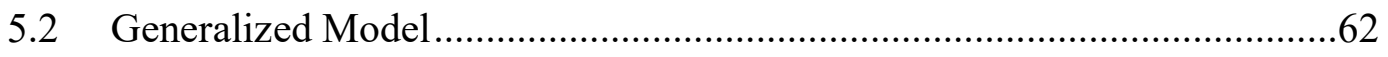

5.3 Role of Condensation in Aerosol Dynamics............................................68

6. PRE-LA4 TEST PROBLEMS AND DEVELOPMENT OF SIMULATION SCALING

6.1 Pre-LA4 Test Problems........................................................................... 75

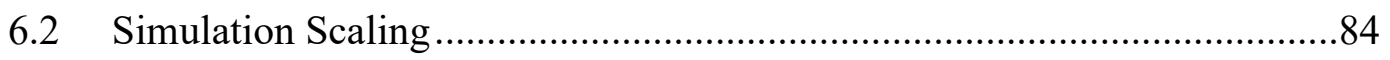

6.3 Coupled Problem with Condensation Benchmark ...................................93

6.4 Coupled Problem with Coagulation and Deposition ..............................102

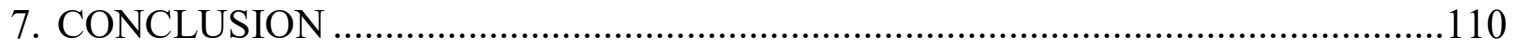

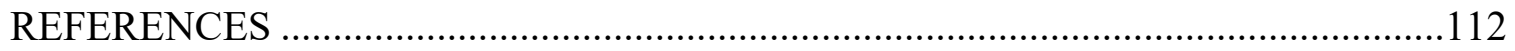

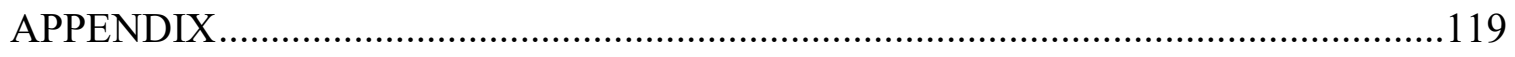

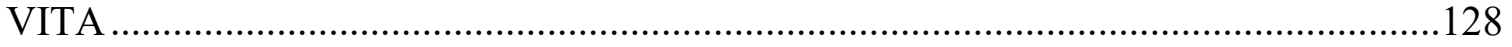




\section{LIST OF FIGURES}

Figure 1: LACE LA4 experimental setup ...............................................................

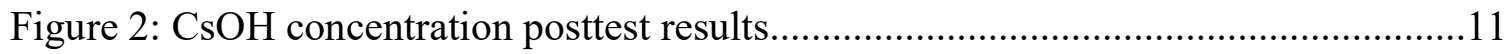

Figure 3: $\mathrm{MnO}$ concentration posttest results ....................................................... 12

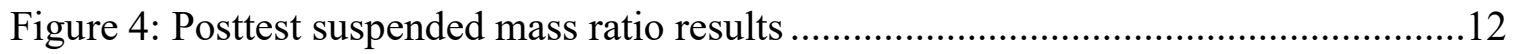

Figure 5: Posttest total aerosol concentration results..................................................13

Figure 6: MELCOR pressure results.................................................................... 18

Figure 7: MELCOR suspended masses .............................................................. 18

Figure 8: MELCOR individual results for suspended mass ......................................18

Figure 9: AEROSOLS-B2 suspended masses and shape factor dependence ..................20

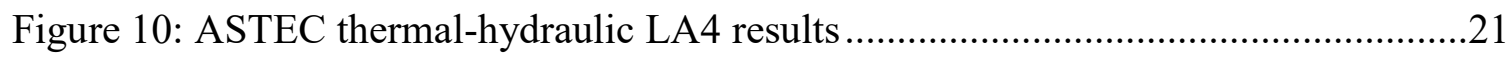

Figure 11: ASTEC results for suspended mass concentration.....................................22

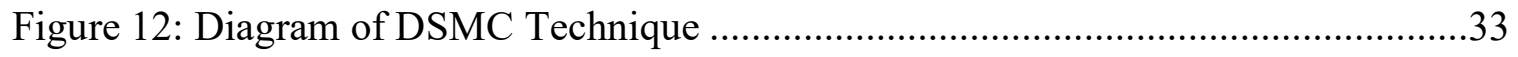

Figure 13: Number and mass distribution for $10^{4}$ single-component aerosols under constant coagulation, condensation, and deposition ............................................... 43

Figure 14: Number and mass distribution for $10^{5}$ single-component aerosols under

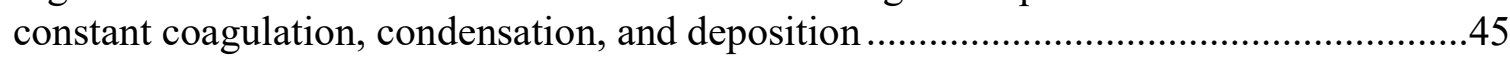

Figure 15: Number and mass distribution for $10^{4}$ two-component aerosols under constant

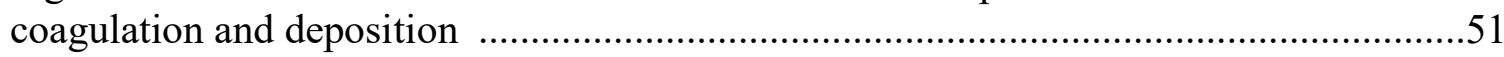

Figure 16: Number and mass distribution for $10^{5}$ two-component aerosols under constant

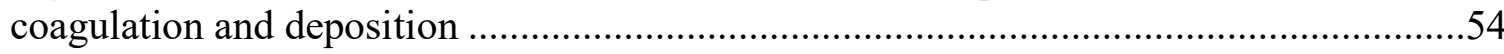

Figure 17: Number and mass distribution for $10^{5}$ two-component aerosols under constant

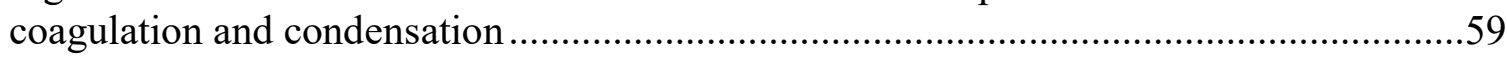

Figure 18: Dry and wet code comparison of DSMC Test Matrix Test Case 1 ................72

Figure 19: Dry and wet code comparison of DSMC Test Matrix Test Case 2 ................73

Figure 20: Dry and wet code comparison of DSMC Test Matrix Test Case 3 .................74 
Figure 21: Total number of suspended aerosol particles for TP1 .78

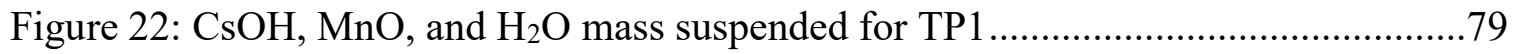

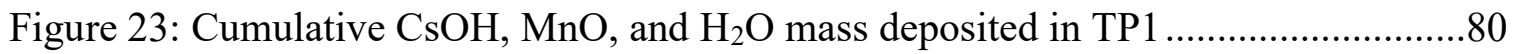

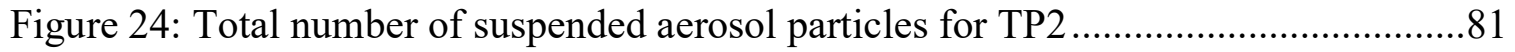

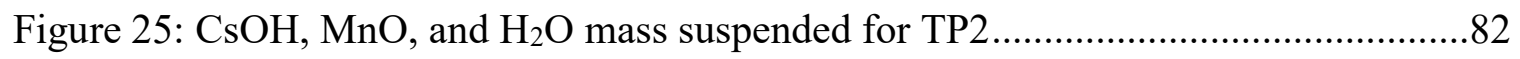

Figure 26: Cumulative $\mathrm{CsOH}, \mathrm{MnO}$, and $\mathrm{H}_{2} \mathrm{O}$ mass deposited in $\mathrm{TP} 2$.........................83

Figure 27: Number of aerosols suspended for the $10^{4}$ and $10^{5}$ initial particles under

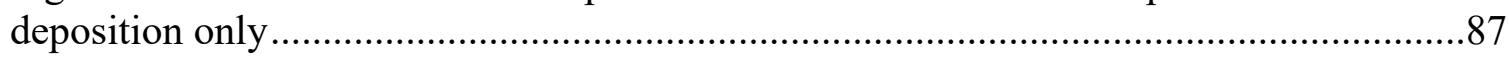

Figure 28: Results for $\mathrm{CsOH}$ mass suspended (top row) and cumulative $\mathrm{CsOH}$ mass deposited (bottom row) for the $10^{4}$ and $10^{5}$ initial particles under deposition only ......

Figure 29: Comparison of the $\mathrm{CsOH}$ mass suspended and mass deposited for the $10^{4}$, scaled $10^{4}$, and $10^{5}$ simulations .88

Figure 30: Number of aerosols suspended for the $10^{4}$ and $10^{5}$ initial particles under coagulation, condensation, and deposition

Figure 31: Mass suspended per component for $10^{4}$ and $10^{5}$ initial aerosols under coagulation, condensation, and deposition

Figure 32: Cumulative mass deposited per component for $10^{4}$ and $10^{5}$ initial aerosols under coagulation, condensation, and deposition

Figure 33: Comparison of suspended and cumulative deposited mass per component with scaling..... 92

Figure 34: Plots (a)-(e) compare the results for the exact and DSMC solutions for varying values of $\mathrm{S}$

Figure 35: Plots (a)-(e) show the exact and DSMC mass concentrations per bin for the various values for $\mathrm{S}$. The solid black, red, and blue lines represent the exact mass concentration when $\mathrm{t}=0 \mathrm{~s}, \mathrm{t}=20 \mathrm{~s}$, and $\mathrm{t}=100 \mathrm{~s}$, respectively. The dashed black, red, and blue lines represent the DSMC mass concentration for $t=0 \mathrm{~s}, t=20 \mathrm{~s}$, and $\mathrm{t}=100 \mathrm{~s}$, respectively 100

Figure 36: Plots (a)-(d) compare the exact and DSMC temperature curves using various values for $\mathrm{S}$. 
Figure 37: Plots (a)-(e) show the steam and aerosol concentrations for condensation, coagulation, and deposition using the DSMC technique for varying S ..........................106

Figure 38: Plots (a)-(e) show the mass concentration per diameter bin from the DSMC solution for coagulation, condensation, and deposition with varying $\mathrm{S}$. The dashed black, red, and blue lines represent the mass concentration per bin for times $t=0 \mathrm{~s}, \mathrm{t}=20 \mathrm{~s}$, and $\mathrm{t}=100 \mathrm{~s}$, respectively

Figure 39: Plots (a)-(e) show the temperature as a function of time from the DSMC solution for coagulation, condensation, and deposition processes with varying $\mathrm{S}$..........108

Figure 40: Sensitivity analysis for cumulative mass deposited for $\mathrm{S}=0$...................109

Figure 41: Sensitivity analysis for cumulative mass deposited for $S=10^{-3}$ 109 


\section{LIST OF TABLES}

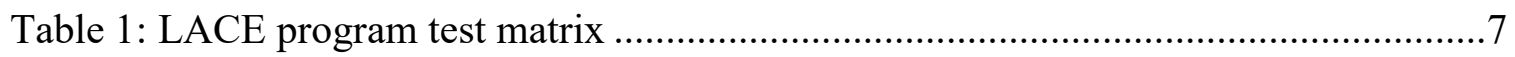

Table 2: Summary of the LACE LA4 experimental procedure ..........................................

Table 3: List of LACE program contributors, codes, and affiliations ................................

Table 4: Summary of problems in Palaniswaamy and Loyalka (2008).............................36

Table 5: Percent error in the DSMC technique for $10^{4}$ single-component aerosols under constant coagulation, condensation, and deposition .......................................................4

Table 6: Percent error in the DSMC technique for $10^{5}$ single-component aerosols under constant coagulation, condensation, and deposition .......................................................46

Table 7: Percent error in the DSMC technique for $10^{4}$ two-component aerosols under constant coagulation and deposition ............................................................................52

Table 8: Percent error in suspended mass for component 1 ..........................................52

Table 9: Percent error in suspended mass for component 2 .............................................53

Table 10: Percent error in the DSMC technique for $10^{5}$ two-component aerosols under

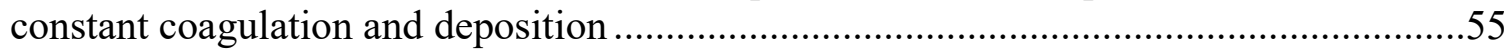

Table 11: Percent error in suspended mass for component 1 ..........................................55

Table 12: Percent error in suspended mass for component 2 ............................................56

Table 13: Percent error in the DSMC technique for $10^{5}$ two-component aerosols under constant coagulation and condensation.......................................................................6

Table 14: Percent error in suspended mass for component 1 ..........................................60

Table 15: Percent error in suspended mass for component 2 ………..............................60

Table 16: DSMC test matrix …………………………............................................69

Table 17: Summary of "dry" test case procedure …………..........................................

Table 18: Summary of "wet" test case procedure..........................................................72

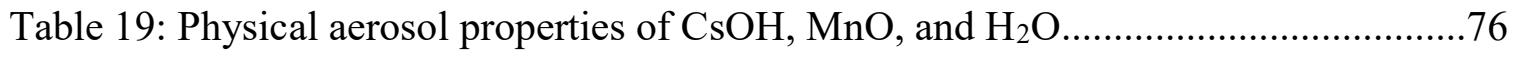

Table 20: Summary of TP1 simulation procedure .........................................................77 
Table 21: Associated errors in the DSMC solution for varying S and time .101

Table 22: Average particle diameters as a function of time for varying values of S......109 


\section{LIST OF RELEVANT ABBREVIATIONS}

$\begin{array}{ll}\text { AMMD } & \text { Aerodynamic Mass Median Diameter } \\ \text { BWR } & \text { Boiling Water Reactor } \\ \text { CsOH } & \text { Cesium Hydroxide } \\ \text { CSTF } & \text { Containment Systems Test Facility } \\ \text { DEMONA } & \text { Demonstration of Nuclear Aerosol Behavior } \\ \text { DSMC } & \text { Direct Simulation Monte Carlo } \\ \text { GDE } & \text { General Dynamic Equation } \\ \text { GSD } & \text { Geometric Standard Deviation } \\ \text { HEDL } & \text { Hanford Engineering Development Laboratory } \\ \text { HTGR } & \text { High Temperature Gas-cooled Reactor } \\ \text { LACE } & \text { LWR Aerosol Containment Experiment } \\ \text { LWR } & \text { Light Water Reactor } \\ \text { MAEROS } & \text { Multi-Component Aerosol Module for Contain } \\ \text { MMD } & \text { Mass Median Diameter } \\ \text { MnO } & \text { Manganese Oxide } \\ \text { NGNP } & \text { Next Generation Nuclear Plant } \\ \text { NRC } & \text { U.S. Nuclear Regulatory Commission } \\ \text { NTC } & \text { No Time Counter } \\ \text { PBR } & \text { Pebble-Bed Reactor } \\ \text { PWR } & \text { Pressurized Water Reactor } \\ \text { THAI } & \text { Thermal-hydraulics, Hydrogen, Aerosols, and Iodine } \\ \text { TRISO } & \text { Tristructural-Isotropic } \\ \text { VHTR } & \text { Very High Temperature Reactor } \\ & \end{array}$




\begin{abstract}
Nuclear aerosols generated under normal operational and post-accident reactor environments are of particular importance in estimation of the nuclear source term. Several light water reactor aerosol containment experiments provided an experimental database for verification and validation of thermal-hydraulic and aerosol transport codes. The Direct Simulation Monte Carlo (DSMC) technique has been shown to model multicomponent aerosol dynamics accurately while maintaining greater fidelity to actual aerosol physics than its sectional, moments, and finite element predecessors. This research focuses on the development of a comprehensive $n$-component source term code for modeling the behavior of aerosolized fission products based on the DSMC technique. Effective DSMC benchmarks provided further confidence in the technique's capabilities for modeling exceedingly complex systems. With the inclusion of the Knudsen, Kelvin, and solute effects in the Mason model, the role of condensation on aerosol evolution showed the differentiation of particles by physical size and chemical properties. High fidelity large-scale simulations posed evident but considerable challenges to computational runtime. Developments in the simulation scaling theory for coagulation, condensation, deposition, and generation processes showed to give comparable results while simultaneously reducing simulation time significantly. The evolution of aerosols coupled to environments was explored, and benchmark simulations provided further evidence that DSMC accurately models aerosol dynamics when coupled with containment thermal-hydraulics.
\end{abstract}




\section{INTRODUCTION}

\subsection{Background}

Sources of potential nuclear aerosols include, but are not limited to, today's commercial Generation III+ Pressurized Water Reactors (PWRs) and Boiling Water Reactors (BWRs). Very High Temperature Reactors (VHTRs) like the Pebble-Bed Reactor (PBR), for example, are High Temperature Gas-cooled Reactors (HTGRs) which generate graphite dust in normal reactor operation from the pebble-to-pebble interactions of the Tristructural-Isotropic (TRISO) fuel kernels. Graphite dust particles are free to deposit throughout the reactor's primary system, but can be radioactive through the sorption of fission products created under normal reactor operation. ${ }^{1,2}$ In a broad sense, the nuclear source term refers to the availability for release of the gaseous radioactive products (originating from graphite dust and fission products) to the environment from a severe reactor accident. The characterization of the release (i.e., the amount and rate of release, radioisotopes released, etc.) will heavily influence dispersion calculations of the radioactivity released. ${ }^{3}$ Models of aerosol behavior and transport are of particular importance in the nuclear industry for simulating and mitigating nuclear accident scenarios where fission products may become aerosolized by the high temperature and pressure environment of a molten reactor core and subsequently leaked to the

\footnotetext{
${ }^{1}$ M. M. Stempniewics, L. Winters, and S. A. Caspersson, “Analysis of Dust and Fission Products in a Pebble Bed NGNP," Nuclear Engineering and Design 251 (October 2012): 433.

${ }^{2}$ Paul W. Humrickhouse, HTGR Dust Safety Issues and Needs for Research and Development, Report\#INL/EXT-11-21097. (Idaho Falls, ID: Idaho National Laboratory, 2011).

${ }^{3}$ M. M. R. Williams and Sudarshan K. Loyalka, Aerosol Science: Theory and Practice: With Special Applications to the Nuclear Industry. (New York: Pergamon Press, 1991).
} 
environment. ${ }^{4,5,6,7}$ For example, the same year that the Shippingport Atomic Power Station (the world's first commercial power plant) went critical in 1957, the WASH-740 report shed light on the effects of a major nuclear accident by mathematically modeling the risk, consequence, and remediation to the general public and the environment. In the following years, source term calculations such as the TID-14844 (1962) and WASH-1400 (1975) reports created the criteria for licensing under the U.S. Nuclear Regulatory Commission (NRC) of most nuclear power plants operational today and estimated the frequency and consequences of nuclear accidents, but not without criticism. ${ }^{8,9}$

Knowledge of aerosol processes and accurate time-dependent predictions of aerosol transport may bound the source term empirically and help facilitate measures for mitigating such accidents. For this reason, computer codes are utilized to simulate the natural transport and processes as well as the role of water filters, pools, containments, etc. in aerosol dynamics (i.e., coagulation, condensation, deposition, fragmentation, chemical reactions, etc.) as a means to verify and validate these codes against experiments. Developed codes may help assess aerosol dispersion from severe accidents

\footnotetext{
${ }^{4}$ B. R. Bowsher and A. L. Nichols, "The Formation of Heterogeneous Aerosols in Severe Reactor Accidents," in Nuclear Science and Technology Proceedings Of CSNI-OECD Workshop on Water-Cooled Reactor Aerosol Code Evaluation and Uncertainty Assessment From 9 to 11 September 1987, EUR 11351 EN, ed. E. della Loggia and J. Royen (Luxemburg: Commission of the European Communities, 1988 ), 170.

5 US Atomic Energy Commission, "Summary Report of the Reactor Safeguard Committee," Report \# WASH-3. (1950).

${ }^{6}$ US Atomic Energy Commission, "Theoretical Possibilities and Consequences of Major Accidents in Large Nuclear Power Plants,” Report\# WASH-740. (1957).

${ }^{7}$ P. Fynbo, Hans Häggblom, and J. Jokiniemi, Aerosol Transport in Severe Reactor Accidents: Final Report of the NKA Project AKTI-160 (Copenhagen: Nordic Liaison Committee for Atomic Energy, 1990).

${ }^{8}$ US Atomic Energy Commission, "Calculation of Distance Factors for Power and Test Reactor Sites," Report\# TID-14844. (1962).

${ }^{9}$ US Nuclear Regulatory Commission, "Reactor Safety Study: An Assessment of Accident Risks in US Commercial Nuclear Power Plants," Report\# WASH-1400, NUREG-75/-014. (1975).
} 
from today's Light Water Reactors (LWRs) as well as that from Next Generation Nuclear Plants (NGNP).

Production codes like AEROSIM, CONTAIN, NAUA, MAAP-3, and

REMOVAL model aerosol transport based on numerical methods such as the sectional and moments techniques. However, these codes are highly limited in the presence of high coagulation and condensation, require unsubstantiated assumptions on aerosol processes, and not all account for aerosol growth by steam condensation, leading to specious results. ${ }^{10,11}$

The motivation behind this work is to explore simulation of transport and evolution of multi-component aerosols accurately by using realistic models for the coagulation, condensation, deposition, and aerosol generation which maintain greater fidelity to actual aerosol physics.

Aerosols are subject to coagulation, fragmentation, condensation, evaporation, deposition, resuspension, and generation. Physical and chemical properties inherent to the aerosol species may also play a role in evolution due to size, shape, charge, and hygroscopic effects. Except for in a few special cases, analytical solutions of the timedependent multi-component aerosols under realistic aerosol processes do not exist due to the highly complex, non-linear nature of aerosol dynamics. On the other hand, numerical techniques are not limited by complex, non-linear mathematics. For this reason, production codes typically only utilize numerical techniques.

${ }^{10}$ Williams and Loyalka, Aerosol Science: Theory and Practice: With Special Applications to the Nuclear Industry, 300.

${ }^{11}$ J. H. Wilson and P. C. Arwood, "Comparison of (Posttest) Predictions of Aerosol Codes with Measurements in LWR Aerosol Containment Experiment (LACE) LA4," Report\# LACE TR-084, ORNL/M-991. (Oak Ridge, TN: Oak Ridge National Laboratory, 1990). 


\subsection{Objectives and Organization}

The objectives of this work are:

- Extend on the previous work in aerosol dynamics through the development of a computational aerosol transport and evolution code based on the Direct Simulation Monte Carlo (DSMC) technique. This code will be generalized for an $n$-component aerosol under any combination of the coagulation, condensation, deposition, and source term reinforcement aerosol processes.

- Demonstrate the efficacy of the DSMC technique by benchmarking the DSMC code against special cases where exact analytical solutions of the timedependent aerosol distribution exist.

- Review and expand upon the previous works on the condensation process, specifically with the aim of generalizing Mason's model for condensation to include the Kelvin, Knudsen, and solute effects.

- Use the generalized Mason model (with Kelvin, Knudsen, and solute effects) to investigate the role of steam condensation for single and multi-component aerosols with hygroscopic and non-hygroscopic properties.

- Simulate a set of test problems in which realistic coagulation, condensation, deposition, and source term reinforcement aerosol processes all play a role in aerosol evolution.

- Develop the simulation scaling theory for the DSMC technique through similar test problems of dissimilar size.

- Explore coupling of aerosol transport and thermal-hydraulics.

- Attempt to model the LACE-4 experiment using the DSMC technique. 
This work is organized as follows; Chapter 2 gives a brief overview of the LACE4 experiment as well as a synopsis of the simulation efforts of the LACE-4 experiment and the lessons learned. Chapter 3 discusses aerosol dynamics modeling and gives a short introduction to the Direct Simulation Monte Carlo (DSMC) technique. Next, Chapter 4 compares the numerical solutions from the DSMC technique with exact solutions for three benchmark problems where analytical solutions exist. Chapter 5 is a discussion about the efficacy of aerosol condensation, the derivation of a new comprehensive model for aerosol growth by condensation, and the overall role of condensation in aerosol dynamics for single and multi-component hygroscopic and nonhygroscopic aerosols. Chapter 6 simulates the evolution of mixed aerosols using realistic aerosol physics models, resolves issues with simulation scaling and applies the scaling theory to a series of test problems, and delves into aerosol evolution coupled to thermalhydraulics. Chapter 7 summarizes the results obtained and draws conclusions from the study. 


\section{LITERATURE REVIEW}

\subsection{LACE Program Overview}

The LWR Aerosol Containment Experiments (LACE) were a series of experiments conducted in 1986 at the Westinghouse Hanford Engineering Development Laboratory (HEDL) to assess the consequences of postulated nuclear power plant accident scenarios and provide a comprehensive database for verifying and validating the nuclear industry's thermal-hydraulic and aerosol transport simulation software. ${ }^{12}$ The LACE Program test matrix is provided in Table 1. The LACE-4 (LA4) experiment, in particular, simulated a late containment failure in the Containment Systems Test Facility (CSTF) vessel using a two-component aerosol species with separate and overlapping aerosol injection periods. The CSTF is a vertical cylindrical steel vessel with a cylinder height of $26.5 \mathrm{~m}$, an overall height of $20.3 \mathrm{~m}$, a $7.62 \mathrm{~m}$ diameter, and an inner free

volume of $852 m^{3} .^{13}$

${ }^{12}$ Frank Rahn, "The LWR Aerosol Containment Experiments (LACE) Project Summary Report," Report\# LACE TR-012, NP-6094-D. (Palo Alto, CA: Electric Power Research Institute, 1988).

${ }^{13}$ I. Kljenak and B. Mavko, "Simulation of LACE LA4 Experiment on Aerosol Behavior in a Nuclear Power Plant Containment with the ASTEC CPA V1.2 Code," Report\# IJS-DP-9291. (Ljubljana, Slovenia: Jozef Stefan Institute, 2006b). 
Table 1: LACE program test matrix

\begin{tabular}{|c|l|}
\hline Test Number & \multicolumn{1}{|c|}{ Simulated Accident Situation } \\
\hline LA1 & Containment bypass (piping and auxiliary building) \\
\hline LA2 & Failure to isolate containment building \\
\hline LA3 & Containment bypass (pipe flow only) \\
\hline LA4 & Late containment failure with overlapping aerosol injection periods \\
\hline LA5 & Rapid depressurization with spiked pool \\
\hline LA6 & Rapid depressurization with aerosol injection \\
\hline
\end{tabular}

For the LA4 experiment, the two aerosols injected into the CSTF were cesium hydroxide $(\mathrm{CsOH})$, a hygroscopic aerosol used to simulate volatile fission products, and manganese (II) oxide (MnO), a non-hygroscopic aerosol simulating semi-volatile fission products and structural compounds. ${ }^{14}$ The $\mathrm{CsOH}$ and $\mathrm{MnO}$ aerosols were generated independently of one another through the chemical reactions of cesium and manganese vapors with that of superheated steam in a nitrogen carrier gas. ${ }^{15}$ These aerosols were then fed directly into the CSTF through a delivery pipe. The experimental schematic of the CSTF and the LA4 experimental procedure may be seen in Figure 1 and Table 2, respectively.

${ }^{14}$ Williams and Loyalka, Aerosol Science: Theory and Practice: With Special Applications to the Nuclear Industry, 397. Accidents."

${ }^{15}$ Bowsher and Nichols, "The Formation of Heterogeneous Aerosols in Severe Reactor 


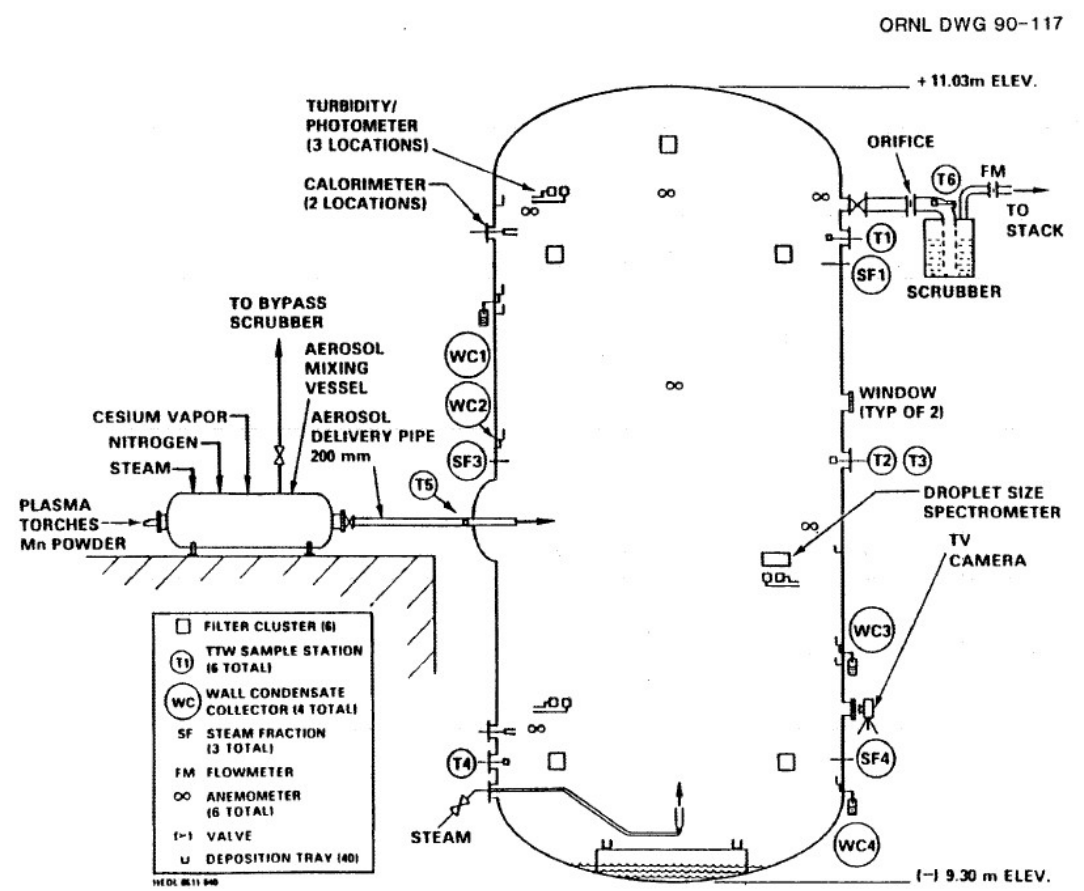

Figure 1: LACE LA4 experimental setup

Table 2: Summary of the LACE LA4 experimental procedure

\begin{tabular}{|c|l|}
\hline Time $(\mathrm{min})$ & \multicolumn{1}{|c|}{ Action } \\
\hline$-50-0$ & Steam injection at high rate with no aerosol \\
\hline $0-30.5$ & CsOH injection and separate steam injection at low rate \\
\hline $30.5-50.5$ & Injection of $\mathrm{CsOH}, \mathrm{MnO}$, and steam \\
\hline $50.5-80.2$ & Injection of $\mathrm{MnO}$ and steam \\
\hline $80.2-280$ & Steam injection only \\
\hline $280-600$ & Vent through scrubber steam at low rate and close valve at minute 440 \\
\hline $600-5700$ & No injection \\
\hline
\end{tabular}

Various international nuclear organizations used the LACE experiments as means to validate and verify their thermal-hydraulic and aerosol simulation codes. ${ }^{16,17}$ The

${ }^{16}$ Kljenak and Mavko, "Simulation of LACE LA4 Experiment on Aerosol Behavior in a Nuclear Power Plant Containment with the ASTEC CPA V1.2 Code."

${ }^{17}$ G. R. Bloom et al., "LWR Aerosol Containment Experiments (LACE) Program," in Proceedings of an International Symposium on Source Term Evaluation for Accident Conditions Held in Columbus, Ohio October 28 - November 1, 1985 (Vienna, Austria: International Atomic Energy Agency, 1986), 321. 
organizations and their aerosol codes used to model the thermal-hydraulics and timedependent aerosol distribution of the LA4 experiment are summarized in Table 3.

Table 3: List of LACE program contributors, codes, and affiliations

\begin{tabular}{|c|c|c|}
\hline Code (Country or Institute) & Code Analyst(s) & Affiliation \\
\hline AEROSIM-M (UK) & $\begin{array}{l}\text { S.A. Ramsdale } \\
\text { I.H. Dunbar }\end{array}$ & $\begin{array}{c}\text { United Kingdom, Safety and } \\
\text { Reliability Directorate }\end{array}$ \\
\hline CONTAIN (ORNL) & M.L. Tobias & $\begin{array}{l}\text { United States, Oak Ridge } \\
\text { National Laboratory }\end{array}$ \\
\hline CONTAIN (SANDIA) & K.D. Bergeron & $\begin{array}{l}\text { United States, Sandia } \\
\text { National Laboratory }\end{array}$ \\
\hline CONTAIN (UK) & $\begin{array}{l}\text { P.N. Smith } \\
\text { G.J. Roberts }\end{array}$ & $\begin{array}{l}\text { United Kingdom, Atomic } \\
\text { Energy Authority }\end{array}$ \\
\hline MAAP-3 (SW) & H. Häggblom & $\begin{array}{l}\text { Sweden, Studsvik } \\
\text { Energiteknik AB }\end{array}$ \\
\hline MCT-2 (US) & P. Bieniarz & $\begin{array}{c}\text { United States, Risk } \\
\text { Management Associates }\end{array}$ \\
\hline NAUA-HYGROS (FN) & J. Jokiniemi & $\begin{array}{l}\text { Finland, Technical } \\
\text { Research Centre }\end{array}$ \\
\hline NAUA (EPRI) & R. Sher & $\begin{array}{c}\text { United States, Electric } \\
\text { Power Research Institute }\end{array}$ \\
\hline NAUA-5 (ENEL) & M. Valisi & Italy, ENEL-CRTN \\
\hline NAUA-5 (Univ. Rome, IT) & $\begin{array}{l}\text { L. Ferroni } \\
\text { L. Sorabella } \\
\text { F. Pagno } \\
\end{array}$ & $\begin{array}{c}\text { Italy, } \\
\text { Energetics Department, } \\
\text { University of Rome } \\
\end{array}$ \\
\hline REMOVAL/2G (JN) & K. Muramatsu & $\begin{array}{l}\text { Japan, Atomic Energy } \\
\text { Research Institute }\end{array}$ \\
\hline SWNAUA (US) & $\begin{array}{l}\text { A. Drozd } \\
\text { J. Baron }\end{array}$ & $\begin{array}{l}\text { United States, } \\
\text { Stone and Webter }\end{array}$ \\
\hline
\end{tabular}

The codes listed in Table 3 were classified as "dry" and "wet" codes. "Dry" codes designated codes which did not model steam condensation onto the aerosol particles whereas "wet" codes allowed for steam to condense onto the surface of the aerosol particles. In addition, "single-component" codes assumed that the composition of the particle is independent of particle size; whereas "multi-component" codes calculated particle compositions that varied with particle size. "Multi-component" codes used for the LA4 experiment include: AEROSIM-M (UK), CONTAIN (ORNL), CONTAIN (SANDIA), CONTAIN (UK), REMOVAL/2G (JN), and SWNAUA (US). The 
numerical scheme of these codes, however, were based on the sectional and moments techniques which were highly limited in the presence of high coagulation and condensation, made unfounded assumptions, and a number of them did not account for aerosol growth by steam condensation, leading to specious, faulty results. ${ }^{18,19}$

\subsection{LA4 Results}

The original LA4 results are shown in Figure 2 through Figure 5. Figure 2 shows the experimentally measured suspended $\mathrm{CsOH}$ concentration in the CSTF vessel compared with the simulation results of the aerosol codes. In Figure 3 we can see that the aerosol code predictions and experimental data for suspended $\mathrm{MnO}$ inside the CSTF vessel. Figure 4 shows the predicted and experimental results of the suspended mass ratio of $\mathrm{MnO}$ to $\mathrm{CsOH}$. Finally, Figure 5 shows the actual and predicted total suspended aerosol concentration.

${ }^{18}$ Williams and Loyalka, Aerosol Science: Theory and Practice: With Special Applications to the Nuclear Industry, 382-385.

${ }^{19}$ Wilson and Arwood, "Comparison of (Posttest) Predictions of Aerosol Codes with Measurements in LWR Aerosol Containment Experiment (LACE) LA4," 114. 

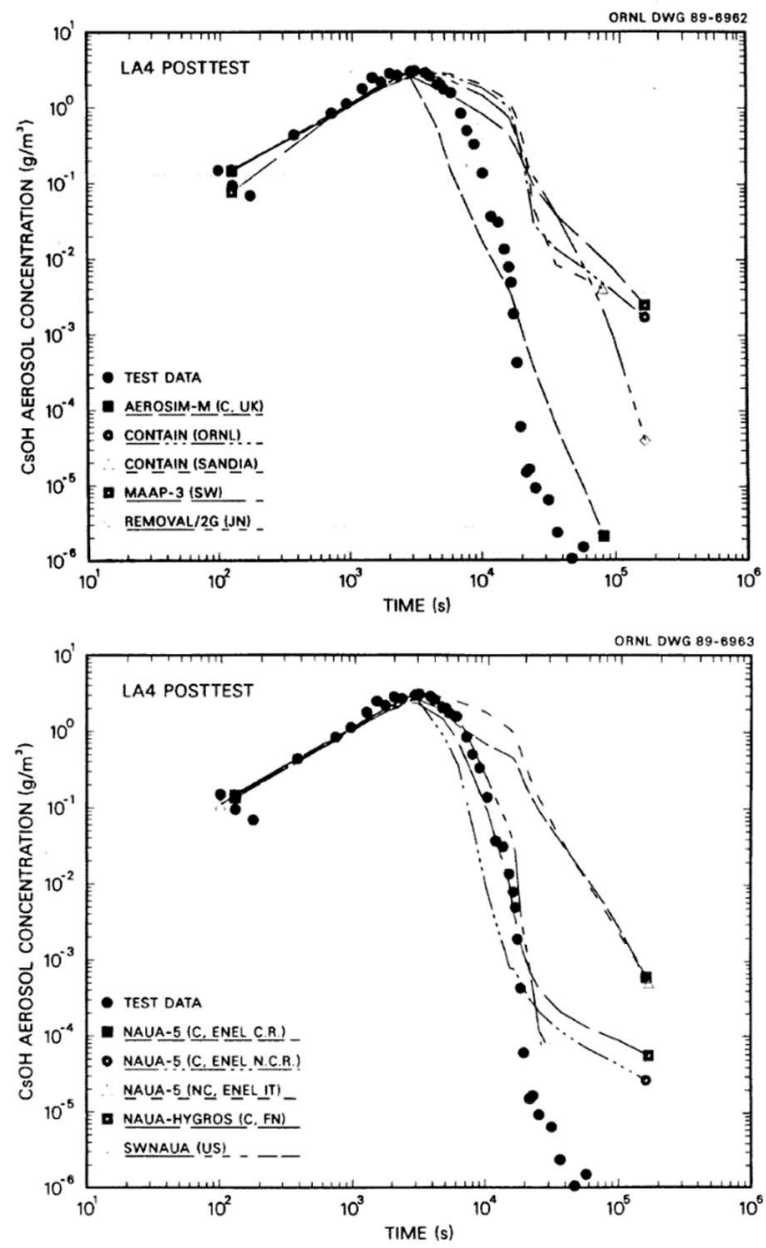

Figure 2: CsOH concentration posttest results 

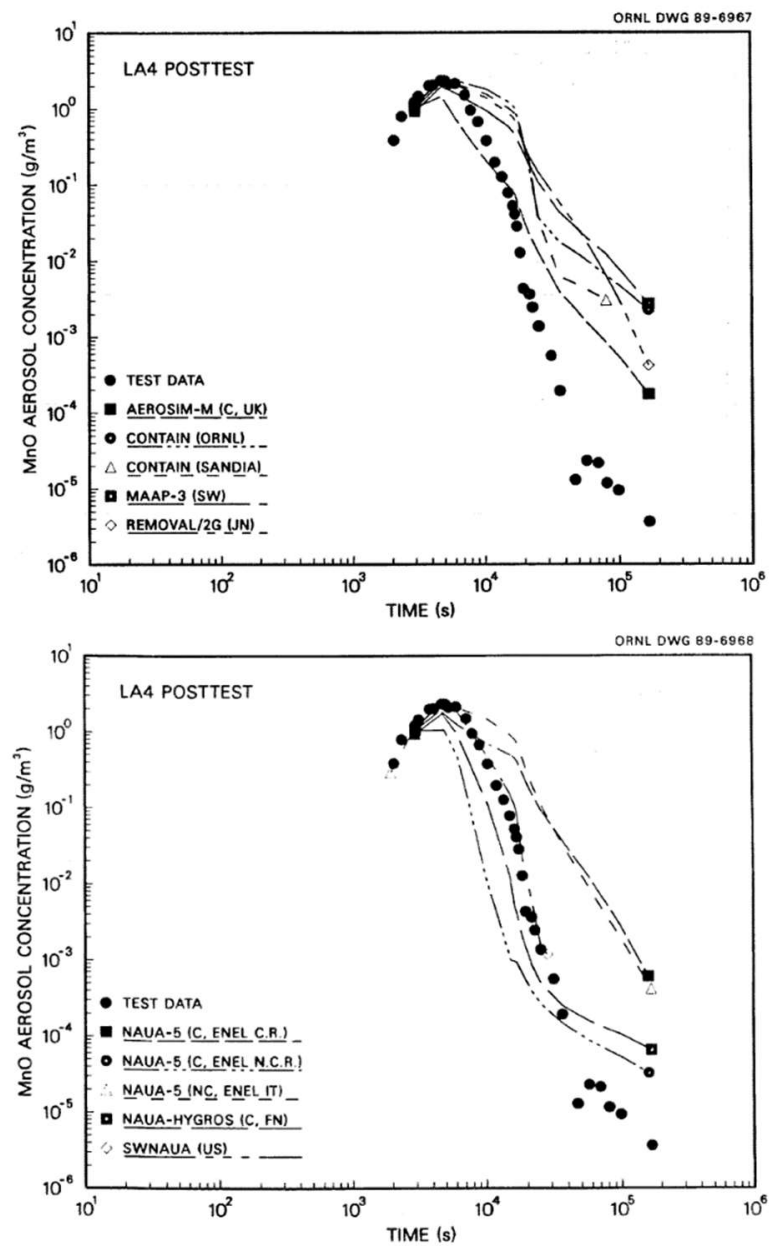

Figure 3: $\mathrm{MnO}$ concentration posttest results

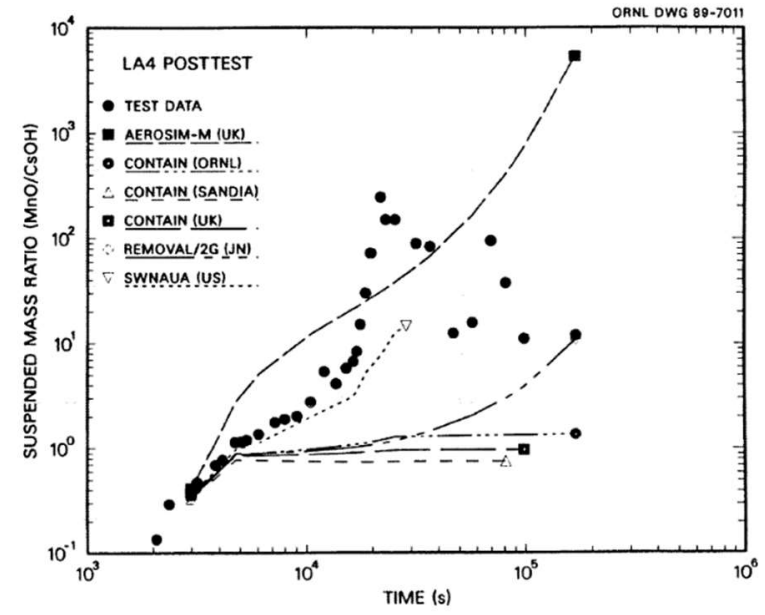

Figure 4: Posttest suspended mass ratio results. 

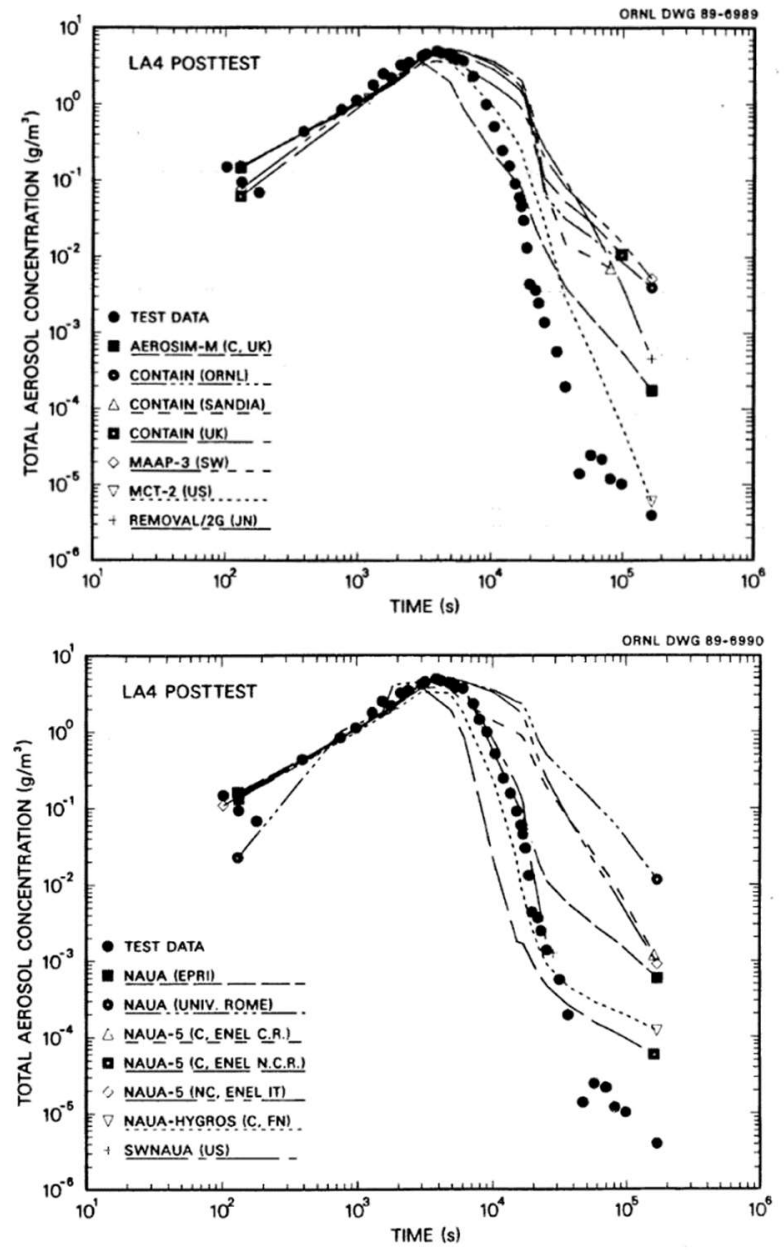

Figure 5: Posttest total aerosol concentration results

Inherent sources of error in the aerosol codes varied based on the assumptions made by the numerical method of solving the aerosol General Dynamic Equation (GDE) and by the code analysts. The "wet" aerosol codes from Table 3 solved the GDE with Mason's equation as the condensation model using the sectional and moments techniques. As cited in Loyalka and Park (1988), the Mason model, which is generally only suitable for "large" particles (i.e., particles with radii greater or equal to $1 \mu \mathrm{m}$ ), may be expressed as: ${ }^{20}$

${ }^{20}$ S. K. Loyalka and J. W. Park, "Aerosol Growth by Condensation: A Generalization of Mason's Formula," Journal of Colloid and Interface Science 125, no. 2 (1988). 


$$
\psi_{\text {Mason }}(v)=4 \pi\left(\frac{3 v}{4 \pi}\right)^{1 / 3} D \rho_{s}\left(\frac{S-1}{(L D / K) \rho_{s} \beta+1}\right)
$$

where $\psi_{\text {Mason }}$ is the mass condensation rate, $v$ is the volume of the particle, $D$ is the diffusion coefficient of the vapor, $L$ is the latent heat of water vapor, $K$ is the thermal conductivity of the mixture, $S$ is the saturation ratio, $\rho_{s}$ is the saturation density of the vapor at ambient conditions, and:

$$
\beta=\frac{L m_{v}}{k T_{\infty}^{2}}
$$

where $m_{v}$ is the vapor mass, $k$ is the Boltzmann constant, and $T_{\infty}$ is the ambient temperature. Specifically, the NAUA-5 (ENEL) group showed the role of condensation on aerosol evolution by providing three calculations. Of these three, only two were "wet" codes (i.e., only two allowed for steam to condense onto the aerosol particles), and of those two "wet" codes only one used a condensation model with the Kelvin effect (and thus a critical radius below which condensation would not occur on the aerosol particle surface). The main issue with the MAAP-3 code (which is based on the moments technique) stems from the assumption that the suspended aerosols would approach some sort of asymptotic size distribution. The CONTAIN code assumes "the density of the dry aerosol to be independent of particle composition (and, therefore, independent of particle size)." 21 This meant that the water density was assumed to be the same as the average density of the dry aerosol under steam condensation on the aerosol. In addition, the AEROSIM-M (UK) model took the total condensation rate as an input for the airborne aerosols. Finally, of all the codes used to simulate the LA4 experiment, only the NAUA

${ }^{21}$ Wilson and Arwood, "Comparison of (Posttest) Predictions of Aerosol Codes with Measurements in LWR Aerosol Containment Experiment (LACE) LA4,” 21. 
(EPRI), NAUA-HYGROS (FN), and SWNAUA (US) codes accounted for the hygroscopic nature of the $\mathrm{CsOH}$ aerosol. All of the aforementioned aerosol evolution codes, however, were incompetent at solving the GDE proficiently when strong coagulation and condensation were present. ${ }^{22}$

Experimental measurements of the LA4 test found that much of the $\mathrm{CsOH}$ condensed onto the surface of the $\mathrm{MnO}$ aerosols due to the extremely hygroscopic properties of $\mathrm{CsOH}$ and the transport of water vapor on the agglomerates. Subsequently, the presence of steam in the LA4 experiment significantly affected the size, form, shape, and number of resulting $\mathrm{CsOH}$ aerosol particles or droplets. According to "The Formation of Heterogeneous Aerosols in Severe Reactor Accidents" by Bowsher and Nichols, the preferential condensation of steam onto the CsOH-rich particles led to the increased gravitational deposition of those particles which then led to the significant and prolonged stabilizing effect of suspended $\mathrm{MnO}$ aerosols. ${ }^{23}$ The average removal rate from the CSTF atmosphere was later shown to be approximately $40 \%$ faster for $\mathrm{CsOH}$ than for $\mathrm{MnO}$ and up to 15 times faster after venting had started. ${ }^{24}$ An alternate explanation is that, though $\mathrm{CsOH}$ and $\mathrm{MnO}$ injection had about the same initial particle size distribution, the staggered injection of the two aerosol species caused a higher settling rate for $\mathrm{CsOH}$ due to the eventual difference in their size distributions. ${ }^{25}$ The

\footnotetext{
${ }^{22}$ Williams and Loyalka, Aerosol Science: Theory and Practice: With Special Applications to the Nuclear Industry, 385. Accidents."

${ }^{23}$ Bowsher and Nichols, "The Formation of Heterogeneous Aerosols in Severe Reactor

${ }^{24}$ Frank Rahn, Technical Foundation of Reactor Safety, Revision 1: Knowledge Base for Resolving Severe Accident Issues, Final Report No. 1022186 (Palo Alto, CA: Electric Power Research Institute, 2010).
} 
experimental findings of the LA4 experiment were best summed up by Bowsher and Nichols:

The various analytical data show that much of the aerosol generated in the LACE tests consisted of reasonable well-mixed spheres of manganese (II) oxide intermixed with amorphous cesium-based debris. Specific samples were particularly heterogeneous, indicating that either cesium hydroxide agglomerated preferentially onto the outside of the manganese oxide particles, or some illdefined process associated with the hygroscopic properties of cesium hydroxide resulted in the subsequent transfer of cesium to the surface of the agglomerates. Clearly steam condensation has an important role to play in determining the transport and deposition properties of these aerosols, particularly those particles enriched in cesium hydroxide. ${ }^{26}$

\subsection{Simulation Efforts Post LA4}

\section{1) FIPLOC-M (1989)}

As a means of verification, FIPLOC-M (a coupled thermal-hydraulic and aerosol transport behavior code) attempted to model the LA4 experiment. The leading analyst, Bieder, wrote two versions of the FIPLOC-M code using both a single, lumped control volume and a single control volume with an 18-compartment nodalization to model the

${ }^{25}$ Ulrich Bieder et al., Nuclear Science and Technology: Coupling Aerosol Behavior and ThermalHydraulics State of the Art Review Final Report (Luxembourg: European Commission, 1995).

${ }^{26}$ Bowsher and Nichols, "The Formation of Heterogeneous Aerosols in Severe Reactor Accidents," 176. 
LA4 test. Ultimately, Bieder concluded that the limitations in the FIPLOC-M program's ability to model aerosol condensation led to the early termination of the work. ${ }^{27,28}$

2) $\underline{\operatorname{MELCOR}(1991)}$

The LA4 simulations were recreated using the MELCOR software package as seen in Kmetyk (1991). ${ }^{29}$ MELCOR was used to predict the time-dependent characteristics of the aerosol distribution by coupling it with MELCOR's thermalhydraulic calculations. The MELCOR results are shown in Figure 6 through Figure 8. In regards to the thermal-hydraulics, the MELCOR code calculated the CSTF pressure quite well, but over-predicted the pool temperature (pool temperature results not shown here). Figure 8 shows that $\mathrm{CsOH}$ removal in MELCOR was well calculated. On the other hand, $\mathrm{MnO}$ was well predicted prior to venting, but under-predicted removal afterward. ${ }^{30}$ The results showed that MELCOR's lack of hygroscopic and non-hygroscopic effects generally led to the over-predicting suspended aerosol size distributions. ${ }^{31}$ Kmetyk noted that the results also suggested that water vapor should be remodeled as a separate aerosol component and that increased size resolution (i.e., more size bins), however computationally expensive, would benefit any future results.

${ }^{27}$ G. Weber, "Verification des Containment Rechenprogramms FIPLOC an DEMONA und LACE Experimenten. Ges. für Reaktorsicherh," GRS-A-1641 (1989).

28 Ulrich Bieder et al., Nuclear Science and Technology: Coupling Aerosol Behavior and Thermal-Hydraulics State of the Art Review Final Report, 83.

${ }^{29}$ L. N. Kmetyk, "MELCOR 1.8.1 Assessment: LACE Aerosol Experiment LA4,” Report\# SAND91-1532. (Albuquerque, NM: Sandia National Laboratories, 1991).

${ }^{30}$ Kyle Ross et al., "MELCOR Best Practices as Applied in the State-of-the-Art Reactor Consequences Analyses (SOARCA) Project,"NUREG/CR-7008 (Washington, District of Columbia: U.S. Nuclear Regulatory Commission, 2014).

${ }^{31}$ Kmetyk, "MELCOR 1.8.1 Assessment: LACE Aerosol Experiment LA4." 


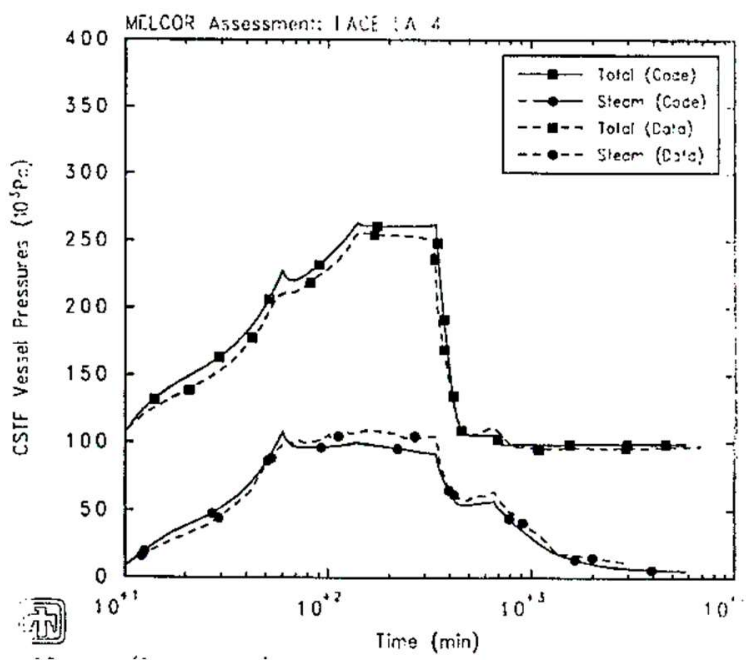

Figure 6: MELCOR pressure results

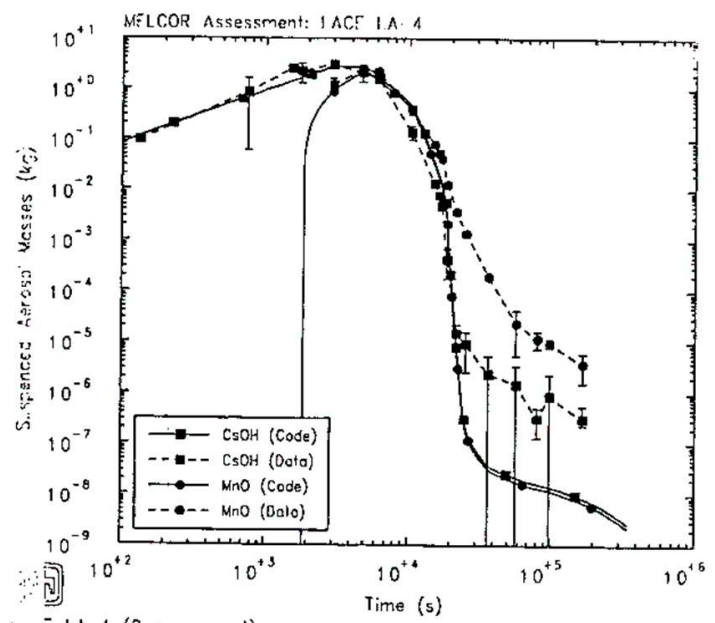

Figure 7: MELCOR suspended masses
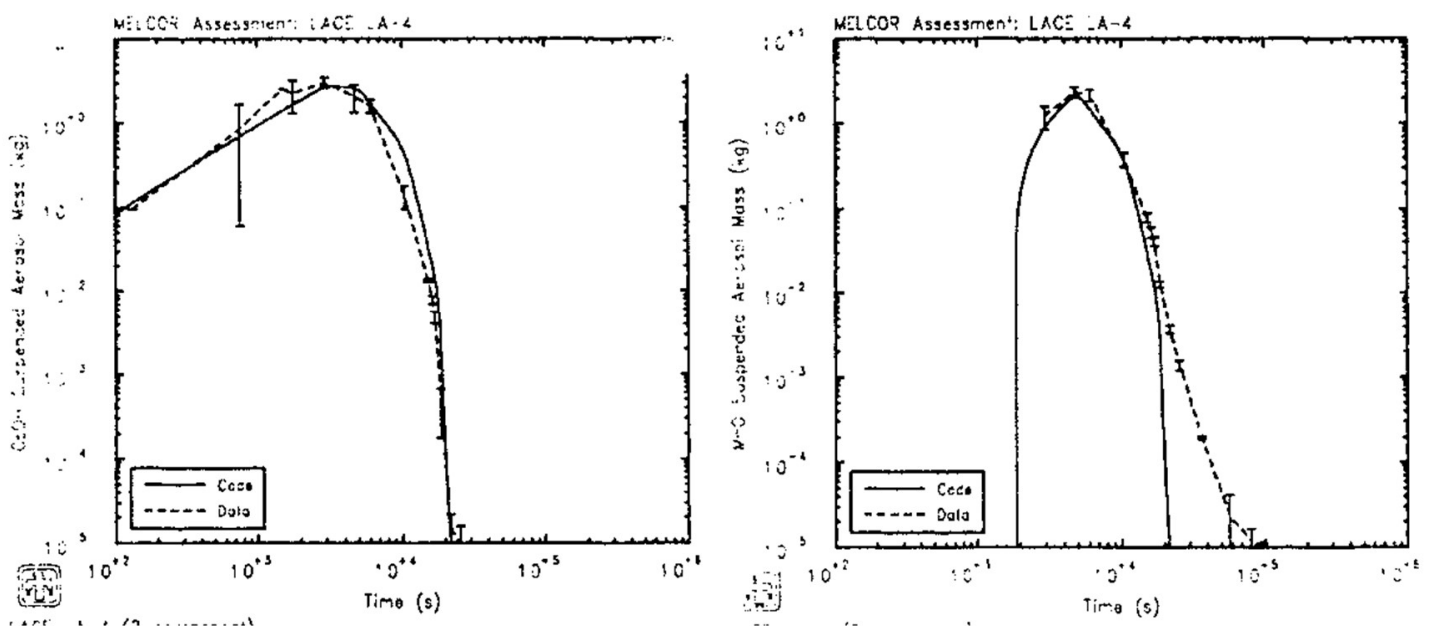

Figure 8: MELCOR individual results for suspended mass 


\section{3) ESCADRE's JERICHO and AEROSOLS-B2 (1996)}

The Ensemble de Systemes de Codes d'Analyse d'accident Des Reacteurs a Eau (ESCADRE) code contains the JERICHO code, a thermal-hydraulics simulator, and the AEROSOLS-B2 which simulates the corresponding aerosol behavior. ${ }^{32}$ As seen in Passalacqua, Renault, \& Tarabelli (1995), the CSTF vessel was split into two zones in the ESCADRE code to simulate stratification. ${ }^{33}$ The results from the ESCADRE code are shown in Figure 9. This study found that, although steam condensation played an important role in determining aerosol behavior, the results also greatly depended on the aerosol dynamic shape factor. Moreover, they found that effective models would have to resolve the problem of stratification because of its effect on deposition by thermophoresis (caused by the thermal gradient in the stratification) and diffusiophoresis (due to high steam condensation flux masses). The authors, however, also noted that the experimental errors in measuring suspended mass concentrations were large in the later stages of the LA4 experiment because the quantity of aerosol mass collected was only slightly greater than the instrument resolution.

32 Roberto Passalacqua, Didier Tarabelli, and Claude Renault, "Light Water Reactor Aerosol Containment Experiment LA4 Simulated by JERICHO and AEROSOLS-B2 Codes," Nuclear Technology 116, no. 3 (1996): 283-92.

${ }^{33}$ Roberto Passalacqua, Claude Renault, and Didier Tarabelli, "Two Compartment ThermalHydraulics Experiment Analyzed By ESCADRE Code,” Energia Nucleare (Rome) 12, no. 1 (1995): 21-30. 

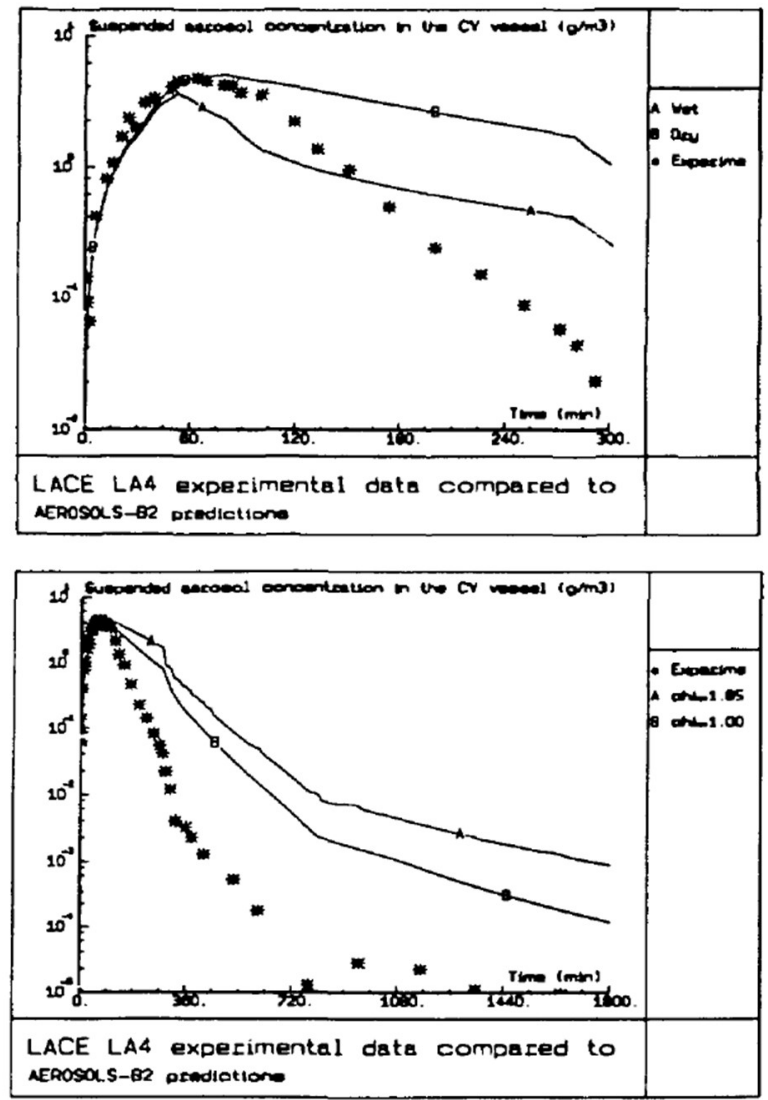

Figure 9: AEROSOLS-B2 suspended masses and shape factor dependence

\section{4) ASTEC (2006-2009)}

In 2006, the aerosol behavior of the LA4 test was modeled by the ASTEC code. ${ }^{34}$ The work was then expanded in Kljenak et al. (2010) to include the coupled thermalhydraulic and aerosol behavior. ${ }^{35}$ The CPA (V1.2) module of the ASTEC code used by Kljenak et al. used a lumped parameter to model the CSTF vessel as a single zone, approximated the aerosol density by mass-averaging over aerosol components, did not include the Kelvin effect, and used a log-normal aerosol size distribution which was divided into 20 sections with aerosols ranging from $5 \times 10^{-8} \mathrm{~m}$ and $1 \times 10^{-4} \mathrm{~m}$ in

${ }^{34}$ Kljenak and Mavko, "Simulation of LACE LA4 Experiment on Aerosol Behavior in a Nuclear Power Plant Containment with the ASTEC CPA V1.2 Code."

${ }^{35}$ Kljenak et al., "Thermal-hydraulic and Aerosol Containment Phenomena Modelling in ASTEC Severe Accident Computer Code," Nuclear Engineering and Design 240, no. 3 (2010): 656-67. 
diameter. The thermal-hydraulic results of the ASTEC code are compared with the experimental data in Figure 10. As we can see from Figure 10, the thermal-hydraulic properties were in fair agreement throughout, though admittedly the authors noted that the ASTEC code had problems with atmosphere saturation. The simulated and experimental results of the $\mathrm{CsOH}$ and $\mathrm{MnO}$ concentrations in the CSTF vessel atmosphere are shown in Figure 11. Considering the experimental uncertainty of $20 \%$ of measurements, the simulated $\mathrm{MnO}$ concentration is in decent agreement with the measured results whereas the simulated $\mathrm{CsOH}$ concentration is considerably different from what was measured. The major discrepancy, according to Kljenak et al., was attributed to the low simulated atmosphere saturation predicted by ASTEC as well as the absence of the Kelvin effect.
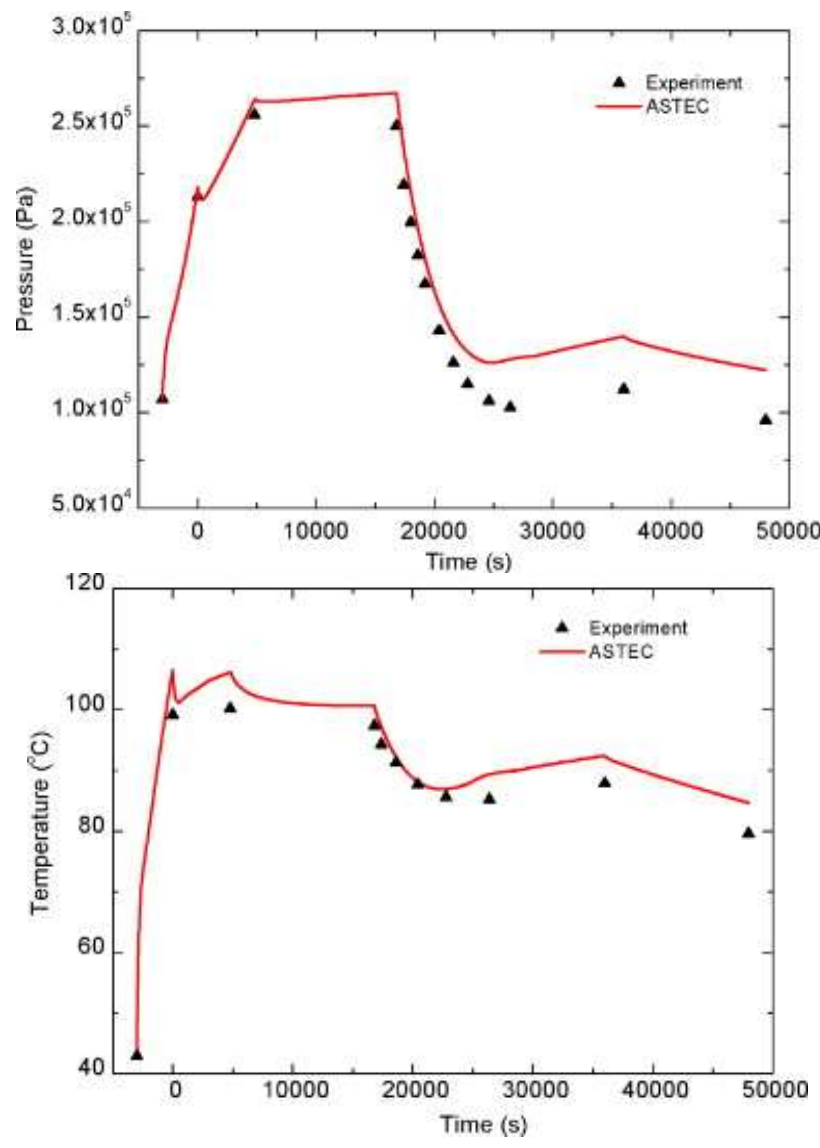

Figure 10: ASTEC thermal-hydraulic LA4 results 


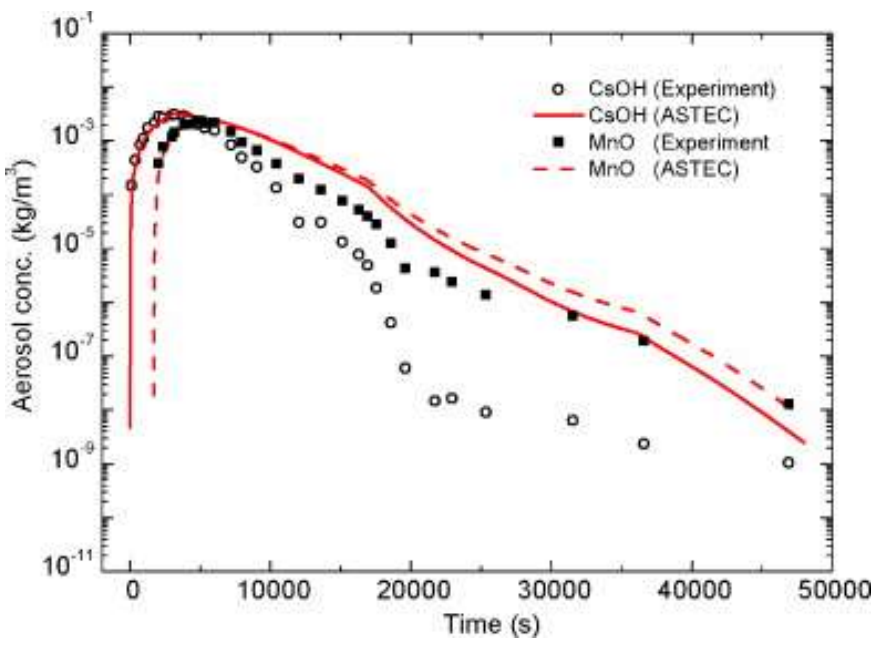

Figure 11: ASTEC results for suspended mass concentration 


\section{AEROSOL DYNAMICS MODELING}

\subsection{The General Dynamic Equation}

Aerosols are subject to coagulation, fragmentation, condensation, evaporation, deposition, resuspension, and source term processes as well as many physical and chemical factors including particle size, shape, charge, and hygroscopicity. For a homogeneous system of spherical particles comprised of $n$-components, the number of particles of a given component, $p$, in the $v_{p}$ to $v_{p}+\mathrm{d} v_{p}$ volume range and mass range $m_{p}$ to $\mathrm{d} m_{p}$ is described by the aerosol distribution function:

$$
n\left(v_{1}, v_{2}, \ldots, v_{N} ; m_{1}, m_{2}, \ldots, m_{N}, t\right)=n(\boldsymbol{v}, \boldsymbol{m}, t)
$$

so that the total volume and mass of the aerosol particle is then calculated by:

$$
\begin{gathered}
\int \mathrm{d} \boldsymbol{v}=\int \mathrm{d} v_{1} \int \mathrm{d} v_{2} \cdots \int \mathrm{d} v_{N} \\
\int \mathrm{d} \boldsymbol{m}=\int \mathrm{d} m_{1} \int \mathrm{d} m_{2} \cdots \int \mathrm{d} m_{N}
\end{gathered}
$$

respectively. The behavior of aerosols is expressed mathematically by the General Dynamic Equation (GDE). The GDE for a well-mixed, multi-species aerosol is an integro-differential equation given as: $:^{36,37,38,39}$

${ }^{36}$ N. A. Fuchs, The Mechanics of Aerosols (New York: Pergamon Press, 1964).

${ }^{37}$ Fred Gelbard and John H. Seinfeld, "Simulation of Multicomponent Aerosol Dynamics," Journal of Colloid and Interface Science 78, no. 2 (1980).

${ }^{38}$ Williams and Loyalka, Aerosol Science: Theory and Practice: With Special Applications to the Nuclear Industry, 126.

${ }^{39}$ Sheldon K. Friedlander, Smoke, Dust, and Haze: Fundamentals of Aerosol Dynamics (New York: Oxford Press, 2000). 


$$
\begin{aligned}
\frac{\partial}{\partial t} n(\boldsymbol{v}, \boldsymbol{m}, t)= & -\sum_{p=1}^{N} \frac{\partial}{\partial v_{p}}\left[I_{p}(\boldsymbol{v}, \boldsymbol{m}, t) n(\boldsymbol{v}, \boldsymbol{m}, t)\right] \\
& +\frac{1}{2} \int_{0}^{\infty} \mathrm{d} \boldsymbol{u} \int_{0}^{\infty} \mathrm{d} \boldsymbol{w} \int_{0}^{\infty} \mathrm{d} \boldsymbol{q} \int_{0}^{\infty} \mathrm{d} \boldsymbol{s} n(\boldsymbol{u}, \boldsymbol{q}, t) n(\boldsymbol{w}, \boldsymbol{s}, t) K(u, q \mid w, s) \\
& \times \prod_{p=1}^{N} \delta\left(v_{p}-u_{p}-w_{p}\right) \delta\left(m_{p}-q_{p}-s_{p}\right) \\
& -n(\boldsymbol{v}, \boldsymbol{m}, t) \int_{0}^{\infty} \mathrm{d} \boldsymbol{u} \int_{0}^{\infty} \mathrm{d} \boldsymbol{q} K(u, q \mid w, s) n(\boldsymbol{u}, \boldsymbol{q}, t) \\
& -R(\boldsymbol{v}, \boldsymbol{m}, t) n(\boldsymbol{v}, \boldsymbol{m}, t)+S(\boldsymbol{v}, \boldsymbol{m}, t)
\end{aligned}
$$

where $q=\sum_{p=1}^{N} q_{p}, s=\sum_{p=1}^{N} s_{p}, I_{p}(\boldsymbol{v}, \boldsymbol{m}, t)$ is the condensation rate, $K(u, q \mid w, s)$ is the coagulation kernel of two particles with volumes $u$ and $w$ and masses $q$ and $s$, $R(\boldsymbol{v}, \boldsymbol{m}, t)$ is the particle removal (or deposition) rate, and $S(\boldsymbol{v}, \boldsymbol{m}, t)$ is a source term.

Particle coagulation is a non-linear process through which random inelastic collision of two particles fuse together to produce a larger, agglomerate particle. The coagulation kernel, $K(u, q \mid w, s)$, depends on the Brownian motion of particles as well as the gravitational and turbulence effects of those particles. Brownian particle coagulation occurs when two particles exhibiting random motion collide to form a single particle of aggregate volume and composition to that of the collided particles. Larger particles under the increased influence of gravity, fall faster than lighter particles. Therefore coagulation due to gravitational effects encompasses the successful agglomeration between a large, fast-moving particle colliding inelastically with a smaller, slower-moving particle. ${ }^{40}$ Finally, the turbulent coagulation kernel accounts for the

${ }^{40}$ Rudolph Sher and Richard R. Hobbins, Transport and Removal of Aerosols in Nuclear Power Plants Following Severe Accidents (La Grange Park, IL: American Nuclear Society, 2011). 
collisions between two particles caused by the turbulent effects produced by the velocity gradients in the fluid motion of the containment atmosphere. The total coagulation kernel is the summation of the Brownian, gravitational, and turbulence kernels. The coagulation kernels for a collision between the $i$-th and $j$-th particles are given in the MultiComponent Aerosol Module for CONTAIN (MAEROS) User Manual which are expressed as: ${ }^{41}$

$$
\begin{gathered}
\beta_{\text {Total }}=\beta_{\text {Brownian }}+\beta_{\text {gravitational }}+\beta_{\text {turbulence }} \\
\beta_{\text {Brownian }}=\frac{2 \pi\left(D_{i}+D_{j}\right)\left(\gamma_{i} d_{i}+\gamma_{j} d_{j}\right)}{\left(\frac{d_{i}+d_{j}}{d_{i}+d_{j}+2 \sqrt{g_{i}^{2}+g_{j}^{2}}}+\frac{8\left(D_{i}+D_{j}\right)}{\sqrt{V_{i}^{2}+V_{j}^{2}}\left(d_{i}+d_{j}\right)}\right)} \\
\beta_{\text {gravitational }}=\varepsilon \frac{\pi}{4}\left(\gamma_{i} d_{i}+\gamma_{j} d_{j}\right)^{2}\left|V_{T_{i}}-V_{T_{j}}\right| \\
\beta_{\text {turbulence }}=\sqrt{\frac{\pi \varepsilon_{T}}{120 \nu}\left(\gamma_{i} d_{i}+\gamma_{j} d_{j}\right)^{6}+\frac{0.00162 \rho_{g}^{1 / 2} \varepsilon_{T}^{3 / 2}}{\eta^{5 / 2}}\left(\gamma_{i} d_{i}+\gamma_{j} d_{j}\right)^{2}\left|\frac{\rho_{p i} C_{i} d_{i}^{2}}{\chi_{i}}-\frac{\rho_{p j} C_{j} d_{j}^{2}}{\chi_{j}}\right|^{2}}
\end{gathered}
$$

where:

$$
\begin{gathered}
D_{i}=\frac{k T C_{i}}{3 \pi d_{i} \eta \chi_{i}} \\
C_{i}=1+K n_{i}\left(1.37+0.4 \operatorname{Exp}\left[-\frac{1.1}{K n_{i}}\right]\right) \\
K n_{i}=\frac{2 \lambda}{d_{i}}
\end{gathered}
$$

${ }^{41}$ Fred Gelbard, "MAEROS User Manual," Report\# NUREG/CR-1391, SAND80-0822 (Albuquerque, NM: Sandia National Laboratories, 1982). 


$$
\begin{gathered}
g_{i}=\frac{1}{3 D_{i} \ell_{i}}\left(\left(d_{i}+\ell_{i}\right)^{3}-\left(d_{i}^{2}+\ell_{i}^{2}\right)^{3 / 2}\right)-d_{i} \\
\ell_{i}=\frac{8 d_{i}}{\pi V_{i}} \\
V_{i}=\sqrt{\frac{8 k T}{\pi m_{i}}} \\
\varepsilon=\left\{\begin{array}{c}
V_{T_{i}}=\frac{\rho_{p i} g d_{i}^{2} C_{i}}{18 \eta \chi_{i}} \\
\frac{\left(d_{i}+d_{j}\right)^{2}}{d_{j}^{2}}, d_{i}<d_{j} \\
\frac{\left(d_{i}+d_{j}\right)^{2}}{d_{i}}>d_{j}
\end{array}\right.
\end{gathered}
$$

where $d$ is the particle diameter, $D$ is the particle diffusion coefficient, $V$ is the particle speed, $V_{T}$ is the particle's terminal settling velocity, $g$ is the gravitational constant, $k$ is Boltzmann's constant, $m$ is the particle mass, $T$ is the absolute temperature, $\gamma$ is the agglomeration shape factor, $K n$ is the Knudsen number, $C$ is the Cunningham correction factor, $\varepsilon_{T}$ is the turbulent energy dissipation rate, $\varepsilon$ is the collision coefficient, $\eta$ is the gas viscosity, $\lambda$ is the mean free path, $\ell$ is the apparent mean free path of the particle, $\nu$ is the kinematic viscosity, $\rho_{g}$ is the gas density, $\rho_{p}$ is the particle density, and $\chi$ is the dynamic shape factor.

Under certain circumstances, aerosol growth may occur due to the presence of steam in the atmosphere condensing onto the surface of the aerosol particles. Condensation therefore not only affects particle size, but particle composition and 
atmospheric thermal-hydraulics as well. Factors such as thermal-hydraulics, hygroscopicity, and particle size and shape all influence condensation rates.

Traditionally, most production codes utilize Mason's radial growth rate equation as the condensation model in the GDE. Mason's equation for radial condensational growth rate is given as: ${ }^{42}$

$$
r \frac{d r}{d t}=\frac{(S-1)}{\left[\frac{L \rho_{L}}{K T_{\infty}}\left(\frac{L M}{R T_{\infty}}-1\right)+\frac{R T \rho_{L}}{D M P_{s}\left(T_{\infty}\right)}\right]}
$$

Mason's radial growth equation may also be rewritten for the mass condensation rate as a function of particle volume as:

$$
\psi_{\text {Mason }}(v)=4 \pi\left(\frac{3 v}{4 \pi}\right)^{1 / 3} D \rho_{s}\left(\frac{S-1}{(L D / K) \rho_{s} \beta+1}\right)
$$

The primary processes which govern aerosol removal from the atmosphere include gravitational sedimentation (or gravitational settling), removal by containment sprays, diffusiophoretic deposition caused by bulk drift caused by concentration gradients in gas mixtures, and thermophoretic deposition caused by temperature gradients. In this work, we only account for gravitational and diffusional deposition. Gravitational deposition is calculated by: ${ }^{43}$

$$
R_{\text {gravity }}=-\frac{A_{\text {floor }} V_{T}}{V_{\text {chamber }}}
$$

where $A_{\text {floor }}$ is the floor area, $V_{\text {chamber }}$ is the chamber volume, $V_{T}$ is the particle settling velocity defined as:

${ }^{42}$ Basil J. Mason, The Physics of Clouds (Oxford: Clarendon Press, 1971), 123.

${ }^{43}$ Gelbard, "MAEROS User Manual," 48. 


$$
V_{T}=\frac{\rho_{p} g d^{2} C}{18 \eta \chi}
$$

where $\rho_{p}$ is the particle density, $g$ is the acceleration due to gravity, $d$ is the particle diameter, $\eta$ is the gas viscosity, $\chi$ is the dynamic shape factor, and $C$ is the Cunningham factor. On the other hand, diffusional deposition is calculated by: ${ }^{44}$

$$
R_{\text {diffusional }}=-\frac{D}{\Delta}\left(\frac{A_{\text {wall }}}{V_{\text {chamber }}}+\frac{A_{\text {floor }}}{V_{\text {chamber }}}+\frac{A_{\text {ceiling }}}{V_{\text {chamber }}}\right)
$$

where $A_{\text {wall }}$ is the wall area, $A_{\text {ceiling }}$ is the area of the ceiling, $\Delta$ is the diffusion boundary layer thickness, and $D$ is the particle diffusivity (or diffusion coefficient). The total deposition rate is then:

$$
R_{\text {Total }}=R_{\text {gravity }}+R_{\text {diffusional }}
$$

During a severe accident, the excessive overheating causes materials in the reactor core to vaporize. Subsequently, these vapors are leaked into the containment through the ruptures in the reactor vessel. In a review of core damage experiments, Sher and Hobbins found that nuclear source term aerosols may be accurately represented by a log-normal distribution with a geometric mean radius and geometric standard deviation (GSD) in the range of $0.045-0.386 \mu m$ and 1.61-2.18, respectively. ${ }^{45}$ Per Seinfeld and Pandis (2006), the log-normal distribution for spherical particles in terms of particle diameter is given as: ${ }^{46}$

\footnotetext{
${ }^{44}$ Gelbard, "MAEROS User Manual," 48.

${ }^{45}$ Sher and Hobbins, Transport and Removal of Aerosols in Nuclear Power Plants Following Severe Accidents, 21.

${ }^{46}$ John H. Seinfeld and Spyros N. Pandis, Atmospheric Chemistry and Physics of Air Pollution (New York: Wiley, 2006), 362.
} 


$$
n_{N}(d, t)=\frac{N(t)}{\sqrt{2 \pi} \ln \left(\sigma_{g}\right)} \frac{1}{d} \operatorname{Exp}\left[-\frac{\left(\ln (d)-\ln \left(d_{m}\right)\right)^{2}}{2 \ln ^{2}\left(\sigma_{g}\right)}\right]
$$

where $d$ is the particle diameter, $N(t)$ is the total aerosol number concentration as a function of time, $d_{m}$ is the geometric mean diameter, and $\sigma_{g}$ is the geometric standard deviation. The log-normal distribution may also be represented in terms of particle volume by: ${ }^{47}$

$$
n_{N}(v, t)=\frac{N(t)}{\sqrt{2 \pi} \ln \left(\sigma_{g, v}\right)} \frac{1}{v} \operatorname{Exp}\left[-\frac{\left(\ln (v)-\ln \left(v_{m}\right)\right)^{2}}{2 \ln ^{2}\left(\sigma_{g, v}\right)}\right]
$$

where

$$
\begin{gathered}
\sigma_{g, v}=\sigma_{g}^{3} \\
v_{m}=\frac{\pi}{6} d_{m}^{3}
\end{gathered}
$$

The geometric mean diameter may be calculated from the customary particle diameter quantities by the Hatch-Choate relations which are: ${ }^{48,49}$

$$
\begin{aligned}
& \text { Count Mode Diameter }=d^{*}=d_{g} \operatorname{Exp}\left[-1.0 \ln ^{2}\left(\sigma_{g}\right)\right] \\
& \text { Count Mean Diameter }=\bar{d}=d_{g} \operatorname{Exp}\left[0.5 \ln ^{2}\left(\sigma_{g}\right)\right]
\end{aligned}
$$

Diameter of Average Surface Area $=d_{a}=d_{g} \operatorname{Exp}\left[1.0 \ln ^{2}\left(\sigma_{g}\right)\right]$

Diameter of Average Mass (or Volume) $=d_{m}=d_{g} \operatorname{Exp}\left[1.5 \ln ^{2}\left(\sigma_{g}\right)\right]$

\footnotetext{
${ }^{47}$ Mark L. Maiello and Mark D. Hoover, Radioactive Air Sampling Methods (Boca Raton: Taylor and Francis, 2011), 81.

${ }^{48}$ Theodore Hatch and Sarah P. Choate, "Statistical description of the size properties of nonuniform particulate substance," Journal of the Franklin Institute 207, no. 3 (March 1929): 369-87

${ }^{49}$ Maiello and Hoover, Radioactive Air Sampling Methods, 143-44.
} 


$$
\begin{gathered}
\text { Surface Area Median Diameter }=d_{a}^{\prime}=d_{g} \operatorname{Exp}\left[2.0 \ln ^{2}\left(\sigma_{g}\right)\right] \\
\text { Surface Area Mean Diameter }=\bar{d}_{a}=d_{g} \operatorname{Exp}\left[2.5 \ln ^{2}\left(\sigma_{g}\right)\right] \\
\text { Mass (or Volume) Median Diameter }=d_{m}^{\prime}=d_{g} \operatorname{Exp}\left[3.0 \ln ^{2}\left(\sigma_{g}\right)\right] \\
\text { Mass (or Volume) Mean Diameter }=\bar{d}_{m}=d_{g} \operatorname{Exp}\left[3.5 \ln ^{2}\left(\sigma_{g}\right)\right]
\end{gathered}
$$

where $d_{g}$ is the count median diameter. Although not shown explicitly above, the source term, $S(\boldsymbol{v}, \boldsymbol{m}, t)$, may also be time-dependent.

\subsection{Methods of Solution}

Except for in very special cases the integro-differential GDE cannot be solved analytically, making numerical methods necessary. Numerical schemes employed in aerosol transport codes include the method of moments, finite element, and sectional techniques. Transport codes such as MAAP-4 use the method of moments which approximates aerosol processes by power series and takes the first three moments to get a set of first order, non-linear differential equations; this process results in a set of equations, which are sometimes simple enough to be solved analytically but are quite simple to solve numerically. ${ }^{50,51}$ However, the method of moments introduces errors by

${ }^{50}$ B. H. McDonald, "Assessing Numerical Models Used in Nuclear Aerosol Transport Models," in Nuclear Science and Technology Proceedings Of CSNI-OECD Workshop on Water-Cooled Reactor Aerosol Code Evaluation and Uncertainty Assessment From 9 to 11 September 1987, EUR 11351 EN, ed. E. della Loggia and J. Royen (Luxemburg: Commission of the European Communities, 1988).

${ }^{51}$ Williams and Loyalka, Aerosol Science: Theory and Practice: With Special Applications to the Nuclear Industry, 272. 
the truncation of higher order terms in the series approximations. ${ }^{52}$ Solutions to the GDE by the finite element method, such as the AEROSOLS/B1 code, require the use of basis (or approximating) functions. The time-only dependent parameters are defined at the interval endpoints of each discrete size bin and assumes the distribution to be linear within each of the intervals. Consequently, Williams and Loyalka found the finite element method susceptible to numerical diffusion, the accuracy is highly dependent on the choice of the basis functions, and that the grid of size intervals must be shifted in the process if the aerosol processes cause the aerosol size distribution to shift to larger or smaller sizes. ${ }^{53}$ Lastly, the aerosol transport codes such as CONTAIN are based on the sectional (or group) technique developed by Gelbard and Seinfeld to track multicomponent aerosols as a function of particle size and time. ${ }^{54}$ In this technique, the particle size domain is divided into $M$ size classes called 'sections' in which a variable (typically mass) is conserved during aerosol processes. In the case of a multi-component aerosol solely under coagulation, the sectional technique requires that all aerosol particles have the same chemical composition (i.e., mass density) for each size bin. The advantage of the sectional technique is that the coagulation kernels are evaluated once per size bin and are treated as constant coefficients for all time. However, the sectional technique is not capable of modeling multi-component aerosols accurately in the presence of high condensation and evaporation rates. ${ }^{55}$ According to Williams and Loyalka, the sectional

\footnotetext{
${ }^{52}$ McDonald, “Assessing Numerical Models Used in Nuclear Aerosol Transport Models,” 191.

${ }^{53}$ Williams and Loyalka, Aerosol Science: Theory and Practice: With Special Applications to the Nuclear Industry, 289-290.

${ }^{54}$ Gelbard and Seinfeld, "Simulation of Multicomponent Aerosol Dynamics."

${ }^{55}$ Fred Gelbard, "Modeling Multicomponent Aerosol Particle Growth By Vapor Condensation," Aerosol Science and Technology 12, no. 2 (1990): 399.
} 
technique is limited due to its susceptibility to numerical diffusion which can be partially resolved through 'moving' sections, but doing so would then require reevaluating the coagulation kernels at each computational step in the presence of coagulation; hence, eliminating the advantage over other numerical techniques. ${ }^{56}$

\subsection{DSMC Technique}

While the sectional technique is beneficial in its computational speed, it has been shown to be insufficient for multi-component aerosol evolution calculations due to the algorithmic limitations of the fundamental assumptions and approximations it requires. On the other hand, the DSMC technique has been shown to accurately predict multicomponent aerosol behavior without requiring such assumptions used in the sectional technique, though at the cost of sacrificing computational time. In the DSMC No Time Counter (NTC) method developed by Bird, a time interval is selected in which randomly generated numbers determine whether an aerosol process may or may not occur in that time interval. ${ }^{57}$ A diagram of how the DSMC technique is implemented has been provided in Figure 12.

${ }^{56}$ Williams and Loyalka, Aerosol Science: Theory and Practice: With Special Applications to the Nuclear Industry, 292.

${ }^{57}$ G. A. Bird, Molecular Gas Dynamics and Direct Simulation of Gas Flows (New York: Oxford University Press, 1994). 


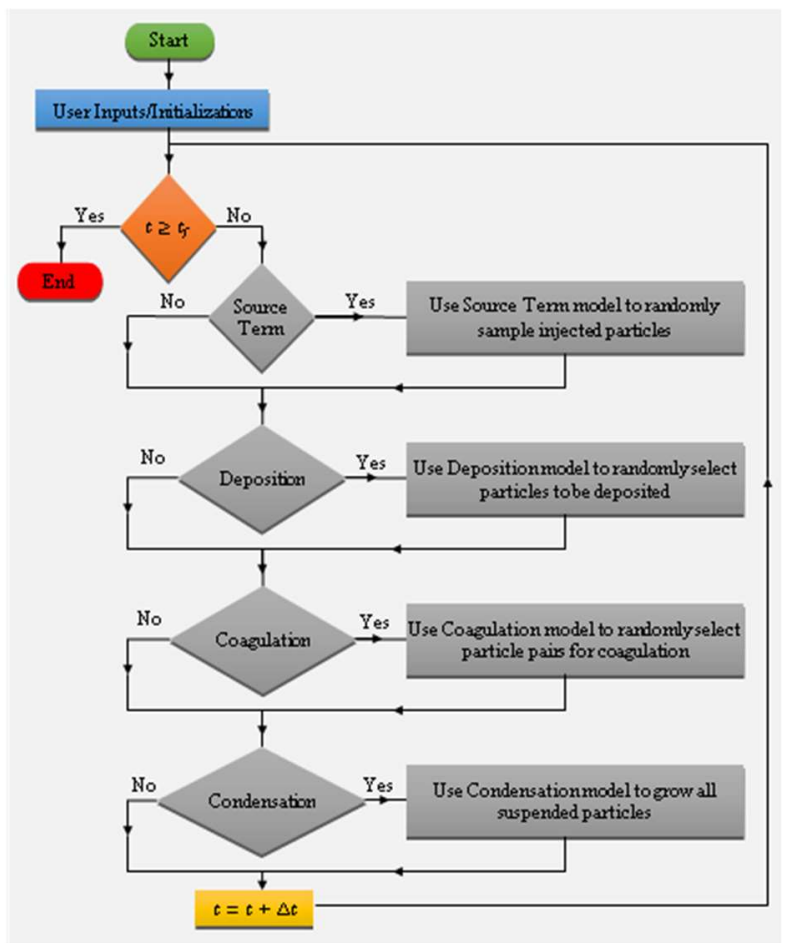

Figure 12: Diagram of DSMC technique

The generalized DSMC code developed in this work closely follows the diagram in Figure 12. As seen in Figure 12, simulation of aerosols under any combination of aerosol processes may be easily simulated by the DSMC technique. In the first part of the DSMC code, the aerosol's physical and chemical properties, initial conditions, aerosol processes, initial time $\left(t_{0}\right)$, time step $(\Delta t)$, termination time $\left(t_{f}\right)$, and containment characteristics are all chosen through the user inputs and initializations. Typically, the time step is chosen to be no larger than one-tenth of the fastest aerosol process. Once the required information has been selected, the DSMC program can execute. Using the initial time step $\left(t=t_{0}\right)$, the program will check if the end time has been reached (i.e., $t \geq t_{f}$ ). If this has happened then the program terminates; otherwise, the program will run for the aerosol processes selected earlier by the user. If the source term has been activated, aerosol particles are sampled randomly from a user-specified 
distribution and injected into the system at a mass injection rate appropriate for the chosen time step. Upon completion of the aerosol injection by the source term, these particles are added to the initial distribution (if one was specified) and the deposition process begins. Using random numbers, the DSMC method then uses the deposition models (if activated) to remove aerosols at the appropriate rate given by $\Delta t$. The particles removed by the deposition process are then tallied by mass per component and added to the deposited mass tally. Once finished, the remaining particles are then sent to the coagulation module. If coagulation has been "turned on", particles coagulate according to the coagulation kernel. For realistic coagulation, the number of collisions possible, $N_{c}$, in some arbitrary time interval, $\Delta t$, is given by:

$$
N_{c}=\frac{1}{2} N(N-1) \beta_{\max } \Delta t \approx \frac{1}{2} N^{2} \beta_{\max } \Delta t
$$

where $N$ is the total number of particles in the system, and $\beta_{\max }$ is the assumed maximum coagulation coefficient. For a particle collision to result in successful coagulation, then it is required that:

$$
\xi \leq \frac{\beta(u, v)}{\beta_{\max }}
$$

where $\xi$ is a uniformly distributed random variable between zero and one (i.e., $\xi \in[0,1]$ ). Particle pairs are selected at random and tested for coagulation until $N_{c}$ collisions have been tested to occur in time interval $\Delta t$. Upon completion of the coagulation process, the remaining particles in the coagulation module are then sent to the condensation module. If coagulation had not been activated, these particles would have been sent directly to the condensation process module. If selected, the condensation module grows 
all aerosol particles at the appropriate condensation rate according to the given condensation model chosen. After the condensation module has finished, the current time is advanced by the time step (i.e., $t=t+\Delta t$ ) and the aerosol processes are repeated until the end time has been reached. In summary, each aerosol process activated runs independently of the others in the same time interval. The current time is then advanced by the chosen time step and the process is then repeated until the total simulation time desired has been reached.

\subsection{Previous Work in DSMC}

\section{1) Palaniswaamy and Loyalka (2008)}

The DSMC technique was used in Palaniswaamy and Loyalka (2008) to model pure condensation and simultaneous coagulation and condensation for a singlecomponent aerosol. ${ }^{58}$ In the pure condensation scenario, two condensation models were considered; one which dealt with constant condensational growth and one in which condensational growth depended on aerosol size. For simultaneous coagulation and condensation, the three cases in Ramabhadran et al. (1976) were considered for constant and size-dependent aerosol processes. ${ }^{59}$ The complete list of test problems considered in Palaniswaamy and Loyalka (2008) are summarized in Table 4. The DSMC method was found to give results in good agreement with the exact analytical solutions for all test cases considered.

\footnotetext{
${ }^{58}$ Geethpriya Palaniswaamy and Sudarshan K. Loyalka, "Direct Simulation, Monte Carlo, Aerosol Dynamics: Coagulation and Condensation," Annals of Nuclear Energy 35, no. 3 (2008).

${ }^{59}$ T. E. Ramabhadran et al., "Dynamics of Aerosol Coagulation and Condensation," AlChe Journal 22, no. 5 (1976).
} 
Table 4: Summary of problems in Palaniswaamy and Loyalka (2008)

\begin{tabular}{|c|c|c|}
\hline Test Problems & Cases & Parameters \\
\hline \multirow{2}{*}{ Condensation } & Test Case I & $I=\sigma_{0}$ \\
\cline { 2 - 3 } & Test Case II & $I=\sigma_{1} v$ \\
\hline \multirow{3}{*}{$\begin{array}{c}\text { Coagulation } \\
\text { and } \\
\text { Condensation }\end{array}$} & Test Case I & $K=K_{0}$ \\
\cline { 2 - 3 } & & $K=\sigma_{1} v$ \\
\cline { 2 - 3 } & Test Case II & $\left.I=K_{0} v+v\right)$ \\
& & $K=K_{0}$ \\
& & $I=\sigma_{0}$ \\
\hline
\end{tabular}

2) Palsmeier and Loyalka (2013)

Simulations of charged aerosol evolution solely undergoing coagulation were performed using the DSMC technique by Palsmeier and Loyalka (2013). ${ }^{6}$ In this study, the authors explored the role of charge on coagulation through two main test problems. This included symmetric bipolar monodisperse aerosols and symmetric bipolar polydisperse aerosols. The work showed that the DSMC technique compared favorably with results obtained from other methods for aerosols ranging in size from $1 \mu \mathrm{m}$ to $6 \mu \mathrm{m}$ in diameter, though it was noted by the authors that the DSMC method could be applied to particles of any size. Complementary work found that electrostatic dispersion played a significant role in the aerosol evolution where charge asymmetry was significant.

${ }^{60}$ John F. Palsmeier and Sudarshan K. Loyalka, "Evolution of Charged Aerosols: Role of Charge on Coagulation," Nuclear Technology 184, no. 1 (2013). 


\section{3) Campbell and Loyalka (2015)}

The sectional technique and coupled DSMC-sectional technique for evolution of aerosols under coagulation only were studied by Campbell and Loyalka (2015). ${ }^{61}$ The consequences of the underlying assumptions of the sectional technique for aerosols under coagulation were explored fully in Campbell and Loyalka. The study also proposed two methods of coupling the DSMC and sectional techniques. This research showed that results heavily depended on "arbitrary" sampling functions rooted in the foundation of the sectional technique. The coupling of the DSMC and sectional techniques was successful but proved to be much more computationally expensive than either method alone. Lastly, Campbell and Loyalka made great strides to reduce the computational time required by the DSMC only program. However, the DSMC technique remained far slower than the sectional technique alone.

${ }^{61}$ Shawn A. Campbell and Sudarshan K. Loyalka, "Computation of Aerosol Evolution under Coagulation," Nuclear Science and Engineering 181, no. 2 (2015). 


\section{BENCHMARK PROBLEMS}

Verification and validation of the DSMC method was carried out through a series of benchmark problems. Because of the complexity and non-linearity of the GDE, simplifications in aerosol models made it possible to solve these benchmark problems analytically. Although the benchmark problems used simplified aerosol physics models, the commodity of having the exact analytical solutions gave strong insights to the verification and validation of the DSMC method as well as to aerosol physics. The derivation of the analytical solutions have been provided and compared with the DSMC solutions in the following sections. We should note here that the following benchmarks were carried out in collaboration with colleagues and a paper relating to this chapter has been accepted for publication.

\subsection{Benchmark 1: Single-Component Coagulation, Condensation, and Deposition}

We wish to solve the GDE for a single-component aerosol with constant coagulation, condensation, and deposition in a spatially homogenous medium. This is an adaptation of Case 1 of Ramabhadran et al. (1976) with a constant deposition term included. ${ }^{62}$ The GDE for this scenario reduces to:

\footnotetext{
${ }^{62}$ Ramabhadran et al., "Dynamics of Aerosol Coagulation and Condensation."
} 


$$
\begin{array}{r}
\frac{\partial}{\partial t} n(v, t)=-\frac{\partial}{\partial v}(I(v, t) n(v, t))+\frac{1}{2} \int_{0}^{v} \mathrm{~d} v^{\prime} K\left(v^{\prime}, v\right) n\left(v-v^{\prime}, t\right) n\left(v^{\prime}, t\right) \\
-n(v, t) \int_{0}^{\infty} \mathrm{d} v^{\prime} K\left(v^{\prime}, v\right) n\left(v^{\prime}, t\right)-R(v, t) n(v, t)
\end{array}
$$

For a single-component aerosol species, Ramabhadran et al. prescribed an initial exponential distribution of the form:

$$
n(v, 0)=\frac{N_{0}}{v_{0}} \operatorname{Exp}\left[-\frac{v}{v_{0}}\right]
$$

where $N_{0}$ is the initial number of particles and $v_{0}$ is the average particle volume. The coagulation, condensation, and deposition models for Case 1 of Ramabhadran et al. are given as:

$$
\begin{gathered}
K\left(v^{\prime}, v\right)=K_{0} \\
I(v, t)=\sigma_{0} v \\
R(v, t)=R_{0}
\end{gathered}
$$

where $K_{0}, \sigma_{0}$, and $R_{0}$ are constants in units of $s^{-1}$. Inserting the condensation models into the reduced GDE, we get:

$$
\begin{array}{r}
\frac{\partial}{\partial t} n(v, t)=-\frac{\partial}{\partial v}\left(\sigma_{0} v n(v, t)\right)+\frac{1}{2} K_{0} \int_{0}^{v} \mathrm{~d} v^{\prime} n\left(v-v^{\prime}, t\right) n\left(v^{\prime}, t\right) \\
-K_{0} n(v, t) \int_{0}^{\infty} \mathrm{d} v^{\prime} n\left(v^{\prime}, t\right)-R_{0} n(v, t)
\end{array}
$$

The above equation can be solved exactly. To solve it analytically, we first begin by defining: 


$$
N(t)=\int_{0}^{\infty} n(v, t) \mathrm{d} v
$$

where $N(0)=N_{0}$. Integrating equation (4.1-2) on $v$ from 0 to $\infty$, we get:

$$
\begin{aligned}
\int_{0}^{\infty} \frac{\partial}{\partial t} n(v, t) \mathrm{d} v= & -\sigma_{0} \int_{0}^{\infty} \frac{\partial}{\partial v}(v n(v, t)) \mathrm{d} v \\
& +\frac{1}{2} K_{0} \int_{0}^{\infty} \mathrm{d} v \int_{0}^{v} \mathrm{~d} v^{\prime} n\left(v-v^{\prime}, t\right) n\left(v^{\prime}, t\right) \\
& -K_{0} \int_{0}^{\infty} n(v, t) \mathrm{d} v \int_{0}^{\infty} \mathrm{d} v^{\prime} n\left(v^{\prime}, t\right)-R_{0} \int_{0}^{\infty} n(v, t) \mathrm{d} v
\end{aligned}
$$

By our definition of $N(t)$, equation (4.1-3) reduces to:

$$
\begin{aligned}
\frac{d}{d t} N(t) & =\frac{1}{2} K_{0} N^{2}(t)-K_{0} N(t) N(t)-R_{0} N(t) \\
& =-\frac{1}{2} K_{0} N^{2}(t)-R_{0} N(t)
\end{aligned}
$$

Using our initial condition $N(0)=N_{0}$, we find the solution to equation (4.1-4) as:

$$
N(t)=\frac{2 N_{0} R_{0}}{\operatorname{Exp}\left[R_{0} t\right]\left(2 R_{0}+K_{0} N_{0}\right)-K_{0} N_{0}}
$$

Now, taking the Laplace Transform on $v$ of the initial condition and equation (4.1-2), we get:

$$
\begin{gathered}
L\{n(v, 0)\}(s)=\bar{n}(s, 0)=\frac{N_{0}}{\left(s+\frac{1}{v_{0}}\right) v_{0}} \\
L\left\{\frac{\partial}{\partial t} n(v, t)\right\}(s)=\frac{\partial}{\partial t} \bar{n}(s, t)=\sigma_{0} s \frac{\partial}{\partial s}(\bar{n}(s, t))+\frac{1}{2} K_{0} \bar{n}^{2}(s, t) \\
-K_{0} \bar{n}(s, t) N(t)-R_{0} \bar{n}(s, t)
\end{gathered}
$$

Substituting our result for $N(t)$ in equation (4.1-5) into equation (4.1-7), we get: 


$$
\begin{array}{r}
\frac{\partial}{\partial t} \bar{n}(s, t)=\sigma_{0} s \frac{\partial}{\partial s}(\bar{n}(s, t))+\frac{1}{2} K_{0} \bar{n}^{2}(s, t) \\
-\frac{2 N_{0} R_{0} K_{0} \bar{n}(s, t)}{\operatorname{Exp}\left[R_{0} t\right]\left(2 R_{0}+K_{0} N_{0}\right)-K_{0} N_{0}} \\
-R_{0} \bar{n}(s, t)
\end{array}
$$

Using the initial condition for $\bar{n}(s, 0)$ in equation (4.1-6), we can now solve the differential equation (4.1-8) for $\bar{n}(s, t)$. This solution for $\bar{n}(s, t)$ can then be used to find $n(v, t)$ by taking the Inverse Laplace Transform of $\bar{n}(s, t)$. From this process, the analytical solution for $n(v, t)$ of a single-component aerosol with constant coagulation, condensation, and deposition is:

$$
n(v, t)=4 N_{0} R_{0}^{2} \frac{\operatorname{Exp}\left[-\sigma_{0} t-\xi(t)\right] \operatorname{Exp}\left[\sigma_{0} t\right] \frac{R_{0}}{\sigma_{0}}}{v_{0}\left(N_{0} K_{0}-\operatorname{Exp}\left[R_{0} t\right]\left(2 R_{0}+N_{0} K_{0}\right)\right)^{2}}
$$

where:

$$
\xi(t)=\frac{2 \operatorname{Exp}\left[\sigma_{0} t\right]^{-1+\frac{R_{0}}{\sigma_{0}}} R_{0} v}{v_{0}\left(-N_{0} K_{0}+\operatorname{Exp}\left[R_{0} t\right]\left(2 R_{0}+N_{0} K_{0}\right)\right)}
$$

Using the values: $N_{0}=10^{4}$ particles $/ \mathrm{m}^{3}, v_{0}=1.8 \times 10^{-22} \mathrm{~m}^{3}$,

$\rho_{c o m p 1}=1000 \mathrm{~kg} / \mathrm{m}^{3}, \rho_{\mathrm{H}_{2} \mathrm{O}}=1000 \mathrm{~kg} / \mathrm{m}^{3}, K_{0}=1.0 \times 10^{-6} \mathrm{~s}^{-1}$,

$\sigma_{0}=1.0 \times 10^{-2} s^{-1}$, and $R_{0}=1.0 \times 10^{-1} s^{-1}$, Figure 13 compares the exact analytical and DSMC solutions to the time-dependent aerosol size distribution using 20 bins spaced logarithmically by volumes ranging from $v_{\min }=10^{-27} \mathrm{~m}^{3}$ to $v_{\max }=10^{-19} \mathrm{~m}^{3}$. The red lines in Figure 13 represent the number of particles per bin from the exact analytical 
solution whereas the blue bars represent the histogram of particles per bin from the DSMC solution. From the "Number Distribution" portion of Figure 13, we see that the number of particles diminishes over the 15 seconds and that the DSMC solution agrees quite well with the exact analytical solution for all times. The decrease in particle number is largely due to aerosol deposition followed by successful coagulation. Aerosol condensation is most evident in the "Component Mass Distribution" part of Figure 13. Since the aerosols were assumed to be initially dry, no water is present in the suspended aerosol composition at time $t=0 \mathrm{~s}$. As time progresses, we can see that water becomes an increasing part of the aerosol particles' composition as water begins to condense onto the surface of the aerosols. Since we have an exact solution, we can directly compute the accuracy of the DSMC solution with the analytical solution. Table 5 compares the total number of suspended particles by the analytical and DSMC solutions as a function of time and computes the error between the two. From the last column in Table 5 the average error in the DSMC solution was found to be $0.42 \%$ of the analytical solution with a standard deviation of 0.41 .

The DSMC method is based on random numbers for statistical accuracy. As the number of particles increases, the error in the DSMC solution decreases. To show this, the same simulation was redone using a larger initial number of particles $\left(N_{0}=10^{5}\right.$ particles $\left./ \mathrm{m}^{3}\right)$ while keeping the same inputs as before. The results from this process are shown in Figure 14 and the associated errors in total aerosol particles suspended are given in Table 6. The results from the analytical and DSMC solution agree very well. From Table 6, we see that the error in the total number of suspended 
aerosol particles predicted by the DSMC solution are within an average of error of $0.31 \%$ with a standard deviation of 0.29 of the analytical solution.

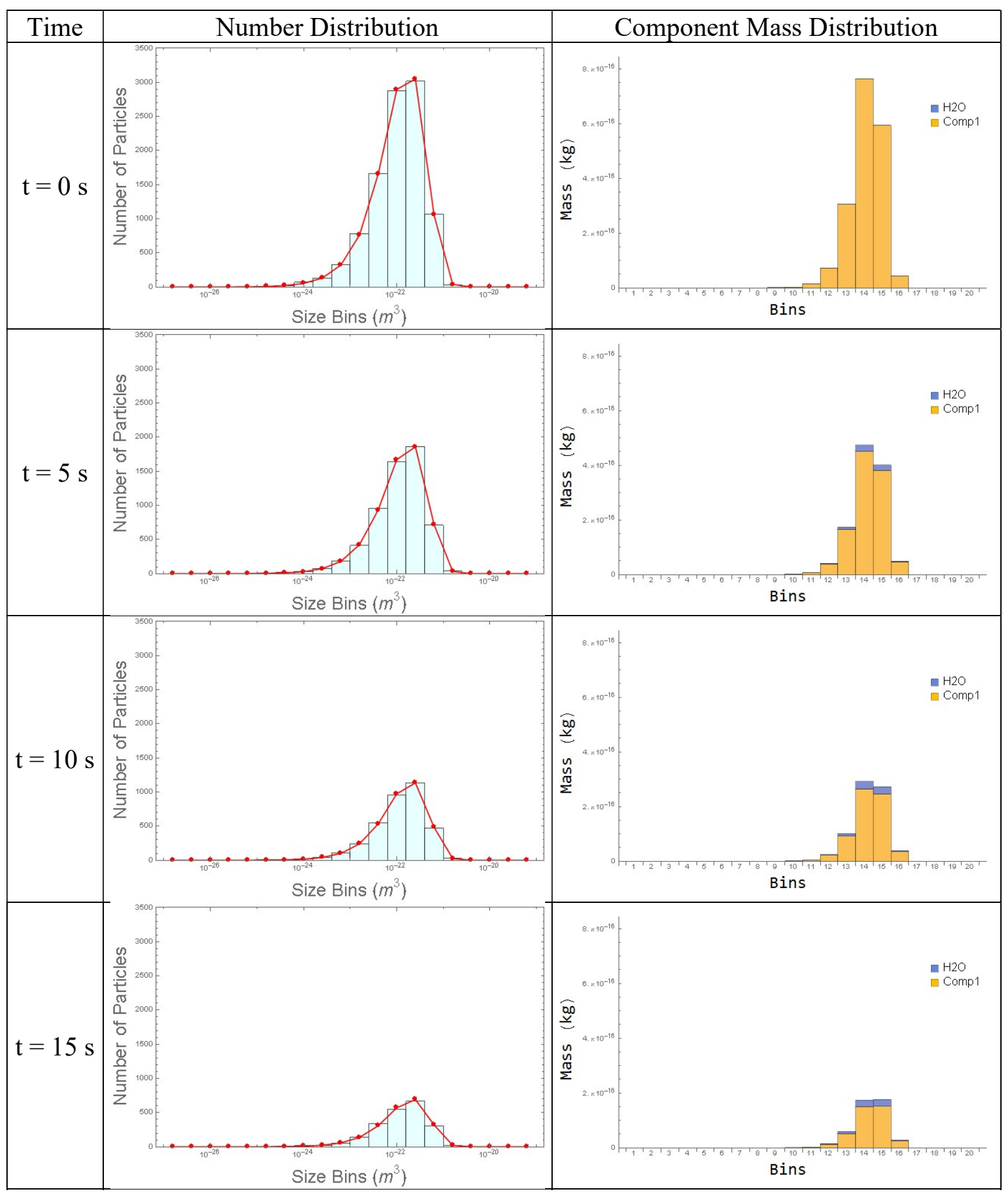

Figure 13: Number and mass distribution for $10^{4}$ single-component aerosols under constant coagulation, condensation, and deposition 
Table 5: Percent error in the DSMC technique for $10^{4}$ single-component aerosols under constant coagulation, condensation, and deposition

\begin{tabular}{|c|c|c|c|}
\hline Time (s) & NExact & NDSMC & Error (\%) \\
\hline $\mathbf{0 . 0}$ & 9999 & 10000 & 0.010001 \\
\hline $\mathbf{1 . 0}$ & 9004 & 9018 & 0.155486 \\
\hline $\mathbf{2 . 0}$ & 8115 & 8098 & 0.209489 \\
\hline $\mathbf{3 . 0}$ & 7313 & 7311 & 0.027349 \\
\hline $\mathbf{4 . 0}$ & 6596 & 6596 & 0.000000 \\
\hline $\mathbf{5 . 0}$ & 5948 & 5936 & 0.201748 \\
\hline $\mathbf{6 . 0}$ & 5367 & 5393 & 0.484442 \\
\hline $\mathbf{7 . 0}$ & 4844 & 4862 & 0.371594 \\
\hline $\mathbf{8 . 0}$ & 4373 & 4399 & 0.594558 \\
\hline $\mathbf{9 . 0}$ & 3946 & 3971 & 0.633553 \\
\hline $\mathbf{1 0 . 0}$ & 3565 & 3560 & 0.140252 \\
\hline $\mathbf{1 1 . 0}$ & 3221 & 3215 & 0.186278 \\
\hline $\mathbf{1 2 . 0}$ & 2910 & 2909 & 0.034364 \\
\hline $\mathbf{1 3 . 0}$ & 2629 & 2626 & 0.114112 \\
\hline $\mathbf{1 4 . 0}$ & 2376 & 2370 & 0.252525 \\
\hline $\mathbf{1 5 . 0}$ & 2148 & 2126 & 1.024210 \\
\hline $\mathbf{1 6 . 0}$ & 1941 & 1938 & 0.154560 \\
\hline $\mathbf{1 7 . 0}$ & 1753 & 1737 & 0.912721 \\
\hline $\mathbf{1 8 . 0}$ & 1587 & 1576 & 0.693132 \\
\hline $\mathbf{1 9 . 0}$ & 1433 & 1414 & 1.325890 \\
\hline $\mathbf{2 0 . 0}$ & 1295 & 1278 & 1.312740 \\
\hline & & & \\
\hline
\end{tabular}




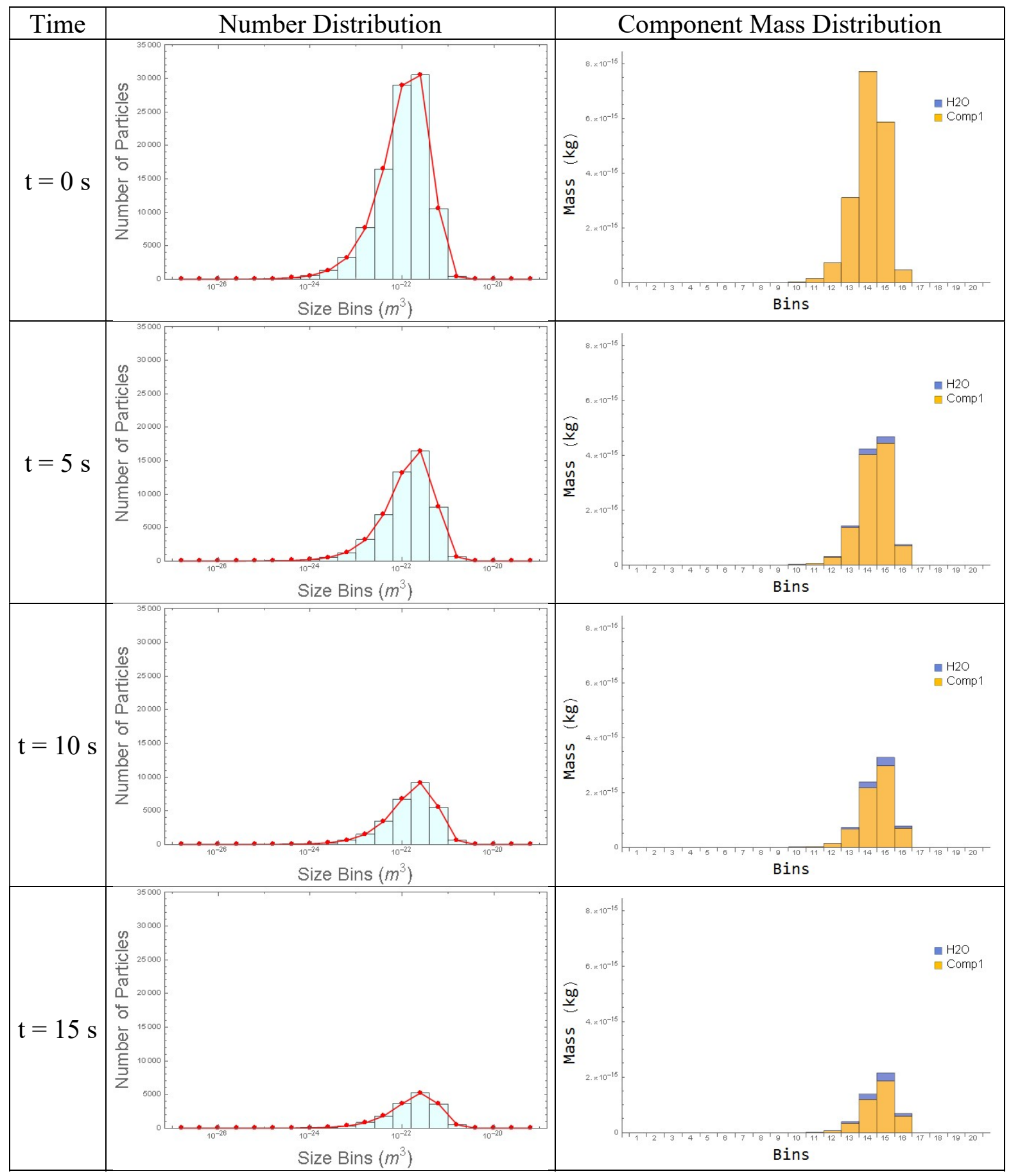

Figure 14: Number and mass distribution for $10^{5}$ single-component aerosols under constant coagulation, condensation, and deposition 
Table 6: Percent error in the DSMC Technique for $10^{5}$ single-component aerosols under constant coagulation, condensation, and deposition

\begin{tabular}{|c|c|c|c|}
\hline Time (s) & NExact & NoSMC & Error (\%) \\
\hline $\mathbf{0 . 0}$ & 100000 & 100000 & 0.000000 \\
\hline $\mathbf{1 . 0}$ & 86374 & 86139 & 0.272073 \\
\hline $\mathbf{2 . 0}$ & 75069 & 74913 & 0.207809 \\
\hline $\mathbf{3 . 0}$ & 65581 & 65427 & 0.234824 \\
\hline $\mathbf{4 . 0}$ & 57545 & 57357 & 0.326701 \\
\hline $\mathbf{5 . 0}$ & 50681 & 50638 & 0.084844 \\
\hline $\mathbf{6 . 0}$ & 44780 & 44676 & 0.232247 \\
\hline $\mathbf{7 . 0}$ & 39673 & 39625 & 0.120989 \\
\hline $\mathbf{8 . 0}$ & 35230 & 35202 & 0.079478 \\
\hline $\mathbf{9 . 0}$ & 31353 & 31373 & 0.063790 \\
\hline $\mathbf{1 0 . 0}$ & 27952 & 27976 & 0.085862 \\
\hline $\mathbf{1 1 . 0}$ & 24960 & 25002 & 0.168269 \\
\hline $\mathbf{1 2 . 0}$ & 22319 & 22376 & 0.255388 \\
\hline $\mathbf{1 3 . 0}$ & 19984 & 20062 & 0.390312 \\
\hline $\mathbf{1 4 . 0}$ & 17913 & 18003 & 0.502428 \\
\hline $\mathbf{1 5 . 0}$ & 16069 & 16127 & 0.360943 \\
\hline $\mathbf{1 6 . 0}$ & 14430 & 14472 & 0.291060 \\
\hline $\mathbf{1 7 . 0}$ & 12967 & 12987 & 0.154238 \\
\hline $\mathbf{1 8 . 0}$ & 11662 & 11729 & 0.574516 \\
\hline $\mathbf{1 9 . 0}$ & 10493 & 10581 & 0.838654 \\
\hline $\mathbf{2 0 . 0}$ & 9448 & 9569 & 1.280690 \\
\hline & & & \\
\hline
\end{tabular}




\subsection{Benchmark 2: Two-Component Coagulation and Deposition}

We now consider the GDE for a two-component aerosol with constant coagulation and deposition in a spatially homogeneous medium. This problem is an extension of the work by Williams and Loyalka (1991) with constant removal and no condensation. ${ }^{63}$ The constant coagulation and deposition models given by Williams and Loyalka are:

$$
\begin{aligned}
& K\left(v_{1}, v_{2}\right)=K_{0} \\
& R\left(v_{1}, v_{2}, t\right)=R_{0}
\end{aligned}
$$

where $K_{0}$ and $R_{0}$ are constants. After substituting the coagulation and deposition models into the GDE for this system, the expression reduces to:

$$
\begin{aligned}
\frac{\partial}{\partial t} n\left(v_{1}, v_{2}, t\right)= & \frac{1}{2} K_{0} \int_{0}^{v_{1}} \mathrm{~d} u_{1} \int_{0}^{v_{2}} \mathrm{~d} u_{2} n\left(v_{1}-u_{1}, v_{2}-u_{2}, t\right) n\left(u_{1}, u_{2}, t\right) \\
& -K_{0} n\left(v_{1}, v_{2}, t\right) \int_{0}^{\infty} \mathrm{d} u_{1} \int_{0}^{\infty} \mathrm{d} u_{2} n\left(u_{1}, u_{2}, t\right)-R_{0} n\left(v_{1}, v_{2}, t\right)
\end{aligned}
$$

For a two-component aerosol species, Williams and Loyalka assumed an initial exponential distribution for both aerosol species of the form:

$$
n\left(v_{1}, v_{2}, 0\right)=\frac{N_{0}}{v_{1,0} v_{2,0}} \operatorname{Exp}\left[-\left(\frac{v_{1}}{v_{1,0}}+\frac{v_{2}}{v_{2,0}}\right)\right]
$$

where $N_{0}$ is the initial number of particles per unit volume in units of particles $/ \mathrm{m}^{3}$, and $v_{1,0}$ and $v_{2,0}$ are the mean particle volumes for the first and second aerosol species in units of $m^{3}$, respectively.

${ }^{63}$ Williams and Loyalka, Aerosol Science: Theory and Practice: With Special Applications to the Nuclear Industry, 258. 
Equation (4.2-1) is one of the special cases where the GDE can be solved exactly.

To solve it analytically, we first begin by defining:

$$
\hat{N}(t)=\int_{0}^{\infty} \mathrm{d} v_{1} \int_{0}^{\infty} \mathrm{d} v_{2} n\left(v_{1}, v_{2}, t\right)
$$

where $\hat{N}(0)=N_{0}$. Integrating equation (4.2-1) on $v$ from 0 to $\infty$, we get:

$$
\begin{array}{r}
\int_{0}^{\infty} \mathrm{d} v_{1} \int_{0}^{\infty} \mathrm{d} v_{2} \frac{\partial}{\partial t} n\left(v_{1}, v_{2}, t\right) \\
=\frac{1}{2} K_{0} \int_{0}^{\infty} \mathrm{d}_{1} \int_{0}^{\infty} \mathrm{d} v_{2} \int_{0}^{v_{1}} \mathrm{~d} u_{1} \int_{0}^{v_{2}} \mathrm{~d} u_{2} n\left(v_{1}-u_{1}, v_{2}-u_{2}, t\right) n\left(u_{1}, u_{2}, t\right) \\
-K_{0} \int_{0}^{\infty} \mathrm{d} v_{1} \int_{0}^{\infty} \mathrm{d} v_{2} n\left(v_{1}, v_{2}, t\right) \int_{0}^{\infty} \mathrm{d} u_{1} \int_{0}^{\infty} \mathrm{d} u_{2} n\left(u_{1}, u_{2}, t\right) \\
-R_{0} \int_{0}^{\infty} \mathrm{d} v_{1} \int_{0}^{\infty} \mathrm{d} v_{2} n\left(v_{1}, v_{2}, t\right)
\end{array}
$$

By our definition of $\hat{N}(t)$, equation (4.2-3) becomes the differential equation:

$$
\frac{d}{d t} \hat{N}(t)=-\frac{1}{2} K_{0} \hat{N}^{2}(t)-R_{0} \hat{N}(t)
$$

Using the initial condition that $\hat{N}(0)=N_{0}$, we can solve equation (4.2-4) to get:

$$
\hat{N}(t)=\frac{2 N_{0} R_{0}}{\operatorname{Exp}\left[R_{0} t\right]\left(K_{0} N_{0}+2 R_{0}\right)-K_{0} N_{0}}
$$

Now, taking the Laplace Transform on $v_{1}$ and $v_{2}$ of the initial distribution and equation (4.2-1), we get:

$$
L\left\{n\left(v_{1}, v_{2}, 0\right)\right\}(s)=\bar{n}\left(s_{1}, s_{2}, 0\right)=\frac{N_{0}}{\left(1+s_{1} v_{1,0}\right)\left(1+s_{2} v_{2,0}\right)}
$$

and: 


$$
\begin{aligned}
L\left\{\frac{\partial}{\partial t} n\left(v_{1}, v_{2}, t\right)\right\}(s) & =\bar{n}\left(s_{1}, s_{2}, t\right) \\
& =\frac{1}{2} K_{0} \bar{n}^{2}\left(s_{1}, s_{2}, t\right)-K_{0} \bar{n}\left(s_{1}, s_{2}, t\right) \hat{N}(t)-R_{0} \bar{n}\left(s_{1}, s_{2}, t\right)
\end{aligned}
$$

Using the initial condition for $\bar{n}\left(s_{1}, s_{2}, 0\right)$ in equation (4.2-6) and equation (4.2-5), we can now solve the differential equation (4.2-7) for $\bar{n}\left(s_{1}, s_{2}, t\right)$. This solution for $\bar{n}\left(s_{1}, s_{2}, t\right)$ can then be used to find $n\left(v_{1}, v_{2}, t\right)$ by taking two Inverse Laplace Transforms of $\bar{n}\left(s_{1}, s_{2}, t\right)$. From this process, the analytical solution for $n\left(v_{1}, v_{2}, t\right)$ of a two-component aerosol with constant coagulation and deposition is:

$$
n\left(v_{1}, v_{2}, t\right)=\gamma(t) \mathrm{I}_{0}\left[2 \sqrt{v_{1} v_{2} \alpha(t)}\right]
$$

where $I_{0}$ is a modified Bessel function of the first kind of order zero and:

$$
\begin{aligned}
& \alpha(t)=\frac{\left(-1+\operatorname{Exp}\left[R_{0} t\right]\right) K_{0} N_{0}}{\left(-K_{0} N_{0}+\operatorname{Exp}\left[R_{0} t\right] K_{0} N_{0}+2 R_{0} \operatorname{Exp}\left[R_{0} t\right]\right) v_{1,0} v_{2,0}} \\
& \gamma(t)=4 N_{0} R^{2} \frac{\operatorname{Exp}\left[-\left(\frac{v_{1}}{v_{1,0}}+\frac{v_{2}}{v_{2,0}}\right)+R_{0} t\right]}{v_{1,0} v_{2,0}\left(K_{0} N_{0}-\operatorname{Exp}\left[R_{0} t\right]\left(K_{0} N_{0}+2 R_{0}\right)\right)^{2}}
\end{aligned}
$$

For a two-component aerosol of equal densities $\left(\rho_{1}=\rho_{2}=1000 \mathrm{~kg} / \mathrm{m}^{3}\right)$ and $N_{0}=10^{4}$ particles $/ \mathrm{m}^{3}, v_{1,0}=1.8 \times 10^{-15} \mathrm{~m}^{3}, v_{2,0}=1.8 \times 10^{-15} \mathrm{~m}^{3}$, $K_{0}=5.0 \times 10^{-6}$, and $R_{0}=10^{-1}$, Figure 15 compares the analytical and DSMC solutions for the time-dependent evolution of the two aerosol species using 20 bins logarithmically spaced by particle volumes ranging from $v_{\text {min }}=10^{-20} \mathrm{~m}^{3}$ to $v_{\max }=10^{-10} \mathrm{~m}^{3}$. As we can see from the "Number Distribution" of Figure 15, the 
number of particles per bin from the analytical solution (red line) is well approximated by the DSMC solution (blue histograms) for all times. Since coagulation and deposition are the only processes allowed in this scenario, we can see that the number of suspended aerosols diminishes rather quickly. The errors for the number distribution have been calculated in Table 7. The average error for total aerosol particles in the DSMC solution is $0.27 \%$ of the analytical solution with a standard deviation of 0.23 . Figure 15 also shows the "Component Mass Distribution." For simplicity, an initially dry, twocomponent aerosol of equal densities and of equal size distribution was chosen such that each aerosol (although of different species) would behave much like the other. By inspection, we can see that this is true for both aerosol species in the mass composition plots because each bin has exactly half of each component for all times. From Table 8 and Table 9, the average errors in the suspended component masses were found to be $0.88 \%$ and $0.49 \%$ for aerosol components 1 and 2 , respectively.

The same simulation was redone with the same two-component aerosol but with $10^{5}$ initial particles, while keeping all the other inputs the same. The graphical results are shown in Figure 16 and the associated errors in the number of suspended aerosols and component mass have been tabulated in Table 10 through Table 12. As we can see from these and previous results that the DSMC method is an accurate method for simulating multi-component aerosol dynamics. 


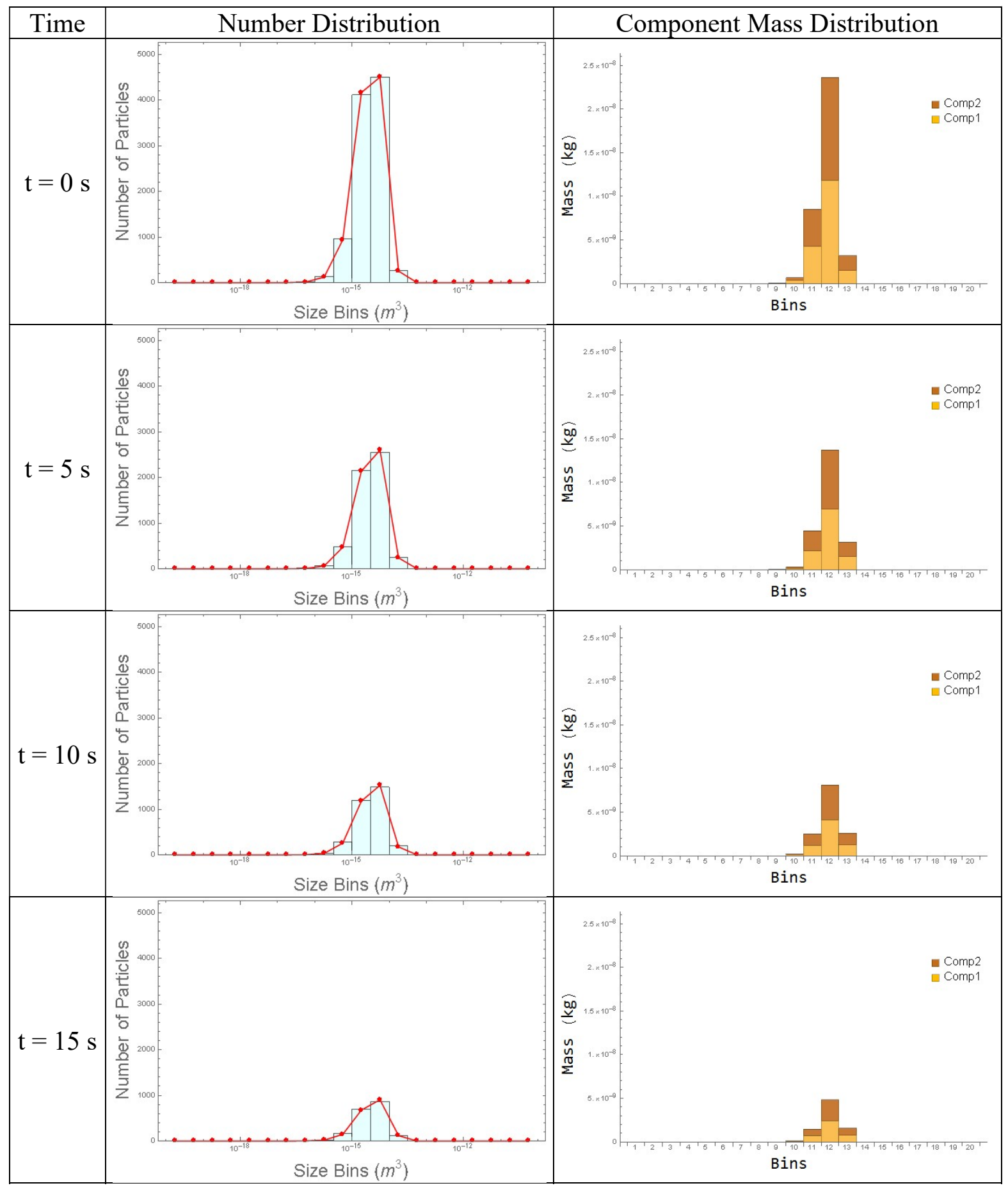

Figure 15: Number and mass distribution for $10^{4}$ two-component aerosols under constant coagulation and deposition 
Table 7: Percent error in the DSMC technique for $10^{4}$ two-component aerosols under constant coagulation and deposition

\begin{tabular}{|c|c|c|c|}
\hline Time (s) & NExact & NDSMC & Error (\%) \\
\hline $\mathbf{0 . 0}$ & 9999 & 10000 & 0.010001 \\
\hline $\mathbf{1 . 0}$ & 8838 & 8876 & 0.429962 \\
\hline $\mathbf{2 . 0}$ & 7832 & 7877 & 0.574566 \\
\hline $\mathbf{3 . 0}$ & 6957 & 6990 & 0.474342 \\
\hline $\mathbf{4 . 0}$ & 6193 & 6203 & 0.161473 \\
\hline $\mathbf{5 . 0}$ & 5523 & 5523 & 0.000000 \\
\hline $\mathbf{6 . 0}$ & 4932 & 4934 & 0.040552 \\
\hline $\mathbf{7 . 0}$ & 4410 & 4416 & 0.136054 \\
\hline $\mathbf{8 . 0}$ & 3950 & 3966 & 0.405063 \\
\hline $\mathbf{9 . 0}$ & 3540 & 3558 & 0.508475 \\
\hline $\mathbf{1 0 . 0}$ & 3177 & 3202 & 0.786906 \\
\hline $\mathbf{1 1 . 0}$ & 2852 & 2855 & 0.105189 \\
\hline $\mathbf{1 2 . 0}$ & 2564 & 2566 & 0.078003 \\
\hline $\mathbf{1 3 . 0}$ & 2306 & 2296 & 0.433651 \\
\hline $\mathbf{1 4 . 0}$ & 2074 & 2072 & 0.096432 \\
\hline $\mathbf{1 5 . 0}$ & 1867 & 1865 & 0.107124 \\
\hline
\end{tabular}

Table 8: Percent error in suspended mass for component 1

\begin{tabular}{|c|c|c|c|}
\hline Time (s) & Exact $\mathbf{m}_{\mathbf{1}} \mathbf{( k g )}$ & DSMC $_{\mathbf{1}} \mathbf{( k g )}$ & Error $\mathbf{m}_{\mathbf{1}}(\mathbf{\%})$ \\
\hline $\mathbf{0 . 0}$ & $1.80644 \times 10^{-8}$ & $1.79374 \times 10^{-8}$ & 0.703060 \\
\hline $\mathbf{1 . 0}$ & $1.63466 \times 10^{-8}$ & $1.62556 \times 10^{-8}$ & 0.556744 \\
\hline $\mathbf{2 . 0}$ & $1.47918 \times 10^{-8}$ & $1.47057 \times 10^{-8}$ & 0.582398 \\
\hline $\mathbf{3 . 0}$ & $1.33848 \times 10^{-8}$ & $1.32269 \times 10^{-8}$ & 1.179300 \\
\hline $\mathbf{4 . 0}$ & $1.21114 \times 10^{-8}$ & $1.19709 \times 10^{-8}$ & 1.159740 \\
\hline $\mathbf{5 . 0}$ & $1.09590 \times 10^{-8}$ & $1.07902 \times 10^{-8}$ & 1.540550 \\
\hline $\mathbf{6 . 0}$ & $9.91625 \times 10^{-9}$ & $9.83682 \times 10^{-9}$ & 0.800951 \\
\hline $\mathbf{7 . 0}$ & $8.97263 \times 10^{-9}$ & $8.86943 \times 10^{-9}$ & 1.150150 \\
\hline $\mathbf{8 . 0}$ & $8.11877 \times 10^{-9}$ & $8.08504 \times 10^{-9}$ & 0.415445 \\
\hline $\mathbf{9 . 0}$ & $7.34615 \times 10^{-9}$ & $7.31390 \times 10^{-9}$ & 0.439053 \\
\hline $\mathbf{1 0 . 0}$ & $6.64704 \times 10^{-9}$ & $6.71255 \times 10^{-9}$ & 0.985537 \\
\hline $\mathbf{1 1 . 0}$ & $6.01445 \times 10^{-9}$ & $6.03227 \times 10^{-9}$ & 0.296282 \\
\hline $\mathbf{1 2 . 0}$ & $5.44206 \times 10^{-9}$ & $5.41054 \times 10^{-9}$ & 0.579253 \\
\hline $\mathbf{1 3 . 0}$ & $4.92415 \times 10^{-9}$ & $4.84821 \times 10^{-9}$ & 1.542120 \\
\hline $\mathbf{1 4 . 0}$ & $4.45552 \times 10^{-9}$ & $4.39902 \times 10^{-9}$ & 1.268000 \\
\hline $\mathbf{1 5 . 0}$ & $4.03149 \times 10^{-9}$ & $3.99271 \times 10^{-9}$ & 0.961910 \\
\hline
\end{tabular}


Table 9: Percent error in suspended mass for component 2

\begin{tabular}{|c|c|c|c|}
\hline Time (s) & Exact $\mathbf{m}_{\mathbf{2}} \mathbf{( k g )}$ & ${\text { DSMC } \mathbf{m}_{\mathbf{2}} \mathbf{( k g )}}$ Error $\mathbf{m}_{\mathbf{2}} \mathbf{( \% )}$ \\
\hline $\mathbf{0 . 0}$ & $1.79785 \times 10^{-8}$ & $1.80718 \times 10^{-8}$ & 0.5193430 \\
\hline $\mathbf{1 . 0}$ & $1.62634 \times 10^{-8}$ & $1.63818 \times 10^{-8}$ & 0.7279040 \\
\hline $\mathbf{2 . 0}$ & $1.47121 \times 10^{-8}$ & $1.48904 \times 10^{-8}$ & 1.2125300 \\
\hline $\mathbf{3 . 0}$ & $1.33089 \times 10^{-8}$ & $1.33580 \times 10^{-8}$ & 0.3692080 \\
\hline $\mathbf{4 . 0}$ & $1.20398 \times 10^{-8}$ & $1.19876 \times 10^{-8}$ & 0.4333920 \\
\hline $\mathbf{5 . 0}$ & $1.08919 \times 10^{-8}$ & $1.08451 \times 10^{-8}$ & 0.4291100 \\
\hline $\mathbf{6 . 0}$ & $9.85361 \times 10^{-9}$ & $9.83954 \times 10^{-9}$ & 0.1427700 \\
\hline $\mathbf{7 . 0}$ & $8.91447 \times 10^{-9}$ & $8.88547 \times 10^{-9}$ & 0.3253190 \\
\hline $\mathbf{8 . 0}$ & $8.06497 \times 10^{-9}$ & $8.13038 \times 10^{-9}$ & 0.8110470 \\
\hline $\mathbf{9 . 0}$ & $7.29654 \times 10^{-9}$ & $7.30996 \times 10^{-9}$ & 0.1838860 \\
\hline $\mathbf{1 0 . 0}$ & $6.60141 \times 10^{-9}$ & $6.65891 \times 10^{-9}$ & 0.8709960 \\
\hline $\mathbf{1 1 . 0}$ & $5.97259 \times 10^{-9}$ & $5.97125 \times 10^{-9}$ & 0.0223747 \\
\hline $\mathbf{1 2 . 0}$ & $5.40372 \times 10^{-9}$ & $5.39841 \times 10^{-9}$ & 0.0983382 \\
\hline $\mathbf{1 3 . 0}$ & $4.88909 \times 10^{-9}$ & $4.84635 \times 10^{-9}$ & 0.8741660 \\
\hline $\mathbf{1 4 . 0}$ & $4.42351 \times 10^{-9}$ & $4.43238 \times 10^{-9}$ & 0.2006510 \\
\hline $\mathbf{1 5 . 0}$ & $4.00229 \times 10^{-9}$ & $3.97543 \times 10^{-9}$ & 0.6712170 \\
\hline
\end{tabular}




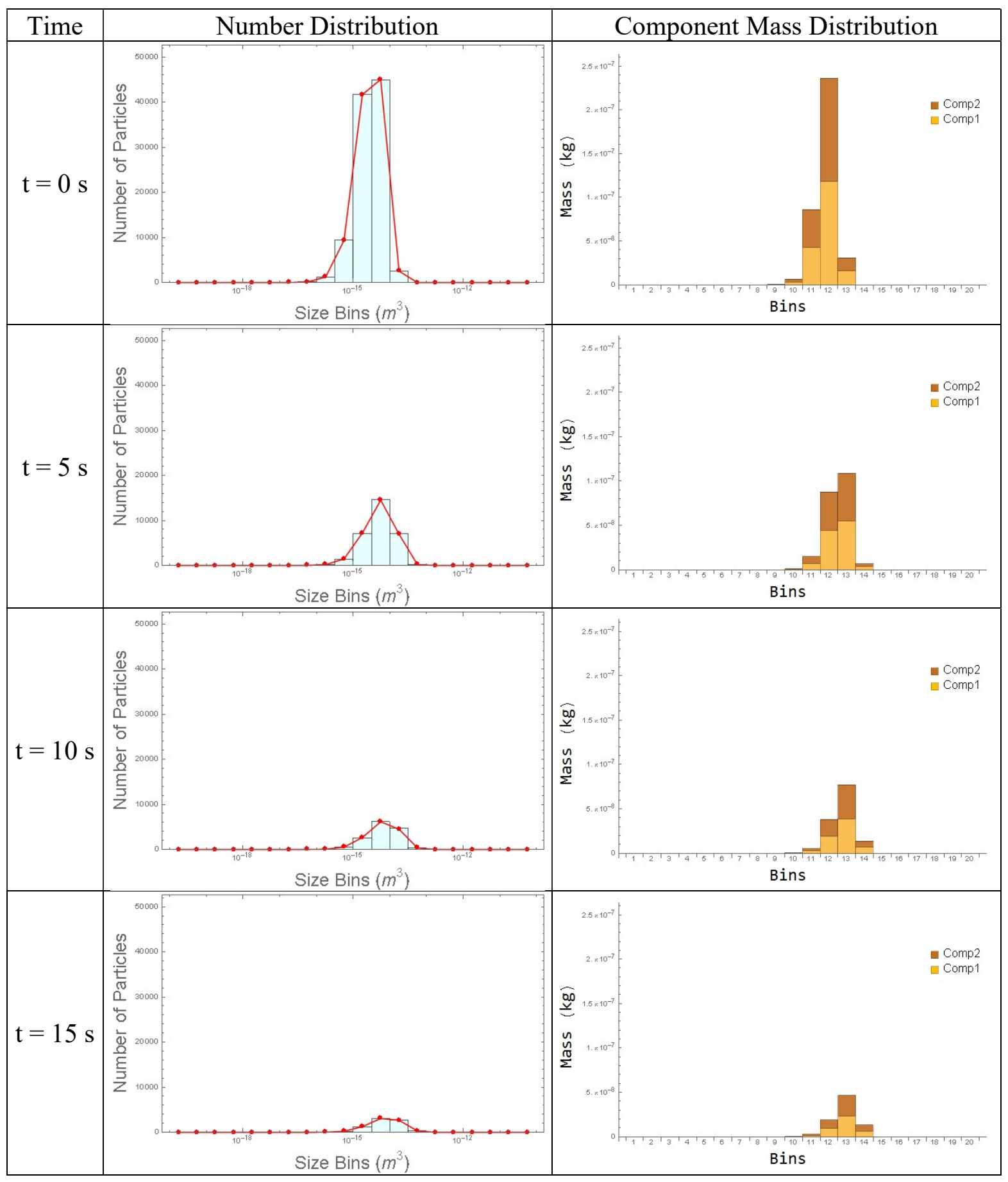

Figure 16: Number and mass distribution for $10^{5}$ two-component aerosols under constant coagulation and deposition 
Table 10: Percent error in the DSMC technique for $10^{5}$ two-component aerosols under constant coagulation and deposition

\begin{tabular}{|c|c|c|c|}
\hline Time (s) & NExact & NosMC & Error (\%) \\
\hline $\mathbf{0 . 0}$ & 99997 & 100000 & 0.003000 \\
\hline $\mathbf{1 . 0}$ & 73094 & 72907 & 0.255835 \\
\hline $\mathbf{2 . 0}$ & 56340 & 56069 & 0.481008 \\
\hline $\mathbf{3 . 0}$ & 44953 & 44653 & 0.667364 \\
\hline $\mathbf{4 . 0}$ & 36746 & 36543 & 0.552441 \\
\hline $\mathbf{5 . 0}$ & 30575 & 30483 & 0.300899 \\
\hline $\mathbf{6 . 0}$ & 25792 & 25737 & 0.213244 \\
\hline $\mathbf{7 . 0}$ & 21985 & 21934 & 0.231976 \\
\hline $\mathbf{8 . 0}$ & 18906 & 18812 & 0.497197 \\
\hline $\mathbf{9 . 0}$ & 16370 & 16349 & 0.128283 \\
\hline $\mathbf{1 0 . 0}$ & 14257 & 14283 & 0.182367 \\
\hline $\mathbf{1 1 . 0}$ & 12477 & 12439 & 0.304560 \\
\hline $\mathbf{1 2 . 0}$ & 10965 & 10944 & 0.191518 \\
\hline $\mathbf{1 3 . 0}$ & 9669 & 9690 & 0.217189 \\
\hline $\mathbf{1 4 . 0}$ & 8551 & 8533 & 0.210502 \\
\hline $\mathbf{1 5 . 0}$ & 7583 & 7559 & 0.316497 \\
\hline
\end{tabular}

Table 11: Percent error in suspended mass for component 1

\begin{tabular}{|c|c|c|c|}
\hline Time (s) & Exact $\mathbf{m}_{\mathbf{1}} \mathbf{( k g )}$ & DSMC $_{\mathbf{1}} \mathbf{( k g )}$ & Error $\mathbf{m}_{\mathbf{1}} \mathbf{( \% )}$ \\
\hline $\mathbf{0 . 0}$ & $1.80644 \times 10^{-7}$ & $1.80036 \times 10^{-7}$ & 0.337005 \\
\hline $\mathbf{1 . 0}$ & $1.63474 \times 10^{-7}$ & $1.62950 \times 10^{-7}$ & 0.320750 \\
\hline $\mathbf{2 . 0}$ & $1.47898 \times 10^{-7}$ & $1.47526 \times 10^{-7}$ & 0.251221 \\
\hline $\mathbf{3 . 0}$ & $1.33967 \times 10^{-7}$ & $1.33267 \times 10^{-7}$ & 0.522270 \\
\hline $\mathbf{4 . 0}$ & $1.21482 \times 10^{-7}$ & $1.21085 \times 10^{-7}$ & 0.326807 \\
\hline $\mathbf{5 . 0}$ & $1.10215 \times 10^{-7}$ & $1.09868 \times 10^{-7}$ & 0.315122 \\
\hline $\mathbf{6 . 0}$ & $9.99955 \times 10^{-8}$ & $9.96937 \times 10^{-8}$ & 0.301817 \\
\hline $\mathbf{7 . 0}$ & $9.07016 \times 10^{-8}$ & $9.05191 \times 10^{-8}$ & 0.201280 \\
\hline $\mathbf{8 . 0}$ & $8.22439 \times 10^{-8}$ & $8.19693 \times 10^{-8}$ & 0.333930 \\
\hline $\mathbf{9 . 0}$ & $7.45492 \times 10^{-8}$ & $7.43320 \times 10^{-8}$ & 0.291340 \\
\hline $\mathbf{1 0 . 0}$ & $6.75534 \times 10^{-8}$ & $6.76429 \times 10^{-8}$ & 0.132519 \\
\hline $\mathbf{1 1 . 0}$ & $6.11978 \times 10^{-8}$ & $6.05983 \times 10^{-8}$ & 0.979618 \\
\hline $\mathbf{1 2 . 0}$ & $5.54281 \times 10^{-8}$ & $5.51398 \times 10^{-8}$ & 0.520055 \\
\hline $\mathbf{1 3 . 0}$ & $5.01934 \times 10^{-8}$ & $5.02397 \times 10^{-8}$ & 0.092293 \\
\hline $\mathbf{1 4 . 0}$ & $4.54467 \times 10^{-8}$ & $4.52715 \times 10^{-8}$ & 0.385473 \\
\hline $\mathbf{1 5 . 0}$ & $4.11442 \times 10^{-8}$ & $4.10263 \times 10^{-8}$ & 0.286618 \\
\hline
\end{tabular}


Table 12: Percent error in suspended mass for component 2

\begin{tabular}{|c|c|c|c|}
\hline Time (s) & Exact $\mathbf{m}_{2}(\mathbf{k g})$ & DSMC $\mathbf{m}_{2} \mathbf{( k g )}$ & Error m2 $\mathbf{( \% )}$ \\
\hline $\mathbf{0 . 0}$ & $1.79785 \times 10^{-7}$ & $1.79542 \times 10^{-7}$ & 0.134757 \\
\hline $\mathbf{1 . 0}$ & $1.62228 \times 10^{-7}$ & $1.62385 \times 10^{-7}$ & 0.096848 \\
\hline $\mathbf{2 . 0}$ & $1.46677 \times 10^{-7}$ & $1.46897 \times 10^{-7}$ & 0.150444 \\
\hline $\mathbf{3 . 0}$ & $1.32947 \times 10^{-7}$ & $1.33082 \times 10^{-7}$ & 0.101405 \\
\hline $\mathbf{4 . 0}$ & $1.20669 \times 10^{-7}$ & $1.20496 \times 10^{-7}$ & 0.143261 \\
\hline $\mathbf{5 . 0}$ & $1.09565 \times 10^{-7}$ & $1.09140 \times 10^{-7}$ & 0.387474 \\
\hline $\mathbf{6 . 0}$ & $9.94614 \times 10^{-8}$ & $9.86625 \times 10^{-8}$ & 0.803236 \\
\hline $\mathbf{7 . 0}$ & $9.02499 \times 10^{-8}$ & $8.93358 \times 10^{-8}$ & 1.012890 \\
\hline $\mathbf{8 . 0}$ & $8.18519 \times 10^{-8}$ & $8.07389 \times 10^{-8}$ & 1.359810 \\
\hline $\mathbf{9 . 0}$ & $7.42027 \times 10^{-8}$ & $7.31524 \times 10^{-8}$ & 1.415460 \\
\hline $\mathbf{1 0 . 0}$ & $6.72435 \times 10^{-8}$ & $6.65770 \times 10^{-8}$ & 0.991116 \\
\hline $\mathbf{1 1 . 0}$ & $6.09187 \times 10^{-8}$ & $5.96485 \times 10^{-8}$ & 2.085130 \\
\hline $\mathbf{1 2 . 0}$ & $5.51759 \times 10^{-8}$ & $5.43151 \times 10^{-8}$ & 1.560040 \\
\hline $\mathbf{1 3 . 0}$ & $4.99653 \times 10^{-8}$ & $4.95232 \times 10^{-8}$ & 0.884728 \\
\hline $\mathbf{1 4 . 0}$ & $4.52403 \times 10^{-8}$ & $4.45425 \times 10^{-8}$ & 1.542440 \\
\hline $\mathbf{1 5 . 0}$ & $4.09576 \times 10^{-8}$ & $4.04401 \times 10^{-8}$ & 1.263520 \\
\hline
\end{tabular}

\subsection{Benchmark 3: Two-Component Coagulation and Condensation}

The evolution of a two-component aerosol under constant condensation and coagulation rates in a spatially homogeneous medium can be described by the following reduced GDE:

$$
\begin{aligned}
& \frac{\partial}{\partial t} n\left(v_{1}, v_{2}, t\right)=-\sum_{p=1}^{2} \sigma_{p} \frac{\partial}{\partial t}\left[v_{p} n\left(v_{1}, v_{2}, t\right)\right] \\
&+\frac{1}{2} K_{0} \int_{0}^{v_{2}} \int_{0}^{v_{1}} n\left(u_{1}, u_{2}, t\right) n\left(v_{1}-u_{1}, v_{2}-u_{2}, t\right) \mathrm{d} u_{1} \mathrm{~d} u_{2} \\
& \quad-K_{0} n\left(v_{1}, v_{2}, t\right) \int_{0}^{\infty} \int_{0}^{\infty} n\left(u_{1}, u_{2}, t\right) \mathrm{d} u_{1} \mathrm{~d} u_{2}
\end{aligned}
$$


An exact analytical solution to equation (4.3-1) has been shown for an initial aerosol distribution of the form: ${ }^{64,65}$

$$
n\left(v_{1}, v_{2}, 0\right)=n_{0}\left(v_{1}, v_{2}\right)=\frac{N_{0}}{v_{1,0} v_{2,0}} \operatorname{Exp}\left[-\left(\frac{v_{1}}{v_{1,0}}+\frac{v_{2}}{v_{2,0}}\right)\right]
$$

where $N_{0}$ is the initial number of particles, and the average initial aerosol volumes are $v_{1,0}$ and $v_{2,0}$ for the first and second aerosol components, respectively.

The solution to equation (4.3-1) with an initial condition as described in equation (4.3-2) can be found by defining a two-dimensional Laplace Transform $\bar{n}\left(s_{1}, s_{2}, t\right)$ and calculating the total particle density $N(t)=\bar{n}(0,0, t)$ with the transformations:

$$
\begin{gathered}
T=\frac{\tau}{1+\tau} \\
\bar{p}=\frac{2 \bar{n}}{(1+T)^{2}}
\end{gathered}
$$

where $\tau=K_{0} N_{0} t / 2$. The general solution for $n\left(v_{1}, v_{2}, t\right)$ is found from solving the resulting partial differential equation for $\bar{p}\left(s_{1}, s_{1}, t\right)$ by the method of characteristics and then finally inverting the Laplace Transform to obtain:

${ }^{64}$ Fred Gelbard and John H. Seinfeld, "Coagulation and Growth of a Multicomponent Aerosol," Journal of Colloid and Interface Science 63, no. 3 (1978): 472-479.

${ }^{65}$ Williams and Loyalka, Aerosol Science: Theory and Practice: With Special Applications to the Nuclear Industry, 258-260. 


$$
\begin{aligned}
n\left(v_{1}, v_{2}, t\right) & \\
=\frac{N_{0}}{(1+\tau)^{2}} \frac{1}{v_{1,0} v_{2,0}} \operatorname{Exp}\left[-2\left(\Lambda_{1}+\right.\right. & \left.\left.\Lambda_{2}\right) \tau-\operatorname{Exp}\left[-2 \Lambda_{1} \tau\right]-\frac{v_{2}}{v_{2,0}} \operatorname{Exp}\left[-2 \Lambda_{2} \tau\right]\right] \\
& \times \mathrm{I}_{0}\left[2\left[\frac{\tau v_{1} v_{2}}{(1+\tau) v_{1,0} v_{2,0}} \operatorname{Exp}\left[2\left(\Lambda_{1}+\Lambda_{2}\right) \tau\right]\right]^{1 / 2}\right]
\end{aligned}
$$

where $I_{0}$ is the modified Bessel function of the first kind of order zero, $\Lambda_{1}=\sigma_{1} /\left(K_{0} N_{0}\right)$, $\Lambda_{2}=\sigma_{2} /\left(K_{0} N_{0}\right)$, and $\tau=K_{0} N_{0} t / 2$

For a two-component aerosol with $\rho_{c o m p 1}=\rho_{c o m p 2}=\rho_{H_{2} O}=1000 \mathrm{~kg} / \mathrm{m}^{3}$ and $N_{0}=10^{5}$ particles $, v_{1,0}=v_{2,0}=1.8 \times 10^{-15} \mathrm{~m}^{3}, K_{0}=10^{-5} \mathrm{~s}^{-1}$, $\sigma_{1}=7.5 \times 10^{-3} s^{-1}, \sigma_{2}=5 \times 10^{-3} s^{-1}$, Figure 17 compares the exact analytical and DSMC solutions for the time-dependent aerosol evolution using 20 bins spaced logarithmically by particle volumes ranging from $10^{-20} \mathrm{~m}^{3}$ to $10^{-10} \mathrm{~m}^{3}$. The red lines in Figure 17 represent the number of particles per bin from the exact analytical solution whereas the blue bars represent the histogram of particles per bin from the DSMC solution. From the "Number Distribution" portion of Figure 17, we see that the DSMC solutions agrees quite well with the exact analytical solution for all times. Since the aerosols were assumed to be initially dry, no water was present in the suspended aerosol composition at time $t=0 \mathrm{~s}$. As time progresses, water becomes an increasing part of the aerosol particles' composition as each component accumulates condensing water. From the right column of Figure 17, we can see the increase in suspended aerosol mass due to condensation while the number of particles decreases due to coagulation. The error between the exact and DSMC solutions has been calculated for total number of 
particles, mass component one, and mass component two in Tables 13-15. The DSMC technique agreed quite well each of the aforementioned quantities and approximated each well within a $1 \%$ error.

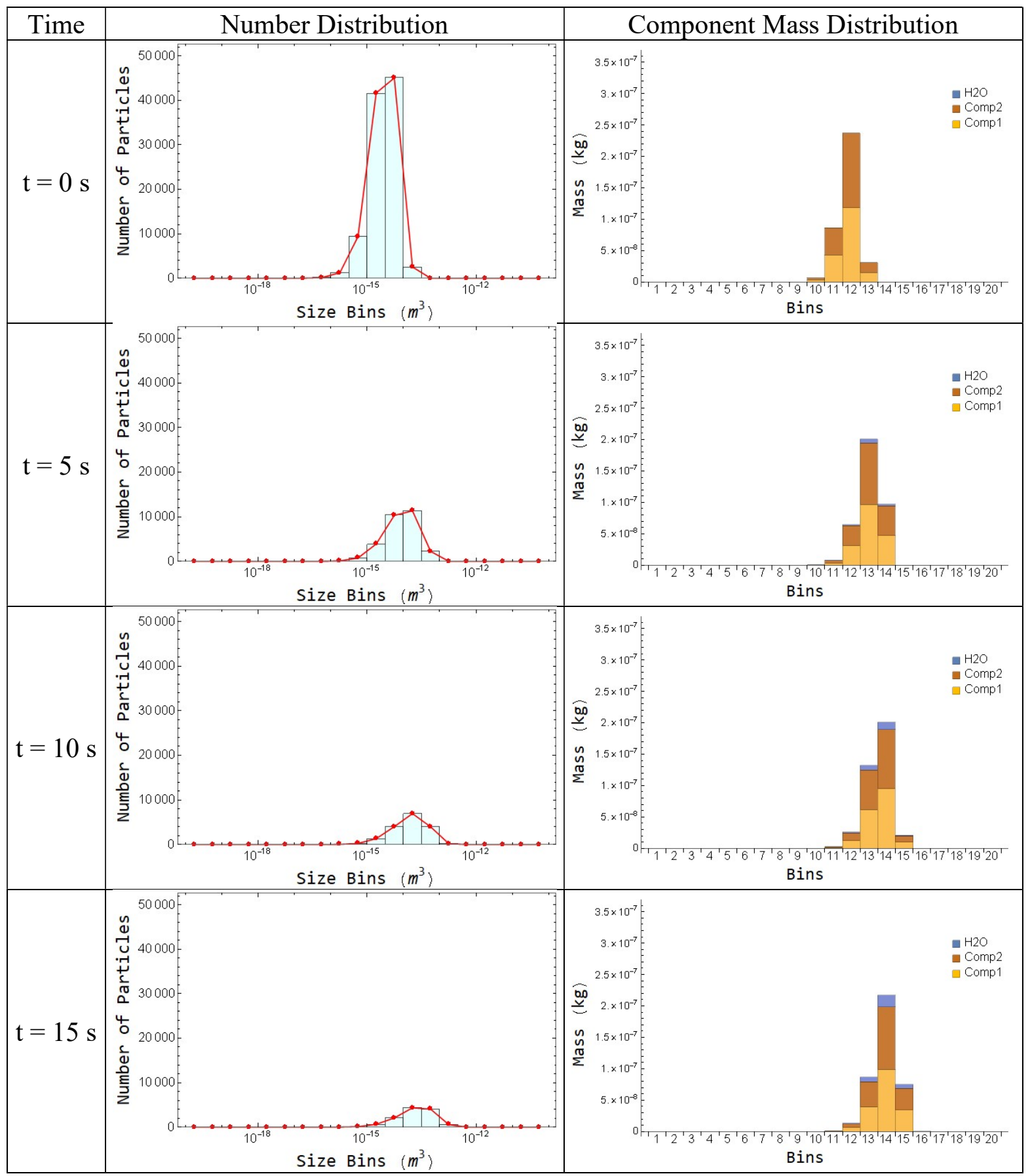

Figure 17: Number and mass distribution for $10^{5}$ two-component aerosols under constant coagulation and condensation 
Table 13: Percent error in the DSMC technique for $10^{5}$ two-component aerosols under constant coagulation and condensation

\begin{tabular}{|c|c|c|c|}
\hline Time (s) & Nexact & NosMc & Error (\%) \\
\hline $\mathbf{0 . 0}$ & 100000 & 100000 & 0.000 \\
\hline $\mathbf{5 . 0}$ & 28571 & 28522 & 0.170 \\
\hline $\mathbf{1 0 . 0}$ & 16667 & 16643 & 0.140 \\
\hline $\mathbf{1 5 . 0}$ & 11765 & 11757 & 0.068 \\
\hline $\mathbf{2 0 . 0}$ & 9091 & 9099 & 0.088 \\
\hline $\mathbf{2 5 . 0}$ & 7407 & 7415 & 0.110 \\
\hline $\mathbf{3 0 . 0}$ & 6250 & 6300 & 0.800 \\
\hline
\end{tabular}

Table 14: Percent error in suspended mass for component 1

\begin{tabular}{|c|c|c|c|}
\hline Time (s) & Exact mi $\mathbf{~ ( k g )}$ & DSMC mi $\mathbf{~}(\mathbf{k g})$ & Error mi $\mathbf{( \% )}$ \\
\hline $\mathbf{0 . 0}$ & $1.79999 \times 10^{-7}$ & $1.79678 \times 10^{-7}$ & 0.18 \\
\hline $\mathbf{5 . 0}$ & $1.86878 \times 10^{-7}$ & $1.86508 \times 10^{-7}$ & 0.20 \\
\hline $\mathbf{1 0 . 0}$ & $1.94019 \times 10^{-7}$ & $1.93619 \times 10^{-7}$ & 0.21 \\
\hline $\mathbf{1 5 . 0}$ & $2.01433 \times 10^{-7}$ & $2.01007 \times 10^{-7}$ & 0.21 \\
\hline $\mathbf{2 0 . 0}$ & $2.09130 \times 10^{-7}$ & $2.08679 \times 10^{-7}$ & 0.22 \\
\hline $\mathbf{2 5 . 0}$ & $2.17121 \times 10^{-7}$ & $2.16646 \times 10^{-7}$ & 0.22 \\
\hline $\mathbf{3 0 . 0}$ & $2.25418 \times 10^{-7}$ & $2.24919 \times 10^{-7}$ & 0.22 \\
\hline
\end{tabular}

Table 15: Percent error in suspended mass for component 2

\begin{tabular}{|c|c|c|c|}
\hline Time (s) & Exact $\mathbf{m}_{\mathbf{2}} \mathbf{( k g )}$ & DSMC $\mathbf{m}_{\mathbf{2}} \mathbf{( k g )}$ & Error $\mathbf{m}_{\mathbf{2}}(\mathbf{\%})$ \\
\hline $\mathbf{0 . 0}$ & $1.79999 \times 10^{-7}$ & $1.80320 \times 10^{-7}$ & 0.18 \\
\hline $\mathbf{5 . 0}$ & $1.84557 \times 10^{-7}$ & $1.84861 \times 10^{-7}$ & 0.17 \\
\hline $\mathbf{1 0 . 0}$ & $1.89229 \times 10^{-7}$ & $1.89531 \times 10^{-7}$ & 0.16 \\
\hline $\mathbf{1 5 . 0}$ & $1.94019 \times 10^{-7}$ & $1.94322 \times 10^{-7}$ & 0.16 \\
\hline $\mathbf{2 0 . 0}$ & $1.98931 \times 10^{-7}$ & $1.99236 \times 10^{-7}$ & 0.15 \\
\hline $\mathbf{2 5 . 0}$ & $2.03967 \times 10^{-7}$ & $2.04275 \times 10^{-7}$ & 0.15 \\
\hline $\mathbf{3 0 . 0}$ & $2.09130 \times 10^{-7}$ & $2.09443 \times 10^{-7}$ & 0.15 \\
\hline
\end{tabular}




\section{CONDENSATION AND MODELS}

\subsection{Introduction}

Condensation plays an important role in aerosol growth and gravitational deposition. Production aerosol transport codes currently use Mason's equation to approximate particle growth by condensation. Mason's equation is derived by solving the coupled mass and heat rate equations with the saturation pressure and ClausiusClapeyron relations. The derivation of the saturation pressure equation, ClausiusClapeyron equation, and combination of these equations have been provided in Appendix A. The development of Mason's equation has been derived explicitly in Appendix B. Assuming spherical particles, Mason's equation for describing the radial growth rate of a given particle due to condensation is:

$$
r \frac{d r}{d t}=\frac{(S-1)}{\left[\frac{L \rho_{L}}{K T_{\infty}}\left(\frac{L M}{R T_{\infty}}-1\right)+\frac{R T \rho_{L}}{D M P_{s}\left(T_{\infty}\right)}\right]}
$$

where $r$ is the particle's radius, $S$ is the saturation ratio, $L$ is the latent heat of water vapor, $M$ is the molar mass, $K$ is the thermal conductivity of the mixture, $T_{\infty}$ is the ambient temperature, $R$ is the universal gas constant, $\rho_{L}$ is the density of liquid water, $D$ is the diffusion coefficient, and $P_{s}\left(T_{\infty}\right)$ is the saturation pressure at infinity. Mason's equation can be transformed to give the mass condensation rate as a function of particle radius as: 


$$
\psi_{\text {Mason }}(r)=\frac{d m}{d t}=4 \pi r(S-1)\left[\frac{L}{K T_{\infty}}\left(\frac{L M}{R T_{\infty}}-1\right)+\frac{1}{D \rho_{s}\left(T_{\infty}\right)}\right]^{-1}
$$

or in terms of particle volume as:

$$
\psi_{\text {Mason }}(v)=4 \pi\left(\frac{3 v}{4 \pi}\right)^{1 / 3} D \rho_{s}\left(\frac{S-1}{(L D / K) \rho_{s} \beta+1}\right)
$$

where the $\frac{1}{T_{\infty}}$ term in equation (5.1-2) is assumed to be negligible so that $\beta=\frac{L m_{v}}{k T_{\infty}^{2}}$ in equation (5.1-3).

\subsection{Generalized Mason Equation}

Mason's equation alone has been shown to be unsuitable for modeling aerosol condensation and improvements to Mason's equation have been widely investigated. ${ }^{66,67,68,69,70,71}$ As cited in Loyalka and Park (1988), Mason's equation is only suitable for "large" particles (i.e., particles with radii greater than $1 \mu \mathrm{m}$ ). Loyalka and Park built upon Mason's work by incorporating the Knudsen effects into Mason's mass

${ }^{66}$ N. Fukuta and L. A. Walter, "Kinetics of Hydrometeor Growth from a Vapor-Spherical Model," Journal of the Atmospheric Sciences 27, no. 8 (1970).

${ }^{67}$ J. C. Barrett and C. F. Clement, "Growth Rates for Liquid Drops," Journal of Aerosol Science 19, no. 2 (1988).

${ }^{68}$ J. Jokiniemi, "Effect of Selected Binary and Mixed Solutions on Steam Condensation and Aerosol Behavior in Containment," Aerosol Science and Technology 12, no. 4 (1990).

${ }^{69}$ M. Kulmala, "Condensational Growth and Evaporation in the Transition Regime: An Analytical Expression," Aerosol Science and Technology 19, no. 3 (1993).

${ }^{70}$ A. Laaksonen et al., "Commentary on Cloud Modelling and the Mass Accommodation Coefficient of Water," Atmospheric Chemistry and Physics 5, no. 2 (2005).

${ }^{71}$ Bal Raj Sehgal, Nuclear Safety in Light Water Reactors: Severe Accident Phenomenology (Amsterdam: Elsevier/Academic Press). 
condensation rate; this modification allowed for Mason's equation to be suitable for particle of all sizes. The modified Mason equation for mass condensation rate with Knudsen effects derived by Loyalka and Park is given as:

$$
\psi_{\text {modified }}(v)=4 \pi\left(\frac{3 v}{4 \pi}\right)^{1 / 3} D \rho_{s}(S-1) \times \frac{f_{c}\left(K n_{c}\right) f_{h}\left(K n_{h}\right)}{(L D / K) \rho_{s} \beta f_{c}\left(K n_{c}\right)+f_{h}\left(K n_{h}\right)}
$$

where $\beta=\frac{L m_{v}}{k T_{\infty}^{2}}$ and the factors $f_{c}\left(K n_{c}\right)$ and $f_{h}\left(K n_{h}\right)$ account for the Knudsen

effects. Per Loyalka and Park, these factors can be written as:

$$
f_{c}\left(K n_{c}\right)=\left[1+K n_{c}\left(\frac{\left(F_{c o n t} / F_{f m}\right)_{c} \xi_{c}+\zeta_{c}}{K n_{c} \xi_{c}+1}\right)\right]^{-1}
$$

and:

$$
f_{h}\left(K n_{h}\right)=\left[1+K n_{h}\left(\frac{\left(F_{\text {cont }} / F_{\text {fm }}\right)_{h} \xi_{h}+\zeta_{h}}{K n_{h} \xi_{h}+1}\right)\right]^{-1}
$$

where $K n_{c}=\frac{\lambda_{D}}{R_{i}}, K n_{h}=\frac{\lambda_{t}}{R_{i}},\left(\frac{F_{\text {cont }}}{F_{f m}}\right)_{c}=\sqrt{\pi} K n_{c},\left(\frac{F_{\text {cont }}}{F_{f m}}\right)_{h}=\frac{5}{4} \sqrt{\pi} K n_{h}$,

$\lambda_{D}=2 D\left(\frac{m_{v}}{2 k T_{\infty}}\right)^{1 / 2}, \lambda_{t}=\frac{4}{5} \frac{K T_{\infty}}{P_{\infty}}\left(\frac{m_{g}}{2 k T_{\infty}}\right)^{1 / 2}, \xi_{c}=1.333, \xi_{h}=1.9234$

$\zeta_{c}=1.0161, \zeta_{h}=1.1759 \frac{5}{8} \sqrt{\pi}$, and $m_{g}$ is the molecular mass of the background gas.

It is important to note that Mason's equation is recovered by simply setting $f_{c}\left(K n_{c}\right)=1$ and $f_{h}\left(K n_{h}\right)=1$ in the modified Mason model.

Condensation plays a crucial role in aerosol growth and ultimately gravitational deposition. Although the modified Mason equation can be applied to particles of all 
sizes, a successful condensation model must include the Kelvin and solute effects. First, the Kevin effect describes the change in vapor pressure due to an individual particle's curvature. For spherical particles, the curvature (and thus the Kelvin effect) will depend solely on particle size; namely, the particle's radius. In addition, the Kelvin effect also defines the equilibrium droplet size (and thus the critical radius). The critical radius derived from the Kelvin effect is the dividing line between evaporation and condensation. A droplet above the critical radius will exhibit evaporation whereas a droplet below the critical radius experiences condensation. On the other hand, aerosol size and composition are altered directly by the coagulation and condensation processes. Changes in particle composition also affects the condensation rate through hygroscopic (or non-hygroscopic) effects. Hygroscopicity is the affinity for absorbing water from its surrounding environment. Examples of hygroscopic chemical compounds include zinc chloride, potassium hydroxide, and many other salts. Particularly, we want to include hygroscopic effects in the condensation process to model $\mathrm{CsOH}$, an extremely hygroscopic substance, and $\mathrm{MnO}$, a non-hygroscopic substance. The dissolvability of molecules in a liquid droplet causes the lowering of vapor pressure compared to that of the vapor pressure of a similar size droplet of pure water; this is characterized as the solute effect.

For the reasons mentioned above, we have expanded upon the work by Loyalka and Park with the objective of incorporating the Kelvin and solute effects to find a more complete and generalized version of Mason's equation. Per Loyalka and Park, the modified mass and heat rate equations are:

$$
\frac{d m}{d t}=4 \pi r D\left(\rho_{s}\left(T_{\infty}\right)-\rho_{s}^{\prime}\left(T_{r}\right)\right) f_{c}\left(K n_{c}\right)
$$




$$
L \frac{d m}{d t}=4 \pi r K\left(T_{\infty}-T_{r}\right) f_{h}\left(K n_{h}\right)
$$

where $f_{c}\left(K n_{c}\right)$ and $f_{h}\left(K n_{h}\right)$ are the Knudsen effects defined previously. The Kelvin and solute effects can be introduced into the mass saturation density by:

$$
\rho_{s}^{\prime}\left(T_{r}\right)=(1+\underbrace{\left(\frac{2 \sigma_{L V} M}{\rho_{L} R T r}\right)}_{\text {Kelvin }}-\underbrace{\left(\frac{i m M}{\frac{4}{3} \pi r^{3} \rho_{L} W}\right)}_{\text {solute }}) \rho_{s}\left(T_{r}\right)=X \rho_{s}\left(T_{r}\right)
$$

where $\sigma_{L V}$ is the specific surface tension of the liquid-vapor interface, $M$ is the molecular weight of water, $\rho_{L}$ is the density of water, $i$ is van't Hoff's factor, $m$ is the mass of the solute, $W$ is the molecular weight, and $X$ is defined as the quantity in parenthesis for simplicity. Using the results from Appendix B and making the appropriate substitutions to the heat rate equation, we get:

$$
\frac{\rho_{s}\left(T_{r}\right)-\rho_{s}\left(T_{\infty}\right)}{\rho_{s}\left(T_{\infty}\right)}=\left(\frac{L M-R T_{\infty}}{R T_{\infty}^{2}}\right)\left(\frac{L}{4 \pi r K}\right) \frac{1}{f_{h}\left(K n_{h}\right)} \frac{d m}{d t}
$$

Dividing the modified mass rate equation by $\rho_{s}\left(T_{\infty}\right)$ and rearranging, we get:

$$
\begin{gathered}
\frac{1}{\rho_{s}\left(T_{\infty}\right)} \frac{d m}{d t}=4 \pi r D\left(\frac{\rho_{s}\left(T_{\infty}\right)-X \rho_{s}\left(T_{r}\right)}{\rho_{s}\left(T_{\infty}\right)}\right) f_{c}\left(K n_{c}\right) \\
\frac{\rho_{s}\left(T_{\infty}\right)-X \rho_{s}\left(T_{r}\right)}{\rho_{s}\left(T_{\infty}\right)}=\frac{1}{4 \pi r D \rho_{s}\left(T_{\infty}\right)} \frac{1}{f_{c}\left(K n_{c}\right)} \frac{d m}{d t}
\end{gathered}
$$

Combining equation (5.2-4) and equation (5.2-5) gives:

$$
\begin{aligned}
\frac{\rho_{s}\left(T_{r}\right)-}{-} \rho_{s}\left(T_{\infty}\right)+\rho_{s}\left(T_{\infty}\right)-X \rho_{s}\left(T_{\infty}\right) \\
\quad=\left[\left(\frac{L}{4 \pi r K}\right)\left(\frac{L M-R T_{\infty}}{R T_{\infty}^{2}}\right) \frac{1}{f_{h}\left(K n_{h}\right)}+\left(\frac{1}{4 \pi r D \rho_{s}\left(T_{\infty}\right)}\right) \frac{1}{f_{c}\left(K n_{c}\right)}\right] \frac{d m}{d t}
\end{aligned}
$$


Rearranging terms and assuming $T_{\infty} \approx T_{r}$ we get:

$$
\begin{gathered}
\frac{\rho_{s}\left(T_{r}\right)-\rho_{s}\left(T_{\infty}\right)+\overbrace{\rho_{s}\left(T_{\infty}\right)}^{\approx \rho_{s}\left(T_{r}\right)}-X \rho_{s}\left(T_{\infty}\right)}{\rho_{s}\left(T_{\infty}\right)}=\frac{\rho_{s}\left(T_{r}\right)-\rho_{s}\left(T_{\infty}\right)+\rho_{s}\left(T_{r}\right)-X \rho_{s}\left(T_{\infty}\right)}{\rho_{s}\left(T_{\infty}\right)} \\
=(S-1)-(X-1) \underbrace{\left(\frac{\rho_{s}\left(T_{r}\right)}{\rho_{s}\left(T_{\infty}\right)}\right)}_{\approx 1}=(S-1)-(X-1) \\
=\left[\left(\frac{L}{4 \pi r K}\right)\left(\frac{L M-R T_{\infty}}{R T_{\infty}^{2}}\right) \frac{1}{f_{h}\left(K n_{h}\right)}+\left(\frac{1}{4 \pi r D \rho_{s}\left(T_{\infty}\right)}\right) \frac{1}{f_{c}\left(K n_{c}\right)}\right] \frac{d m}{d t}
\end{gathered}
$$

Solving for the mass rate gives:

$$
\begin{aligned}
\frac{d m}{d t}=[(S-1) & -(X-1)] \\
& \times\left[\left(\frac{L}{4 \pi r K}\right)\left(\frac{L M-R T_{\infty}}{R T_{\infty}^{2}}\right) \frac{1}{f_{h}\left(K n_{h}\right)}+\left[\frac{1}{4 \pi r D \rho_{s}\left(T_{\infty}\right)}\right) \frac{1}{f_{c}\left(K n_{c}\right)}\right]^{-1} \\
=4 \pi r[(S-1)-(X-1)] & \times\left[\left(\frac{L}{K}\right)\left(\frac{L M-R T_{\infty}}{R T_{\infty}^{2}}\right) \frac{1}{f_{h}\left(K n_{h}\right)}+\left(\frac{1}{D \rho_{s}\left(T_{\infty}\right)}\right) \frac{1}{f_{c}\left(K n_{c}\right)}\right]^{-1} \\
=4 \pi r D \rho_{s}\left(T_{\infty}\right)[(S-1)-(X-1)] & \times \frac{\rho_{s}\left(T_{\infty}\right)}{\rho_{s}\left(T_{\infty}\right)} \frac{D}{D} \frac{f_{c}\left(K n_{c}\right)}{f_{c}\left(K n_{c}\right)} \frac{f_{h}\left(K n_{h}\right)}{f_{h}\left(K n_{h}\right)} \\
\times & {\left[\left(\frac{L D}{K}\right)\left(\frac{L M}{R T_{\infty}^{2}}-\frac{1}{T_{\infty}}\right) \rho_{s}\left(T_{\infty}\right) f_{c}\left(K n_{c}\right)+f_{h}\left(K n_{h}\right)\right]^{-1} f_{c}\left(K n_{c}\right) f_{h}\left(K n_{h}\right) }
\end{aligned}
$$

Defining $\hat{\beta}=\frac{L M}{R T_{\infty}^{2}}-\frac{1}{T_{\infty}}$ and the mass condensation rate as a function of particle radius as $\psi_{\text {General }}(r)$, we can rearrange the above expression to get: 


$$
\begin{aligned}
\psi_{\text {General }}(r) & \cong \frac{d m}{d t} \\
& =4 \pi r D \rho_{s}\left(T_{\infty}\right)[(S-1)-(X-1)] \frac{f_{c}\left(K n_{c}\right) f_{h}\left(K n_{h}\right)}{\left(\frac{L D}{K}\right) \rho_{s}\left(T_{\infty}\right) \hat{\beta} f_{c}\left(K n_{c}\right)+f_{h}\left(K n_{h}\right)}
\end{aligned}
$$

where $\psi_{\text {General }}(r)$ is in units of $k g / s$. Thus, assuming spherical particles, Mason's generalized equation for the mass condensation rate as a function of particle radius with the Knudsen, Kelvin, and solute effects is:

$$
\begin{aligned}
\psi_{\text {General }}(r)=4 \pi r D \rho_{s}\left(T_{\infty}\right) & {\left[(S-1)-\left(\frac{2 \sigma_{L V} M}{\rho_{L} R T r}\right)+\left(\frac{i m M}{\frac{4}{3} \pi r^{3} \rho_{L} W}\right)\right] } \\
& \times \frac{f_{c}\left(K n_{c}\right) f_{h}\left(K n_{h}\right)}{\left(\frac{L D}{K}\right) \rho_{s}\left(T_{\infty}\right) \hat{\beta} f_{c}\left(K n_{c}\right)+f_{h}\left(K n_{h}\right)}
\end{aligned}
$$

where $\beta$ from equation (5.1-3) and equation (5.2-1) is replaced with $\hat{\beta}=\frac{L M}{R T_{\infty}^{2}}-\frac{1}{T_{\infty}}$ to avoid as many assumptions as possible and the $\left(\frac{2 \sigma_{L V} M}{\rho_{L} R T r}\right)$ and $\left(\frac{i m M}{\frac{4}{3} \pi r^{3} \rho_{L} W}\right)$ terms in equation (5.2-6) are the Kelvin and solute effects, respectively. Assuming spherical particles, a similar expression for the mass condensation rate as a function of particle volume may be found as:

$$
\begin{aligned}
\psi_{\text {General }}(v)=4 \pi\left(\frac{3 v}{4 \pi}\right)^{1 / 3} D \rho_{s}\left(T_{\infty}\right) & \left.(S-1)-\left(\frac{2 \sigma_{L V} M}{\rho_{L} R T r}\right)+\left(\frac{i m M}{\frac{4}{3} \pi r^{3} \rho_{L} W}\right)\right] \\
& \times \frac{f_{c}\left(K n_{c}\right) f_{h}\left(K n_{h}\right)}{\left(\frac{L D}{K}\right) \rho_{s}\left(T_{\infty}\right) \hat{\beta} f_{c}\left(K n_{c}\right)+f_{h}\left(K n_{h}\right)}
\end{aligned}
$$


Since the condensation and evaporation processes are interdependent, it is important to note here that any negative condensation predicted by the generalized Mason equation is implicitly representative of evaporation. It is also important to note here that for our purposes, only water is allowed to condense (or evaporate) onto (or off) the aerosol surfaces.

\subsection{Role of Aerosol Condensation}

Steam condensation is a relatively fast process which plays an important part in aerosol growth and gravitational deposition. Assuming spherical particles, the role of condensation has been evaluated for "dry" and "wet" codes for three test cases and all aerosol processes (i.e., coagulation, condensation, deposition, and source term) included. The three test cases used the realistic coagulation (with coagulation mechanisms including Brownian, gravitational, and turbulent coagulation kernels), realistic deposition (with mechanisms including particle diffusion and gravitational settling), and source term

processes. As previously stated, "dry" codes do not allow for aerosol particle growth (or reduction) by condensation (or evaporation). On the other hand, "wet" codes in this study will use Mason's generalized equation for the mass condensation rate with the Knudsen, Kelvin, and solute effects from equation (5.2-7). A summary of the test cases considered has been provided in Table 16. 
Table 16: DSMC test matrix

\begin{tabular}{|c|c|c|c|c|c|c|}
\hline & \multicolumn{3}{|c|}{ Dry Codes } & \multicolumn{3}{c|}{ Wet Codes } \\
\hline Test Case 1 & $\checkmark$ & & & $\checkmark$ & & $\checkmark$ \\
\hline Test Case 2 & & $\checkmark$ & & & $\checkmark$ & $\checkmark$ \\
\hline Test Case 3 & $\checkmark$ & $\checkmark$ & & $\checkmark$ & $\checkmark$ & $\checkmark$ \\
\hline & CsOH & MnO & $\mathrm{H}_{2} \mathrm{O}$ & $\mathrm{CsOH}$ & $\mathrm{MnO}$ & $\mathrm{H}_{2} \mathrm{O}$ \\
\hline & \multicolumn{4}{c|}{ Aerosol Components } \\
\hline
\end{tabular}

Due to the rapid nature of the condensation process, gravitational deposition increases significantly with increased condensation. In order to show the role that condensation plays in aerosol evolution, the mass deposition will be used to quantify how condensation changes the number of suspended aerosol particles. $\mathrm{CsOH}$ and $\mathrm{MnO}$ aerosols were used in all three test cases due to their hygroscopic and non-hygroscopic natures which heavily influences how each aerosol species will evolve by the condensation process. For all test cases, no initial aerosol distribution is assumed and all particles are introduced solely by the source term within the first five seconds of the simulation, and the cumulative aerosol mass deposited is tracked for a simulated time of 60 seconds. For our purposes, the source term aerosols are injected into the homogenous system with a source rate of $0.949 \times 10^{-9} \mathrm{~kg} / \mathrm{s}$. Source term aerosol particles were sampled randomly from a log-normal distribution with a $1.83 \times 10^{-18} \mathrm{~m}^{3}$ mean particle volume, and a 1.81 geometric standard deviation. Table 17 and Table 18 summarize the "dry" and "wet" test case procedures, respectively. Figure 18 though Figure 20 compare the results of the "dry" and "wet" codes in the DSMC test matrix for each test case. 
Test Case 1 considers a $\mathrm{CsOH}$ source term with and without condensation for the "wet" and "dry" simulations, respectively. Figure 18 compares the results of the "dry" and "wet" simulations for Test Case 1. Figure 18a shows that $\mathrm{CsOH}$ was deposited over time and that no $\mathrm{MnO}$ or $\mathrm{H}_{2} \mathrm{O}$ were deposited for the "dry" simulation. This was expected since $\mathrm{CsOH}$ was the only aerosol present in the simulation and because $\mathrm{H}_{2} \mathrm{O}$ was not removed from the supersaturated atmosphere through the condensation process because $\mathrm{H}_{2} \mathrm{O}$ was not allowed to condense onto the $\mathrm{CsOH}$ aerosol particles and could therefore not deposit alongside them. On the other hand, Figure $18 \mathrm{~b}$ shows that $\mathrm{CsOH}$ and $\mathrm{H}_{2} \mathrm{O}$ were both deposited and no $\mathrm{MnO}$ was deposited. The results summarized in Figure 18 for Test Case 1 show that $\mathrm{CsOH}$ alone deposits up to 12.5 times faster in "wet" codes than "dry" codes. The faster deposition rate for $\mathrm{CsOH}$ was expected due to the highly hygroscopic nature of $\mathrm{CsOH}$ which led to rapid aerosol condensational growth which in turn led to higher rates of $\mathrm{CsOH}$ deposition.

The aerosol evolution for a $\mathrm{MnO}$ source term with and without condensation for the "wet" and "dry" simulations were considered in Test Case 2. Figure 19 compares the results of the "dry" and "wet" simulations in parts a) and b) for Test Case 2. As seen in Figure 19a, MnO is the only aerosol deposited because it is the only aerosol species present throughout the simulation and because $\mathrm{H}_{2} \mathrm{O}$ was not condensed onto the $\mathrm{MnO}$ aerosols. Figure 19b, on the other hand, shows that condensation onto the MnO aerosols does occur despite $\mathrm{MnO}$ being a non-hygroscopic aerosol. Comparing the "dry" and "wet" results of Test Case 2 reveals that the condensation process of a single species, non-hygroscopic aerosol ( $\mathrm{MnO}$ in this case) deposits roughly 2.5 times faster in "wet" codes than in "dry" codes. It is important to note here that a particle's hygroscopicity is 
only one part of the condensation process. Since condensation also depends on thermalhydraulics and particle size (through the Knudsen and Kelvin effects), these two mechanisms may (or may not) dominate the non-hygroscopic nature of $\mathrm{MnO}$ and allow for condensational growth for aerosols within particular size ranges.

Finally, Test Case 3 considers a two-species aerosol source term and their respective evolution for "dry" and "wet" simulations. Test Case 3 is an important case to consider because it quantifies the evolution of a mixed aerosol though component mixing (due to coagulation), particle growth of mixed multi-species aerosols with hygroscopic and non-hygroscopic effects, and the associated deposition of those aerosols due to particle growth by coagulation and condensation. Figure 20 compares the results of the "dry" and "wet" simulations in parts a) and b) for Test Case 3. In Test Case 3, both $\mathrm{CsOH}$ and $\mathrm{MnO}$ were injected into our homogenous system independently of one another, each with a $0.949 \times 10^{-9} \mathrm{~kg} / \mathrm{s}$ source rate. From Figure 20a we can see that only $\mathrm{CsOH}$ and $\mathrm{MnO}$ were deposited in the "dry" simulation whereas Figure 20b shows that $\mathrm{CsOH}, \mathrm{MnO}$, and $\mathrm{H}_{2} \mathrm{O}$ were deposited in the "wet" simulation. The "dry" and "wet" results for Test Case 3 showed that $\mathrm{CsOH}$ and $\mathrm{MnO}$ deposited approximately 12 times and 3 times faster, respectively, when condensation is considered.

Table 17: Summary of "dry" test case procedure

\begin{tabular}{|c|l|}
\hline Time (s) & \multicolumn{1}{c|}{ Action } \\
\hline $\mathbf{0}$ & No initial aerosols present \\
\hline $\mathbf{0}-\mathbf{5}$ & $\begin{array}{l}\text { Coagulation, deposition, and source terms processes are allowed to occur. Each source term } \\
\text { aerosol is sampled randomly from a log-normal distribution with a source rate of } 0.949 \times \\
10^{-9} \mathrm{~kg} / \mathrm{s} .\end{array}$ \\
\hline $\mathbf{5}-\mathbf{6 0}$ & $\begin{array}{l}\text { Suspended aerosols remaining go through coagulation and deposition processes only. No } \\
\text { aerosols are injected. }\end{array}$ \\
\hline
\end{tabular}


Table 18: Summary of "wet" test case procedure

\begin{tabular}{|c|l|}
\hline Time (s) & \multicolumn{1}{c|}{ Action } \\
\hline $\mathbf{0}$ & No initial aerosols present \\
\hline $\mathbf{0}-\mathbf{5}$ & $\begin{array}{l}\text { Coagulation, condensation, deposition, and source terms processes are allowed to occur. Each } \\
\text { source term aerosol is sampled randomly from a log-normal distribution with a source rate of } \\
0.949 \times 10^{-9} \mathrm{~kg} / \mathrm{s} .\end{array}$ \\
\hline $\mathbf{5 - 6 0}$ & $\begin{array}{l}\text { Suspended aerosols remaining go through coagulation, condensation, and deposition processes } \\
\text { only. No aerosols are injected. }\end{array}$ \\
\hline
\end{tabular}

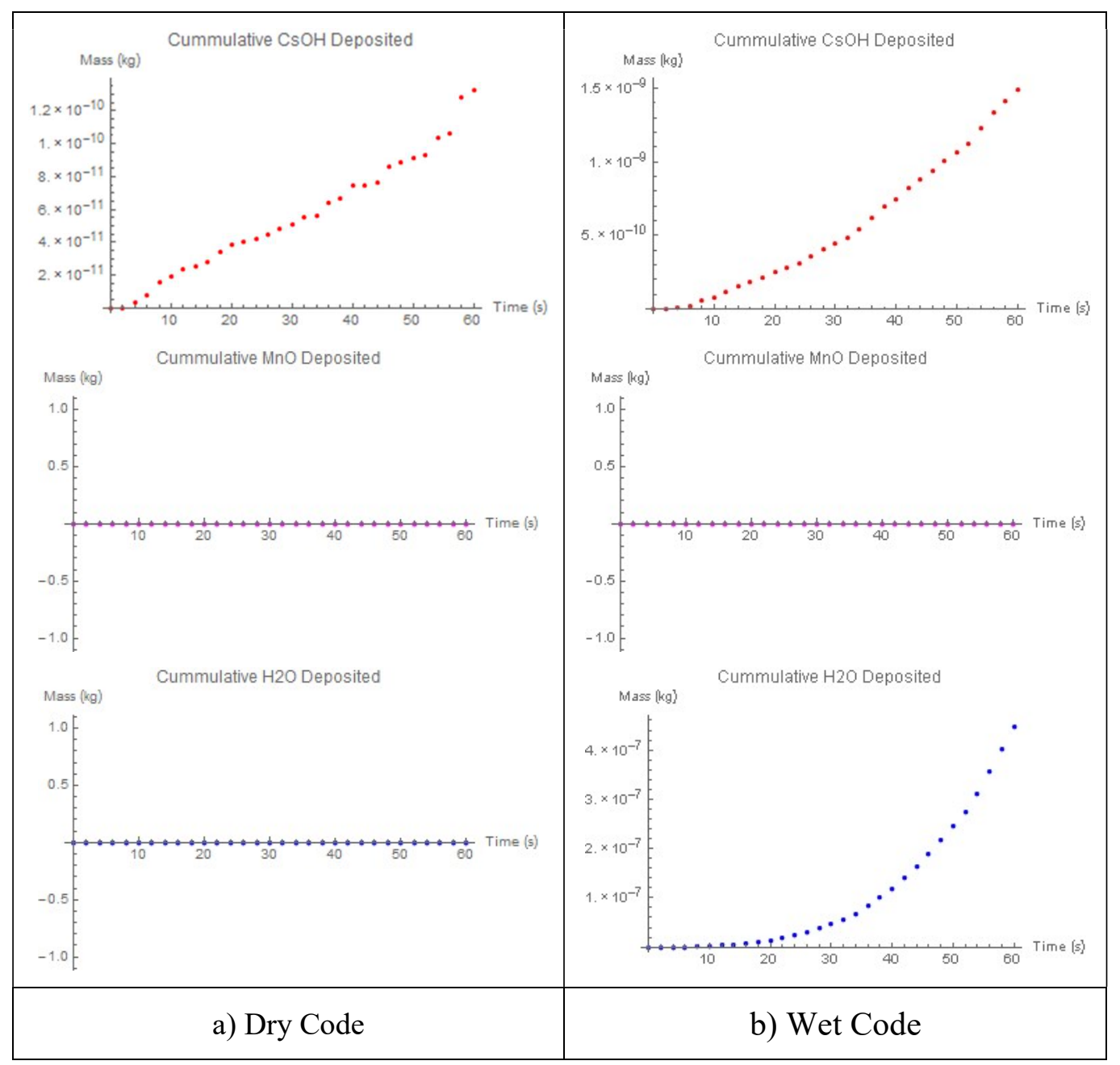

Figure 18: Dry and wet code comparison of DSMC Test Matrix Test Case 1 


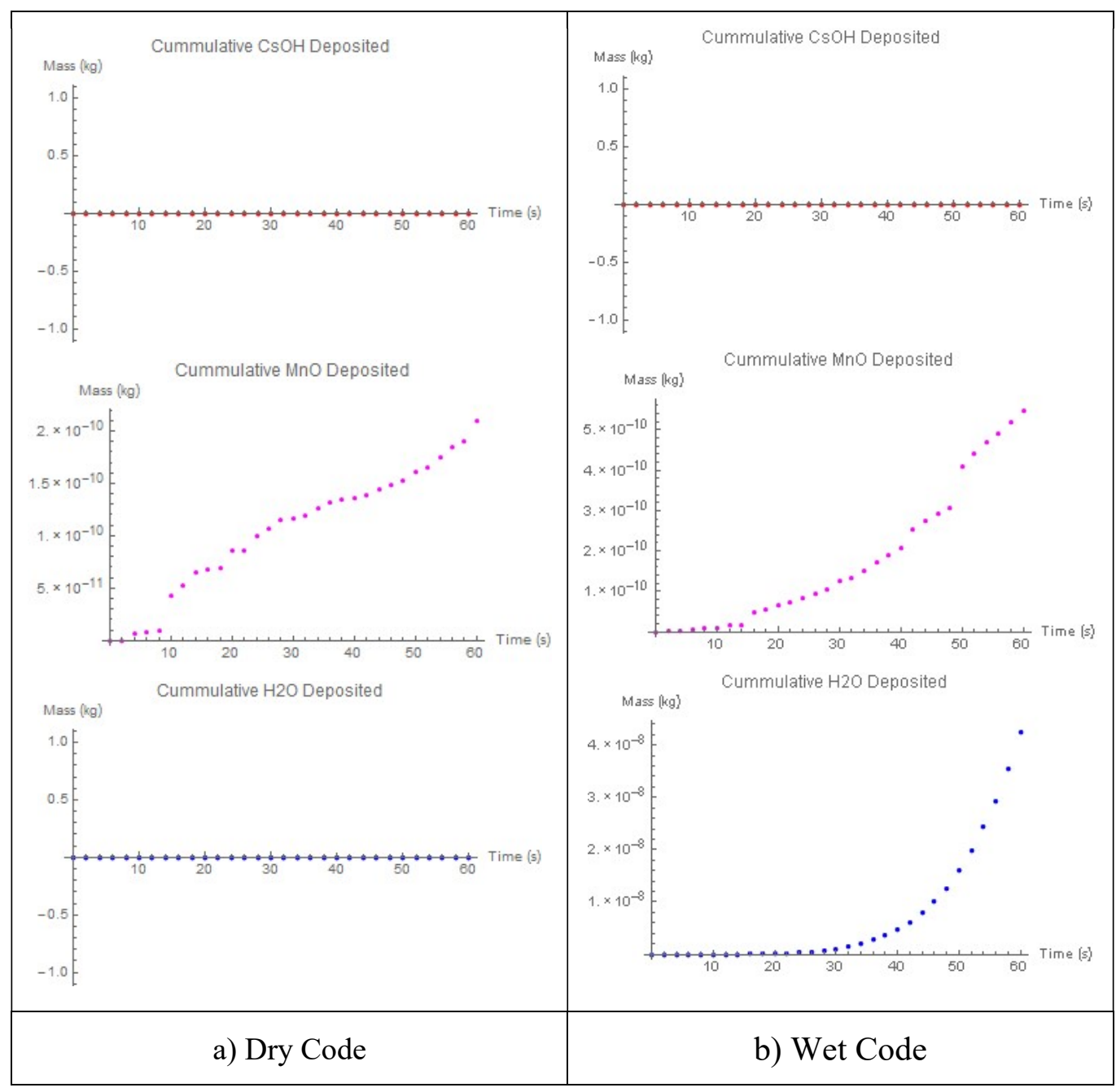

Figure 19: Dry and wet code comparison of DSMC Test Matrix Test Case 2 


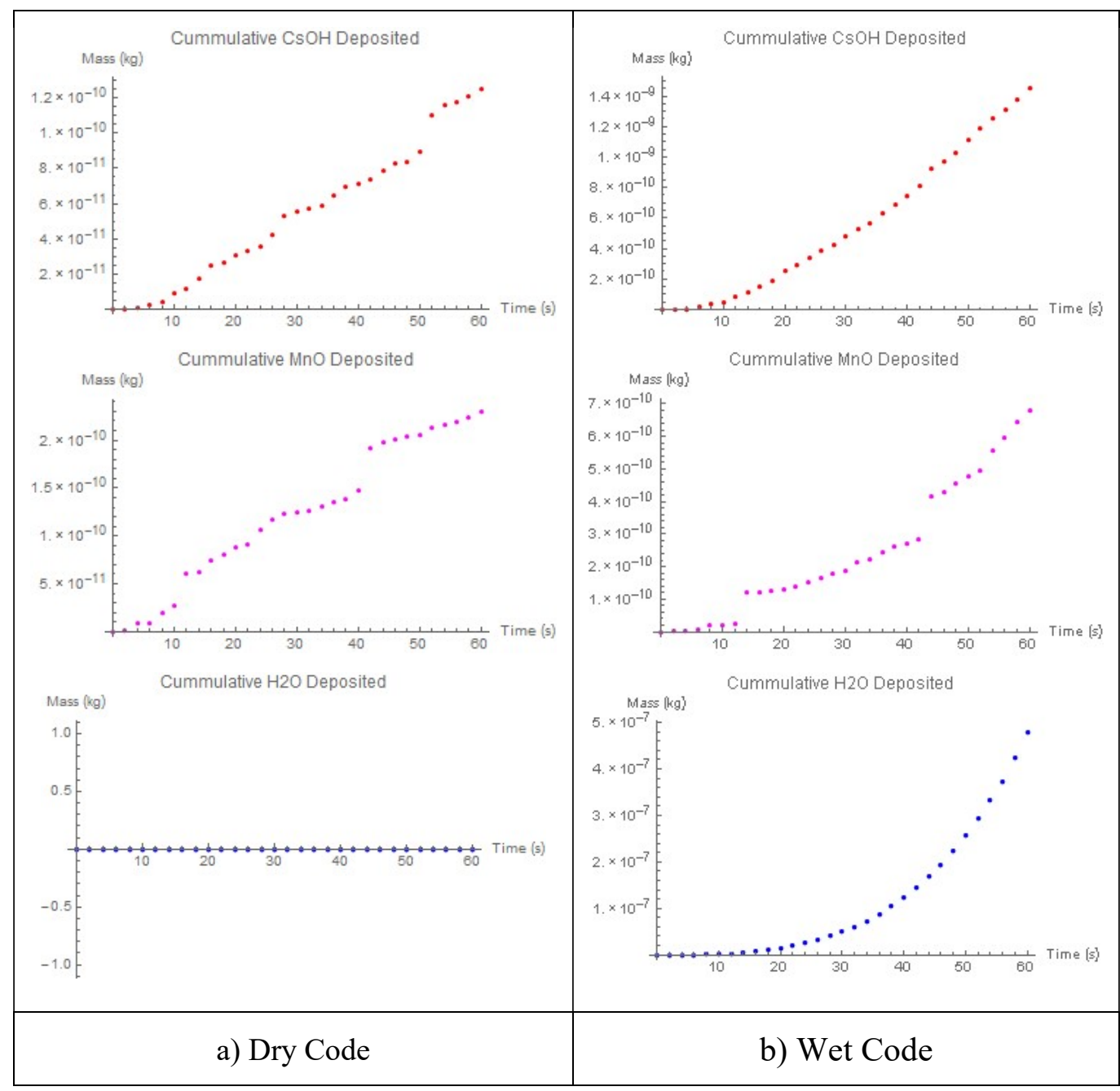

Figure 20: Dry and wet code comparison of DSMC Test Matrix Test Case 3 


\section{PRE-LA4 TEST PROBLEMS AND DEVELOPMENT OF SIMULATION SCALING}

\subsection{Test Problems}

We wish to use the DSMC technique to elucidate the role of all realistic aerosol processes in aerosol evolution considering a smaller, but still significant, number of particles. To demonstrate the role of each realistic aerosol process, we simulated the aerosol evolution of separate and overlapping aerosol injection periods with $10^{4}$ and $10^{5}$ initially suspended aerosols.

In Test Problem 1 (TP1), we assume $10^{4}$ initially dry, spherical, unmixed aerosols of equal parts $\mathrm{CsOH}$ and $\mathrm{MnO}$. These aerosols are sampled randomly from a log-normal distribution suspended in a cubic containment with a volume of $1 \mathrm{~m}^{3}$ and side lengths of $1 \mathrm{~m}$. The initial log-normal distribution was chosen to have an average aerosol volume, $v_{m}$, of $4.1888 \times 10^{-18} m^{3}$ (i.e., $1 \mu m$ average radii) and a geometric standard deviation (GSD) of $\sigma_{g}=1.81$. For TP1, water directly alters the composition of suspended aerosols through the condensation of steam. Moreover, this simulation utilized the realistic aerosol coagulation, condensation, and deposition processes. The realistic models for the coagulation and deposition processes used in our simulations are well 
documented in Palaniswaamy and Loyalka (2006) and Gelbard (1982), respectively. ${ }^{72,73}$ To account for hygroscopicity, the generalized Mason model with the Knudsen, Kelvin, and solute effects was chosen as the condensation model. In addition, aerosols sampled randomly from a log-normal distribution were introduced through a source term with separate and overlapping injection periods. The source term used in TP1 introduced both $\mathrm{CsOH}$ and $\mathrm{MnO}$ aerosols randomly sampled log-normally with an average aerosol volume of $4.1888 \times 10^{-21} \mathrm{~m}^{3}$ (i.e., particles with $0.1 \mu \mathrm{m}$ average radii) and $1.81 \mathrm{GSD}$. The source term injected $\mathrm{CsOH}$ aerosols at a mass rate of $0.5 \mathrm{ng} / \mathrm{s}$ from time $t=2 \mathrm{~s}$ to time $t=4 \mathrm{~s}$. Then, $\mathrm{CsOH}$ and $\mathrm{MnO}$ aerosols are injected separately from time $t=4 \mathrm{~s}$ to time $t=6 \mathrm{~s}$, each at a mass injection rate of $0.5 \mathrm{ng} / \mathrm{s}$. Finally, $\mathrm{MnO}$ is injected alone at a rate of $0.5 \mathrm{ng} / \mathrm{s}$ from time $t=6 \mathrm{~s}$ to time $t=8 \mathrm{~s}$. Table 19 summarizes the physical properties of $\mathrm{CsOH}, \mathrm{MnO}$, and $\mathrm{H}_{2} \mathrm{O}$ for the initial aerosol distribution and source term. Upon completion of the source term injection periods, the simulation continued coagulating, condensing, and depositing the remaining suspended aerosol particles until $10^{3}$ or fewer suspended particles remained. A summary of the TP1 simulation procedure has been provided in Table 20.

Table 19: Physical aerosol properties of $\mathrm{Cs} \mathrm{OH}, \mathrm{MnO}$, and $\mathrm{H}_{2} \mathrm{O}$

\begin{tabular}{|c|c|c|c|c|c|}
\hline \multirow{2}{*}{} & \multirow{2}{*}{ Density $\left[\mathbf{k g} / \mathbf{m}^{\mathbf{3}}\right]$} & \multicolumn{2}{|c|}{$\begin{array}{c}\text { Initial Log-normal } \\
\text { Distribution Properties }\end{array}$} & $\begin{array}{c}\text { Source Term Log-normal } \\
\text { Distribution Properties }\end{array}$ \\
\cline { 3 - 6 } & & $\overline{v_{0}}\left[\mathrm{~m}^{3}\right]$ & $\overline{\sigma_{0}}$ & $\bar{v}\left[\mathrm{~m}^{3}\right]$ & $\bar{\sigma}$ \\
\hline $\mathbf{C s O H}$ & 3680 & $4.1888 \times 10^{-18}$ & 1.81 & $4.1888 \times 10^{-21}$ & 1.81 \\
\hline $\mathbf{M n O}$ & 5440 & $4.1888 \times 10^{-18}$ & 1.81 & $4.1888 \times 10^{-21}$ & 1.81 \\
\hline $\mathbf{H}_{\mathbf{2}} \mathbf{O}$ & 1000 & & & & \\
\hline
\end{tabular}

72 Palaniswaamy and Loyalka, "Direct Simulation Monte Carlo Aerosol Dynamics: Coagulation and Collisional Sampling," Nuclear Technology 156, no. 1 (2006).

${ }^{73}$ Gelbard, "MAEROS User Manual." 
Table 20: Summary of TP1 simulation procedure

\begin{tabular}{|c|l|}
\hline Time (s) & \multicolumn{1}{c|}{ TP1 Procedure } \\
\hline $\mathbf{0}$ & $\begin{array}{l}\text { CsOH and } \mathrm{MnO} \text { aerosols are sampled randomly from a log-normal distribution } \\
\text { until } 10^{4} \text { initially dry, spherical, and unmixed aerosols are obtained }\end{array}$ \\
\hline $\mathbf{0}$ - 2 & $\mathrm{CsOH}$ and $\mathrm{MnO}$ aerosols coagulate, condense, and deposit freely \\
\hline $\mathbf{2}$ - 4 & $\begin{array}{l}\mathrm{CsOH} \text { and } \mathrm{MnO} \text { aerosols coagulate, condense, and deposit freely while } \mathrm{CsOH} \\
\text { aerosol is injected alone at } 0.5 \text { nanograms per second }\end{array}$ \\
\hline $\mathbf{4 - 6}$ & $\begin{array}{l}\mathrm{CsOH} \text { and } \mathrm{MnO} \text { aerosols coagulate, condense, and deposit freely while } \mathrm{CsOH} \\
\text { and } \mathrm{MnO} \text { aerosols are each injected at } 0.5 \text { nanograms per second }\end{array}$ \\
\hline $\mathbf{6 - 8}$ & $\begin{array}{l}\text { CsOH and } \mathrm{MnO} \text { aerosols coagulate, condense, and deposit freely while } \mathrm{MnO} \\
\text { aerosol injected alone at } 0.5 \text { nanograms per second }\end{array}$ \\
\hline $\mathbf{8}+$ & Aerosols coagulate, condense, and deposit until $10^{3}$ or fewer particles remain \\
\hline
\end{tabular}

Test Problem 2 (TP2) is identical to that of TP1 with the only exception that $10^{5}$ initially dry, spherical, unmixed aerosols sampled randomly from a log-normal distribution are suspended in the same cubic containment of volume $1 \mathrm{~m}^{3}$ and $1 \mathrm{~m}$ side lengths. Table 19 and Table 20 also summarize the TP2 simulation inputs and procedures with the notable difference of $10^{5}$ initial aerosols.

Figure 21 shows the total number of aerosol particles suspended as a function of time in the TP1 simulation. From this graph, it is clear that the source term is the dominant process during the separate and overlapping injection periods. By the end of the source term a time $t=8 s$, suspended aerosols total over 230,000 particles. The TP1 simulation predicted that the aerosol processes left unrestrained would deposit and grow by coagulation and condensation until $10^{3}$ particles remain after $t=86.1 \mathrm{~s}$. The total amount of component mass suspended and cumulative mass deposited throughout the simulation can be seen in Figure 22 and Figure 23, respectively. From Figure 22 and Figure 23 we see that the suspended $\mathrm{CsOH}$ mass drops off faster than $\mathrm{MnO}$. Due to the hygroscopicity of $\mathrm{CsOH}$, this effect was expected, stemming primarily through increased condensational growth which led to increased gravitational deposition of $\mathrm{CsOH}$-rich 
aerosols. Although it is not visually evident from Figure 21 through Figure 23, coagulation is present throughout the simulation but is overshadowed by the aforementioned processes. Since the number of coagulations depends heavily on the number of particles (i.e., coagulation $\propto N^{2}$ ), the coagulation rate reaches its maximum when the total number of particles is at its maximum when $t=8 \mathrm{~s}$.

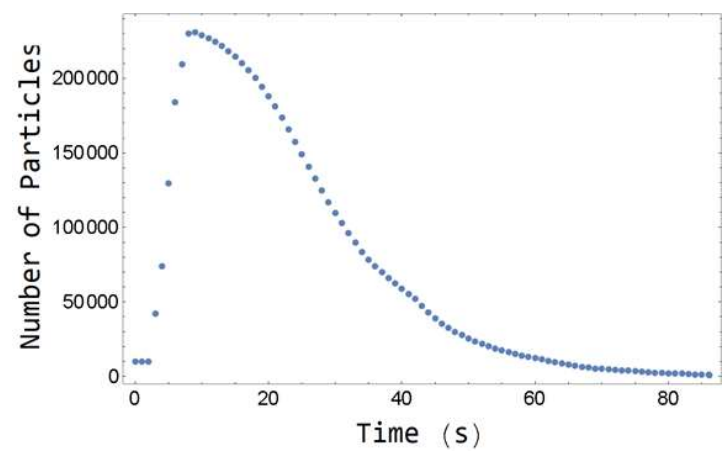

Figure 21: Total number of suspended aerosol particles for TP1 

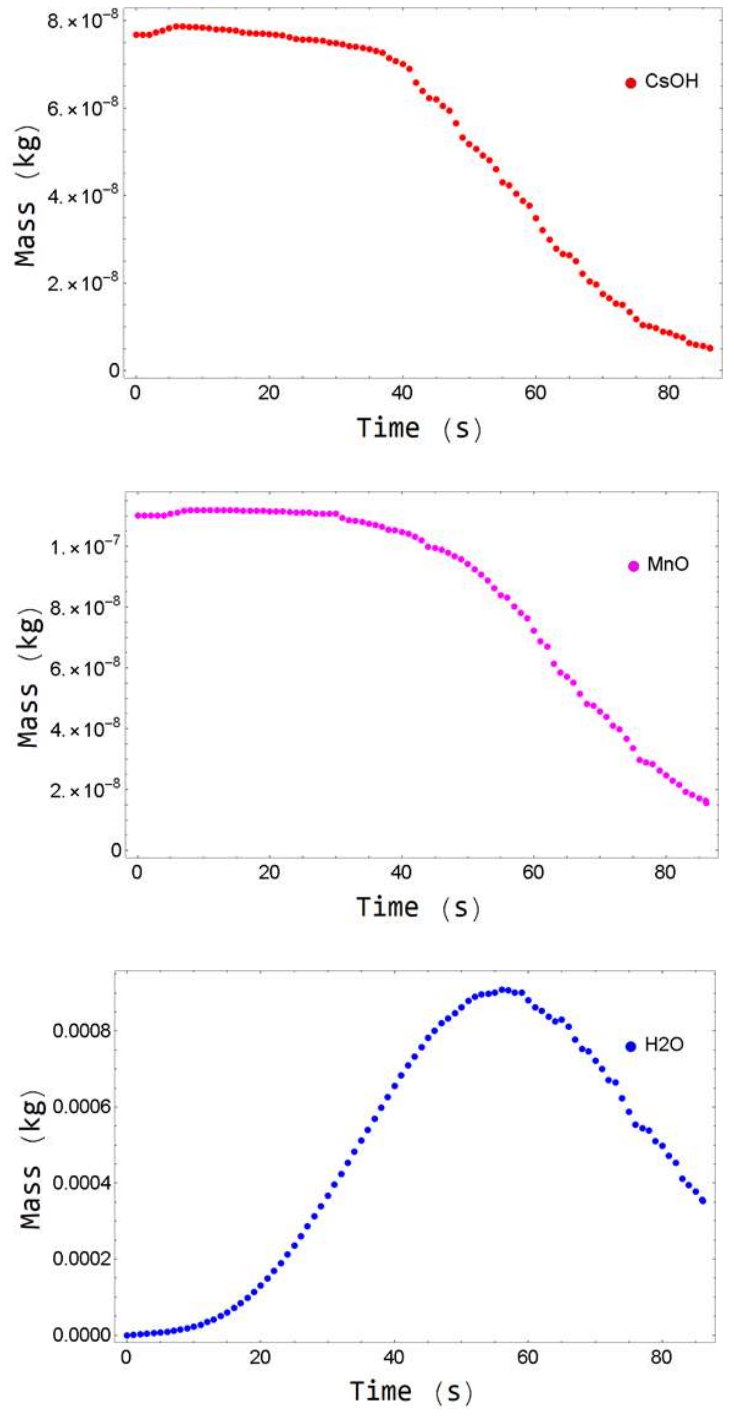

Figure 22: $\mathrm{Cs} \mathrm{OH}, \mathrm{MnO}$, and $\mathrm{H}_{2} \mathrm{O}$ mass suspended for TP1 

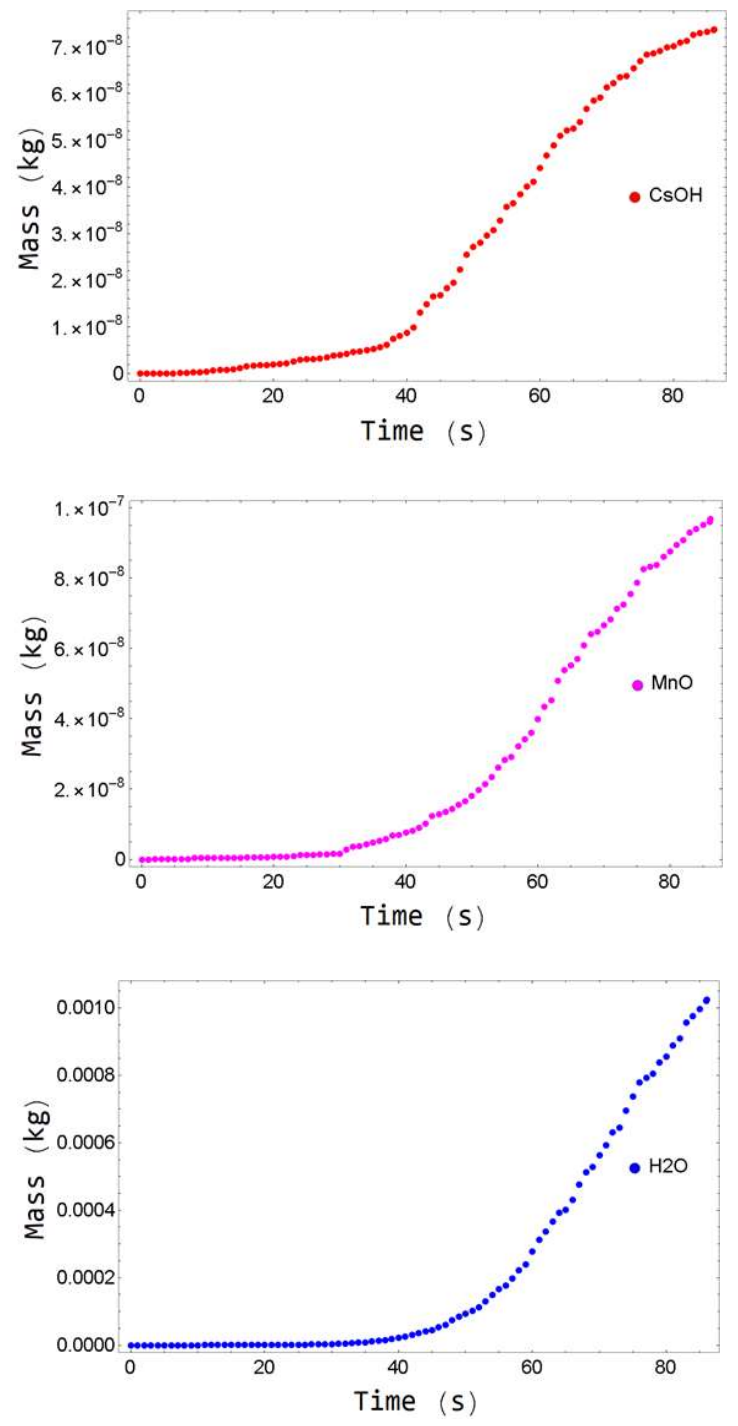

Figure 23: Cumulative $\mathrm{Cs} \mathrm{OH}, \mathrm{MnO}$, and $\mathrm{H}_{2} \mathrm{O}$ mass deposited in TP1

On the other hand, the number of suspended aerosol particles as a function of time for TP2 have been plotted in Figure 24. From this graph we can see that the source term dominates all other processes during the separate and over lapping injection periods. At the end of the source term at $t=8 s$, suspended aerosols total approximately 290,000 particles. The TP2 simulation predicted that the aerosol processes left unrestrained would grow and deposit aerosols until $10^{3}$ particles remain after $t=75.3 \mathrm{~s}$. The total amount of component aerosol mass suspended throughout the simulation as a function of 
time has been provided in Figure 25 and the cumulative mass deposited for each aerosol component has been summarized in Figure 26. Once again, due to the hygroscopicity of $\mathrm{CsOH}$, Figure 26 shows that $\mathrm{CsOH}$ deposits faster than $\mathrm{MnO}$ as a result of increased gravitational deposition caused by rapid condensational growth. Although coagulation is proportional to the square of the number of suspended particles (i.e., coagulation $\propto N^{2}$ ) and the coagulation rate reaches its maximum at $t=8 \mathrm{~s}$, the coagulation process is overshadowed by all other aerosol processes and is not visually evident from Figure 24 through Figure 26.

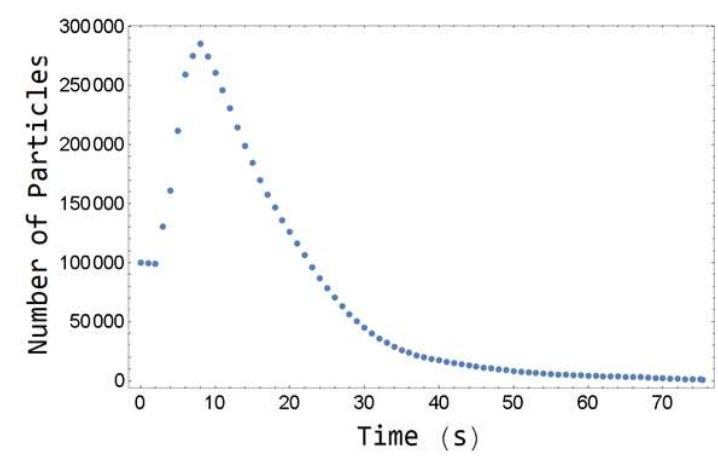

Figure 24: Total number of suspended aerosol particles for TP2 

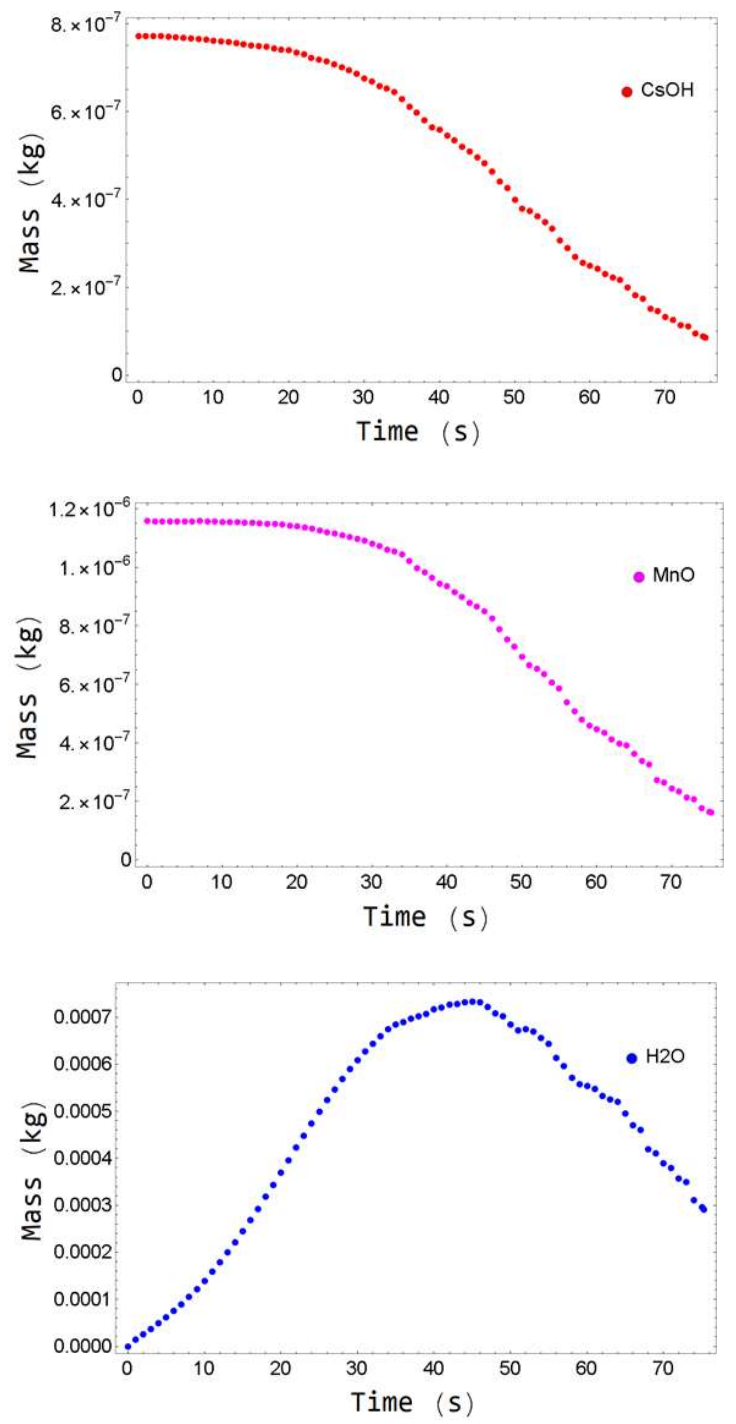

Figure 25: $\mathrm{Cs} \mathrm{OH}, \mathrm{MnO}$, and $\mathrm{H}_{2} \mathrm{O}$ mass suspended for $\mathrm{TP2}$ 

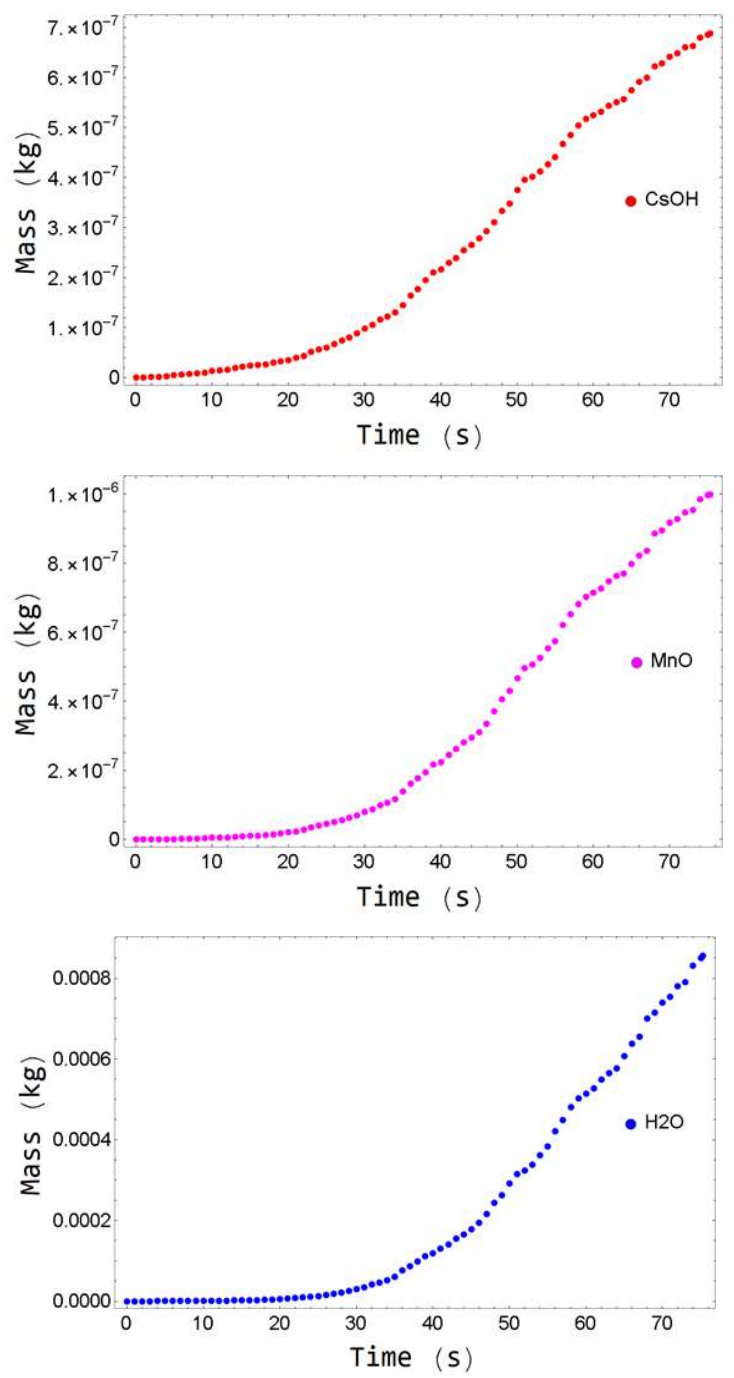

Figure 26: Cumulative $\mathrm{Cs} \mathrm{OH}, \mathrm{MnO}$, and $\mathrm{H}_{2} \mathrm{O}$ mass deposited in $\mathrm{TP2}$

Comparing the results from TP1 and TP2, we see that the number of suspended aerosol particles diminishes faster in TP2 than in TP1. Part of the reason for this can be explained through the coagulation rate's strong dependence on particle number. Since the number of particles was an order of magnitude larger in $\mathrm{TP} 2$, the aerosols grew, combined, and ultimately deposited faster in TP2. It is also important to note that the particle density may have also played a role physically since both TP1 and TP2 assumed the same containment volume. Consequently, despite having more particles, TP2 with $10^{5}$ particles deposited faster than in the TP1 case with $10^{4}$ particles. 


\subsection{Simulation Scaling}

While much progress was made to reduce computational time for smaller systems, a scaling factor must inevitably be introduced before larger, more meaningful experiments such as the Marviken, Demonstration of Nuclear Aerosol Behavior (DEMONA), LA4, and Thermal-hydraulics, Hydrogen, Aerosols, and Iodine (THAI) may be fully and adequately simulated by the DSMC technique. Through particle scaling (or weighting), limitations in computational power may be worked around by letting each simulated particle be representative of many real particles. Though accurate, the DSMC technique is computationally expensive when considering large systems; thus, before simulating the LA4 experiment the effects of scaling for each aerosol process must be known. Simulations may be scaled down by volume, time, or particle number. For our purposes, the last of these will be considered to scale the aerosol processes.

Coagulation is the only aerosol process for which scaling has been demonstrated theoretically. Scaling for the coagulation kernel is well documented in the literature by Bird (1994). Bird showed that the number of collisions in a given time step, $\Delta t$, between two systems of unequal size is given by:

$$
N_{c}=\frac{1}{2} N_{s}^{2} f_{s} \beta_{\text {max }} \Delta t
$$

where $N_{s}$ is the number of simulated particles, and $f_{s}$ is a scaling factor defined by:

$$
f_{s}=\frac{N}{N_{s}}
$$

Condensation, on the other hand, is a process that is not scalable because condensation is not dependent on particle number. The condensation between two particle systems of dissimilar size need not be considered when fewer simulated particles are chosen to 
represent many. Along this line, the source term is scaled simply by injecting fewer particles than what is actually injected. This fraction is simply the inverse of the scale factor (i.e., $\frac{N_{s}}{N}$ ). Thus, the source term is scaled by simply multiplying the mass injection rate by the inverse of the scaling factor. Finally, aerosol deposition is a linear process which depends directly on particle number and therefore requires scaling. Though not in the literature, deposition is scaled by simply multiplying the deposited mass by the scaling factor. Since each simulated particle represents many real particles, then it is straight forward that each particle which has deposited is therefore the deposition of the many particles it represents in the real system.

The purpose of this section is to substantiate the claims made above in regards to scaling for single and multi-component aerosols. To verify the effects of scaling, a smaller test case with fewer particles must be shown to yield comparable results of a larger test through the successful implementation of the scaling factor. To show this, two simulations of dissimilar initial particle numbers are considered. In the first set of simulations (Part A), an initially dry, single-component aerosol distribution of $\mathrm{CsOH}$ with $10^{4}$ and $10^{5}$ particles distributed log-normally are considered undergoing deposition alone. For the second set of simulations (Part B), an initially dry, unmixed, twocomponent aerosol of equal parts $\mathrm{CsOH}$ and $\mathrm{MnO}$ are distributed log-normally and are undergoing coagulation, condensation, and deposition. For both cases, the number of suspended particles and the component mass deposited will be compared for the $10^{4}$ and $10^{5}$ in each simulation set. Part A and Part B simulations were evaluated for 600 and 240 simulated seconds, respectively. 
In Part A, two simulations with $10^{4}$ and $10^{5}$ initial single-component aerosols under deposition only are compared. Figure 27 compares the number of suspended aerosols for the $10^{4}$ and $10^{5}$ simulations. The $10^{4}$ and $10^{5}$ simulations ran for $36.28 \mathrm{~min}$ and $5.95 \mathrm{hr}$, respectively. As we can see from Figure 27, the similarity in the shape of the plots for the $10^{4}$ and $10^{5}$ simulations show that the two simulations diminished in particle number at a rate proportional to the scaling factor (in this case the scaling factor is 10). Figure 28 compares the suspended and deposited $\mathrm{CsOH}$ aerosol mass for the $10^{4}$ and $10^{5}$ simulations. Comparing the results from the suspended and deposited masses in Figure 28 we can see that the shapes of the curves are very similar and that they differ only by approximately the scaling factor. The scaling theory was thus applied to the simulation of $10^{5}$ particles using only $10^{4}$ particles with a scaling factor of 10 . The scaled $10^{4}$ simulation completed in a runtime of $30.7 \mathrm{~min}$. Figure 29 compares the $\mathrm{CsOH}$ mass suspended and deposited for the $10^{4}$, scaled $10^{4}$, and $10^{5}$ cases. From parts a) and b) of Figure 29 we can see that the simulation of $10^{5}$ particles with fewer particles (in this case $10^{4}$ scaled by the factor, $f_{s}=10$ ), gives a rough, crude approximation of the suspended and deposited mass for larger systems under deposition alone. The scaled $10^{4}$ results were satisfactory considering that the scaled $10^{4}$ simulation gave comparable results in a fraction of the time to that of the full $10^{5}$ simulation. 


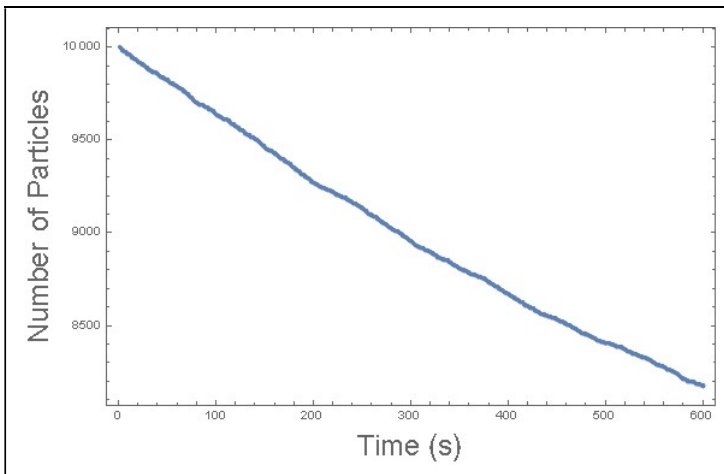

a) $10^{4}$ initial particles

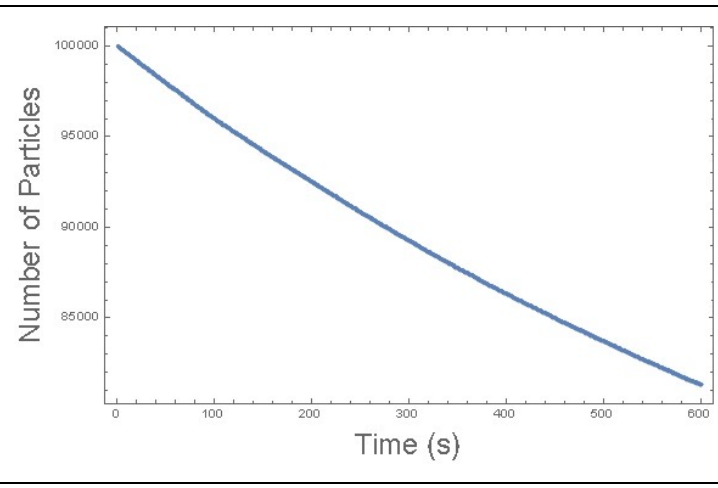

b) $10^{5}$ initial particles

Figure 27: Number of aerosols suspended for the $10^{4}$ and $10^{5}$ initial particles under deposition only



Figure 28: Results for CsOH mass suspended (top row) and cumulative CsOH mass deposited (bottom row) for the $10^{4}$ and $10^{5}$ initial particles under deposition only 


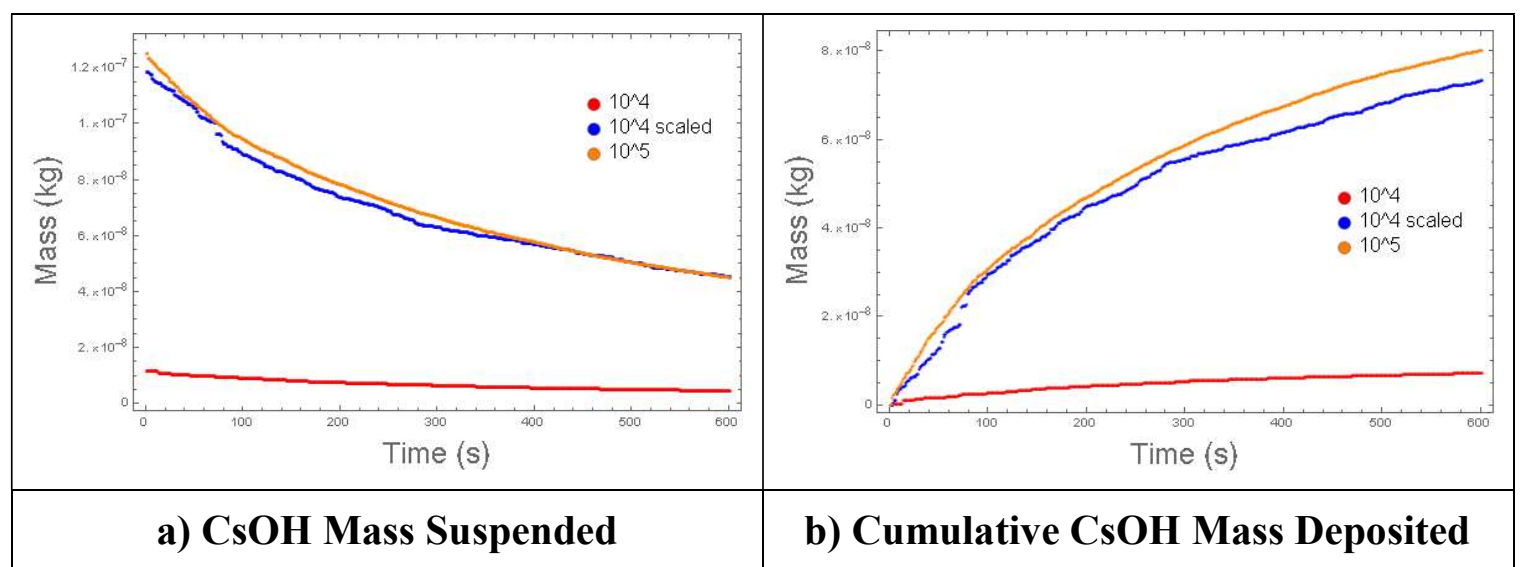

Figure 29: Comparison of the CsOH mass suspended and mass deposited for the $10^{4}$, scaled $10^{4}$, and $10^{5}$ simulations

Next, in Part B we consider a two-component aerosol of equal parts $\mathrm{CsOH}$ and $\mathrm{MnO}$ under coagulation, condensation, and deposition with $10^{4}$ and $10^{5}$ initial aerosol particles. In Part B, we wish to show that scaling mixed, multi-component aerosols can be scaled in the same way as in Part A for all aerosol processes (excluding the source term for the time being). $\mathrm{CsOH}$ and $\mathrm{MnO}$ aerosols were chosen in Part $\mathrm{B}$ for their hygroscopic and non-hygroscopic properties with the ultimate purpose of showing that scaling is appropriate for hygroscopic and non-hygroscopic aerosols. Since the condensation process was allowed to occur, $\mathrm{H}_{2} \mathrm{O}$ suspended and deposited was also tracked for Part B. The $10^{4}$ and $10^{5}$ simulations were completed in a runtime of $18.99 \mathrm{~min}$ and $3.14 \mathrm{hr}$, respectively. Figure 30 shows the suspended number of particles in the $10^{4}$ and $10^{5}$ simulations as a function of time. It may be concluded from Figure 30 , that the similarity in the shapes of the curves suggest that scaling is suitable in comparing particle number evolution. Figure 31 shows the suspended aerosol component mass and the cumulative component mass deposited is provided in Figure 32. From Figure 31 and Figure 32, we may conclude that the mixed hygroscopic and nonhygroscopic aerosols evolve similarly in the $10^{4}$ and $10^{5}$ cases by comparing the shapes 
of their curves. The scaling theory was then applied to simulate the $10^{5}$ case with $10^{4}$ particles and a scaling factor of 10 . The scaled $10^{4}$ simulation completed in a runtime of $17.02 \mathrm{~min}$. Figure 33 compares the mass suspended and cumulative mass deposited per aerosol mass component directly for the $10^{4}$, scaled $10^{4}$, and $10^{5}$ results. From the results of Figure 33, we see that $\mathrm{CsOH}, \mathrm{MnO}$, and $\mathrm{H}_{2} \mathrm{O}$ mass suspension and cumulative mass deposited is well predicted when applying the scaling theory. MnO suspended was slightly over-predicted, but the overall results were satisfactory when considering that the scaled $10^{4}$ simulation ran in $17.02 \mathrm{~min}$ whereas the full $10^{5}$ simulation required a runtime of $3.14 \mathrm{hr}$.



Figure 30: Number of aerosols suspended for the $10^{4}$ and $10^{5}$ initial particles under coagulation, condensation, and deposition 


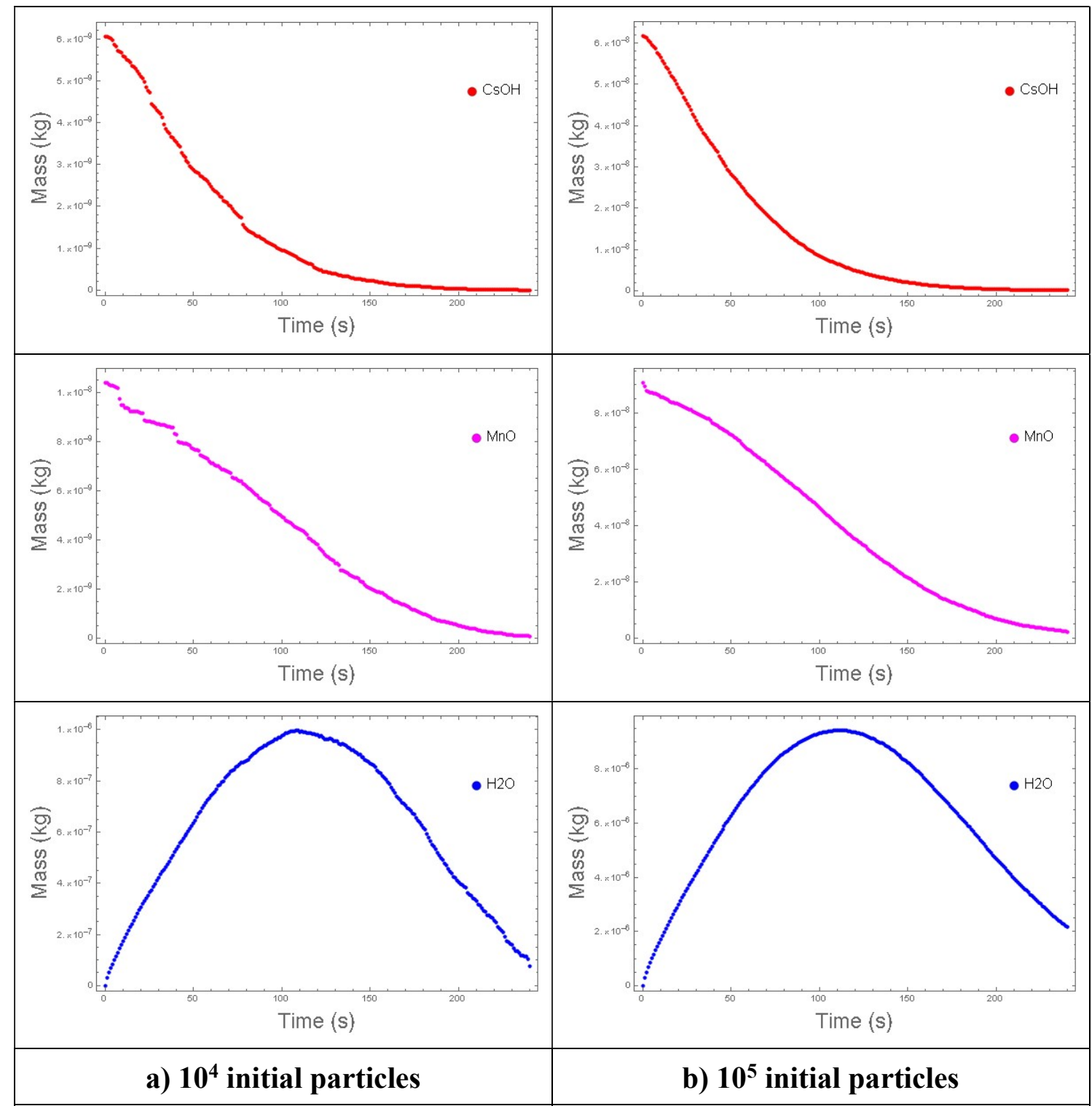

Figure 31: Mass suspended per component for $10^{4}$ and $10^{5}$ initial aerosols under coagulation, condensation, and deposition 


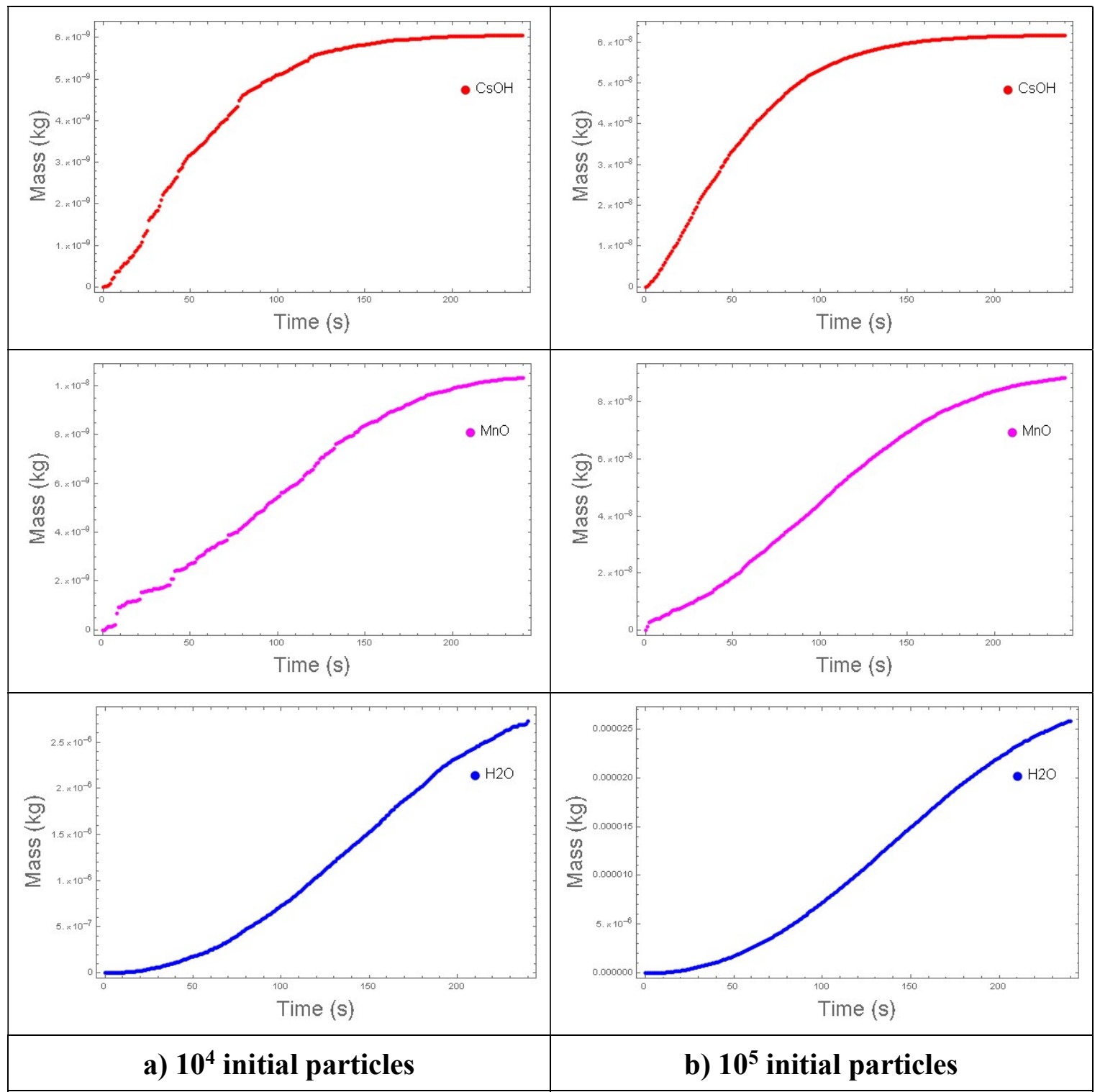

Figure 32: Cumulative mass deposited per component for $10^{4}$ and $10^{5}$ initial aerosols under coagulation, condensation, and deposition 


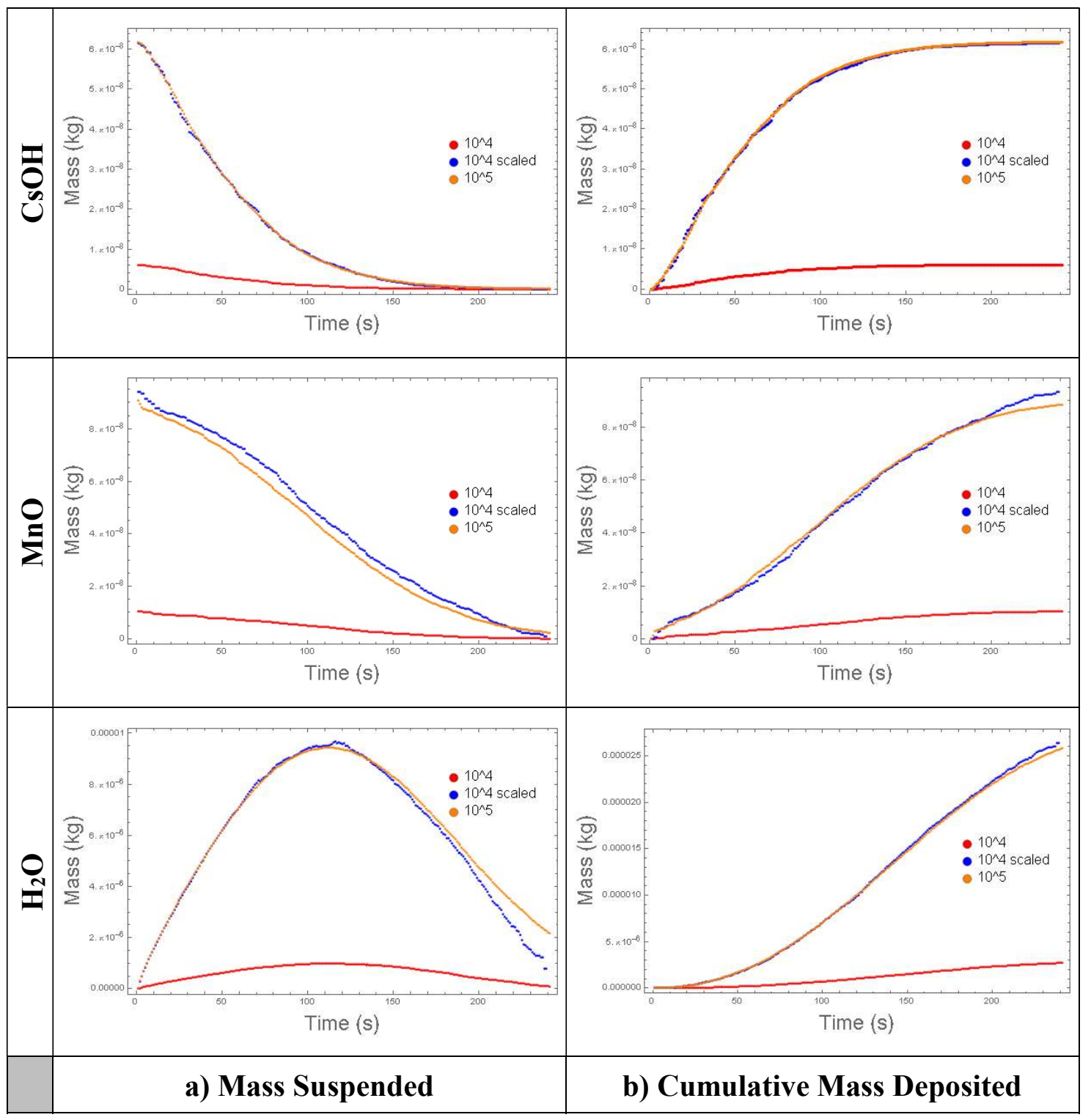

Figure 33: Comparison of suspended and cumulative deposited mass per component with scaling 


\subsection{Coupled Problem with Condensation Benchmark}

A single-species aerosol growing purely through condensation was considered by Gelbard (1990). ${ }^{74}$ For this problem, the aerosol behavior is coupled to the thermalhydraulic conditions of the environment. For such a case, the GDE reduces to:

$$
\frac{\partial}{\partial t} n(v, t)+\frac{\partial}{\partial v}[I(v, t) n(v, t)]=0
$$

where $n(v, t)$ is the number density function of particles of mass $v$ at time $t$ with the initial condition $n(v, 0)=n_{0}(v)$, and $I(v, t)$ is the mass condensation rate. For a condensation model of the form:

$$
I(v, t)=h(t) f(v)
$$

where $h(t)$ and $f(v)$ are some prescribed functions, exact analytical solutions of equation (6.3-1) may be obtained by the method of characteristics (see Williams (1983), ${ }^{75}$ Brock (1983) ${ }^{76}$ Williams and Loyalka $\left.(1991){ }^{77}\right)$. These solutions include integrals over the functions $h(t)$ and $f(v)$. In general, $h(t)$ will be dependent on the environment concentration of the vapor, and hence will change as dependent on the condensation of the vapor on the particles themselves, that is $n(v, t)$. In such circumstances, the solution will in fact be an integral equation for $n(v, t)$. This integral equation will generally not

\footnotetext{
74 Gelbard, "Modeling Multicomponent Aerosol Particle Growth By Vapor Condensation."

${ }^{75}$ M. M. R. Williams, "The Time-Dependent Behavior of Aerosols with Growth and Deposition. I. Without Coagulation," Journal of Colloid and Interface Science 93, no. 1 (1983). no. 2 (1983).

${ }^{76}$ J. R. Brock, "New Aspects of Aerosol Growth Processes," Aerosol Science and Technology 2,

${ }^{77}$ Williams and Loyalka, Aerosol Science: Theory and Practice: With Special Applications to the Nuclear Industry.
} 
be solvable analytically, but it may be possible to do so in some special circumstances. Gelbard considered such a special situation, where water aerosols are enclosed in an adiabatic chamber containing gas (air) and water vapor condensing on them. Then, one can express:

$$
h(t)=A\left(M_{v a p}(t)-M_{v a p, e q}(T(t))\right)
$$

where $A$ is a time scale parameter (chosen as $3.6 \mathrm{~m}^{3} / \mathrm{s}$ per $\mathrm{kg}$ such that equilibrium is established in approximately one minute), $M_{v a p}(t)$ is the condensable vapor mass

concentration, and $M_{v a p, e q}(T(t))$ is the equilibrium vapor concentration at temperature $T$ at time $t$. Gelbard also used:

$$
f(v)=v
$$

Hence, the mass condensation rate is then:

$$
I(v, t)=A\left(M_{v a p}(t)-M_{v a p, e q}(T(t))\right) v
$$

For the closed adiabatic system considered by Gelbard, mass is conserved and one has:

$$
\frac{d M_{T o t}}{d t}=0
$$

and so:

$$
M_{\text {Tot }}=M_{\text {vap }}(t)+\underbrace{\int_{0}^{\infty} v n(v, t) \mathrm{d} v}_{\equiv M_{\text {aero }}(t)}=M_{\text {vap }}(t)+M_{\text {aero }}(t)
$$

where $M_{\text {aero }}(t)$ is the total aerosol mass concentration, and $M_{\text {Tot }}$ is a constant equal to the total condensable vapor and aerosol mass concentrations. Conservation of Energy, 
involving Latent heat released from the vapor condensation and gas temperature rise, while neglecting other quantities as those are small, leads to:

$$
\Delta U=\Delta Q-W
$$

Taking:

$$
\begin{gathered}
\Delta U=M_{g} C_{V}\left(T(t)-T_{0}\right) \\
W=0
\end{gathered}
$$

and the heat released due to condensation as:

$$
\Delta Q=L\left(M_{v a p}(0)-M_{v a p}(t)\right)
$$

we have:

$$
M_{g} C_{V}\left(T(t)-T_{0}\right)=L\left(M_{v a p}(0)-M_{v a p}(t)\right)
$$

where $M_{g}$ is the suspending gas mass concentration, $C_{V}$ is the suspending gas specific heat at constant volume heat capacity, $T_{0}$ is the initial temperature, $T(t)$ is the temperature at time $t$, and $L$ is the specific energy released by condensation.

For small temperature variations, one can show that the equilibrium vapor mass concentration may be approximated from the saturation pressure and Clausius-Clapeyron equations (see Appendix C) as:

$$
M_{v a p, e q}(T(t))=M_{v a p, e q, 0}+S\left(T(t)-T_{0}\right)
$$

where $M_{v a p, e q, 0}$ is the initial equilibrium vapor mass concentration at $T_{0}$, and $S$ is a quantity with units of $\mathrm{kg} / \mathrm{Km}^{3}$ which approximates the change in the equilibrium vapor mass concentration with changing temperature. $S$ defined in Appendix $\mathbf{C}$ as: 


$$
S=M_{v a p, e q, 0}\left(\frac{L M-R T_{0}}{R T_{0}^{2}}\right)
$$

The general solution to the system of equations for $n(v, t)$ in equation (6.3-1)

with initial condition $n(v, 0)=n_{0}(v)$ coupled to equations (6.3-2) and (6.3-3) is found by the method of characteristics (see Appendix D). Substituting the appropriate quantities from equations (6.3-2), (6.3-3), and (6.3-4), we may rewrite:

$$
h(t)=p+q M_{\text {aero }}(t)
$$

where:

$$
\begin{gathered}
p=A\left[M_{\text {Tot }}-M_{\text {vap }, e q, 0}-\frac{S L}{M_{g} C_{V}}\left(M_{v a p}(0)-M_{\text {Tot }}\right)\right] \\
q=-A\left[1+\frac{S L}{M_{g} C_{V}}\right]
\end{gathered}
$$

Integration along the characteristic $\frac{d v}{d t}=I(v, t)=h(t) f(v)$ using separation of variables, the left-hand side is:

$$
\int_{v(0)}^{v} \frac{\mathrm{d} v^{\prime}}{v^{\prime}}=\ln \left(\frac{v}{v(0)}\right)
$$

and the right-hand side is:

$$
G(t) \equiv \int_{0}^{t} h(t) \mathrm{d} t=\int_{0}^{t}\left(p+q M_{\text {aero }}(t)\right) \mathrm{d} t=p t+q \int_{0}^{t} M_{\text {aero }}(t) \mathrm{d} t
$$

Setting the left and right-hand sides equal, we may solve for $v(0)$ as:

$$
v(0)=g(t) v
$$

where: 


$$
g(t)=\operatorname{Exp}\left[-p t-q \int_{0}^{t} M_{\text {aero }}(t) \mathrm{d} t\right]
$$

Along the characteristic, we also have that:

$$
\frac{d}{d t}(f(v) n(v, t))=0
$$

Integrating the above equation directly results in:

$$
n(v, t)=\frac{f(v(0)) n(v(0), t)}{f(v)}=\frac{f(v(0)) n_{0}(v)}{f(v)}
$$

But, since $f(v)=v$ and $f(g(t) v)=g(t) v$, we find the exact analytical solution as:

$$
n(v, t)=g(t) n_{0}(g(t) v)
$$

To demonstrate that coupled aerosol growth and containment thermal-hydraulics are well approximated by the DSMC technique, we have expanded on the work of Gelbard to show the behavior of vapor and aerosol concentrations for constant and temperature-dependent equilibrium vapor mass concentrations. We note here that the equilibrium vapor mass concentration, $M_{v a p, e q}$, is constant for $S=0$ and temperaturedependent for $S \neq 0$. The time-dependent vapor and aerosol concentrations were evaluated for $S=\left\{0,10^{-5}, 10^{-4}, 10^{-3}, 10^{-2}\right\}$. For all values of $S$, equations (6.3-2) and (6.3-3) may not be neglected and $n(v, t), M_{v a p}(t)$, and $T(t)$ must be determined simultaneously.

For this problem, Gelbard assumed an initial log-normal distribution with a mass median diameter $\left(d_{m}^{\prime}\right)$ of $0.1 \mu \mathrm{m}$ and geometric standard deviation $\left(\sigma_{g}\right)$ of 1.5 . 
Through the Hatch-Choate relations, the count mean and geometric mean diameters are calculated as:

$$
\begin{gathered}
d_{m}^{\prime}=d_{g} \operatorname{Exp}\left[3.0 \ln ^{2}\left(\sigma_{g}\right)\right]=0.1 \times 10^{-6} m \\
d_{g}=6.10666 \times 10^{-8} \mathrm{~m} \\
d_{m}=d_{g} \operatorname{Exp}\left[1.5 \ln ^{2}\left(\sigma_{g}\right)\right]=7.81451 \times 10^{-8} \mathrm{~m}
\end{gathered}
$$

and the log-normal distribution is then normalized by:

$$
n_{0}(v)=\frac{M_{a e r o, 0}}{m_{\text {aero }, 0}} \times n\left(v, \sigma_{g}, v_{m}\right)
$$

where $m_{a e r o, 0}$ is the initial aerosol mass. The following values were also assumed by Gelbard:

$$
\begin{array}{ccc}
A=3.6 \frac{\mathrm{m}^{3}}{\mathrm{~kg} \cdot \mathrm{s}} & M_{\text {Tot }}=0.051 \frac{\mathrm{kg}}{\mathrm{m}^{3}} & M_{\text {vap }, e q, 0}=0.0226 \frac{\mathrm{kg}}{\mathrm{m}^{3}} \\
\rho=1000 \frac{\mathrm{kg}}{\mathrm{m}^{3}} & L=2260 \times 10^{3} \frac{\mathrm{J}}{\mathrm{kg}} & M_{g}=1.1839 \frac{\mathrm{kg}}{\mathrm{m}^{3}} \\
M_{\text {vap }}(0)=0.05 \frac{\mathrm{kg}}{\mathrm{m}^{3}} & C_{V}=1463 \frac{\mathrm{J}}{\mathrm{kg} \cdot \mathrm{K}} & T_{0}=298 \mathrm{~K} \\
\Delta t=1.0 \mathrm{~s} &
\end{array}
$$

Gelbard's exact solution for the steam and aerosol mass concentrations as a function of time has been plotted in Figure 34. The DSMC solution using $10^{5} \log$ normally sampled aerosols and a scale factor of $1.92 \times 10^{10}$ is also plotted in Figure 34 . The associated errors in the DSMC solution have tabulated in Table 21 below. Using 20 diameter bins scaled logarithmically from $10^{-8} \mathrm{~m}$ to $10^{-4} \mathrm{~m}$, Figure 35 compares the steam and aerosol concentrations approximated by the exact and DSMC mass per diameter bin. Together, Figure 34, Figure 35, and Table 21 show that the exact solution 
is well approximated by the DSMC technique. The corresponding temperature curves provided in Figure 36 show that the temperature of the system increases due to latent heat released by the condensation process.

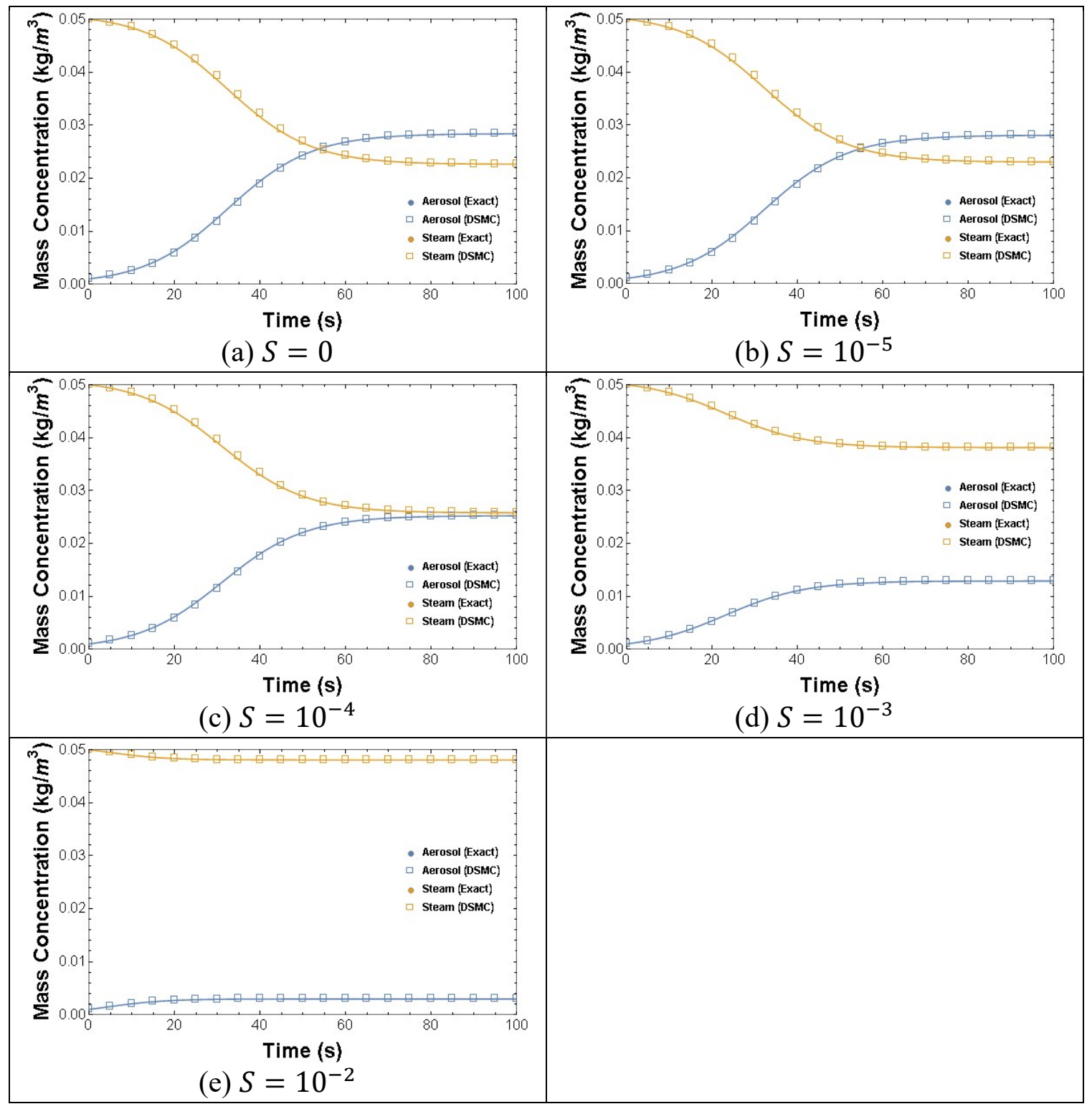

Figure 34: Plots (a)-(e) compare the results for the exact and DSMC solutions for varying values of $S$ 


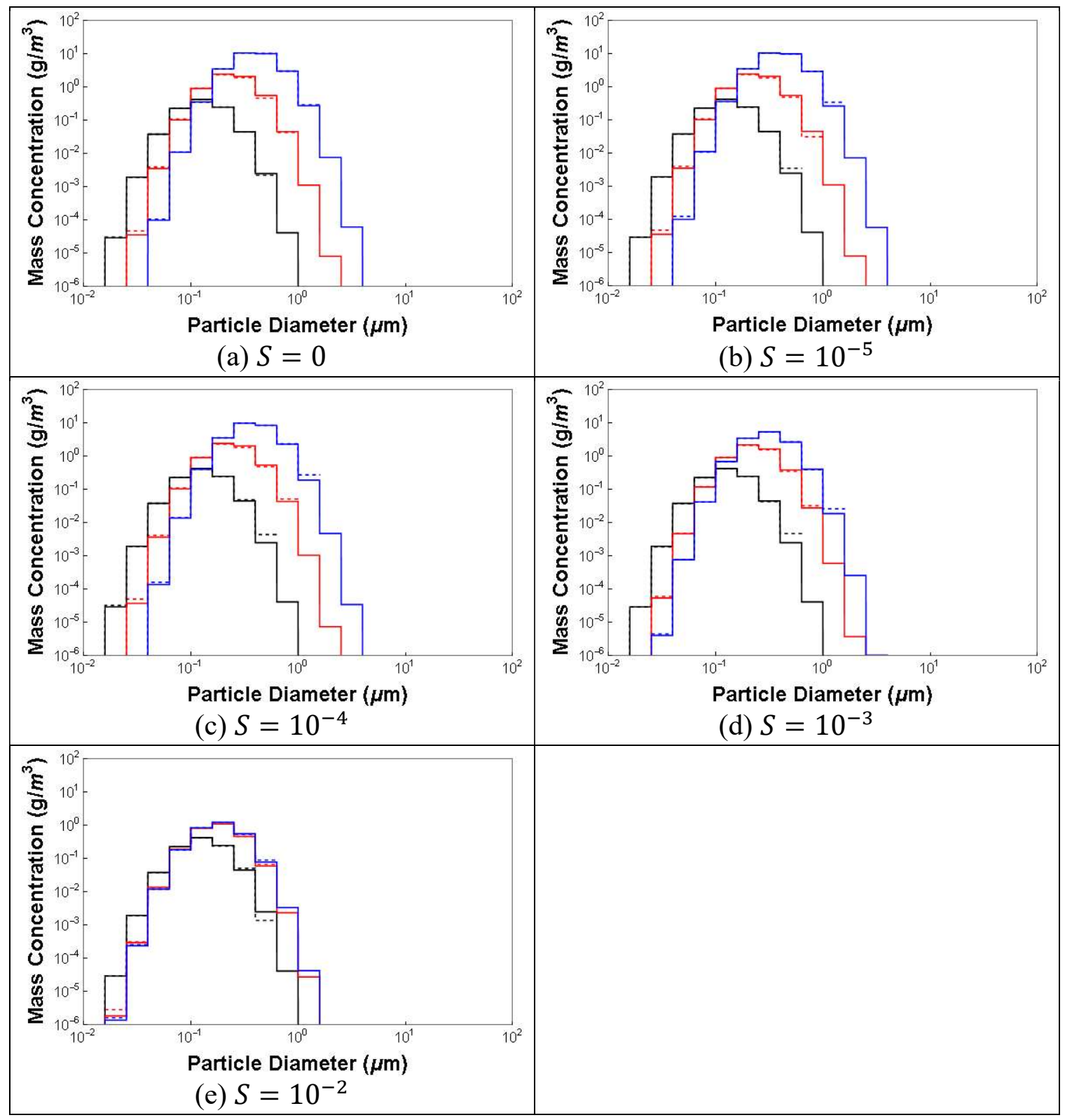

Figure 35: Plots (a)-(e) show the exact and DSMC mass concentrations per bin for the various values for S. The solid black, red, and blue lines represent the exact mass concentration when $t=0 \mathrm{~s}, t=20 \mathrm{~s}$, and $t=100 \mathrm{~s}$, respectively. The dashed black, red, and blue lines represent the DSMC mass concentration for $t=0 \mathrm{~s}, t=20 \mathrm{~s}$, and $t=100 \mathrm{~s}$, respectively. 
Table 21: Associated errors in the DSMC technique for varying $S$ and time

\begin{tabular}{|c|c|c|c|c|}
\hline & $t(s)$ & $m_{D S M C}(k g)$ & $m_{\text {Exact }}(\boldsymbol{k g})$ & Error (\%) \\
\hline \multirow{11}{*}{$\begin{array}{l}0 \\
11 \\
\text { us }\end{array}$} & 0 & 0.001000 & 0.001000 & $4.8974 \times 10^{-10}$ \\
\hline & 10 & 0.002514 & 0.002615 & 0.038946 \\
\hline & 20 & 0.005868 & 0.006247 & 0.060752 \\
\hline & 30 & 0.011786 & 0.012480 & 0.055641 \\
\hline & 40 & 0.018869 & 0.019467 & 0.030720 \\
\hline & 50 & 0.024137 & 0.024376 & 0.009799 \\
\hline & 60 & 0.026773 & 0.026808 & 0.001309 \\
\hline & 70 & 0.027822 & 0.027806 & 0.000590 \\
\hline & 80 & 0.028200 & 0.028183 & 0.000609 \\
\hline & 90 & 0.028331 & 0.028321 & 0.000357 \\
\hline & 100 & 0.028376 & 0.028371 & 0.000175 \\
\hline \multirow{11}{*}{$\begin{array}{l}10 \\
1 \\
0 \\
\text { ㅁ } \\
11 \\
\text { us }\end{array}$} & 0 & 0.001000 & 0.001000 & $4.89746 \times 10^{-10}$ \\
\hline & 10 & 0.002513 & 0.002615 & 0.0388753 \\
\hline & 20 & 0.005860 & 0.006237 & 0.0604652 \\
\hline & 30 & 0.011740 & 0.012425 & 0.0550725 \\
\hline & 40 & 0.018732 & 0.019315 & 0.0301524 \\
\hline & 50 & 0.023896 & 0.024125 & 0.0095012 \\
\hline & 60 & 0.026466 & 0.026498 & 0.0012123 \\
\hline & 70 & 0.027486 & 0.027469 & 0.0006113 \\
\hline & 80 & 0.027853 & 0.027836 & 0.0006101 \\
\hline & 90 & 0.027981 & 0.027971 & 0.0003551 \\
\hline & 100 & 0.028024 & 0.028019 & 0.0001741 \\
\hline \multirow{11}{*}{ 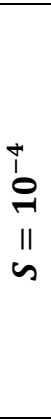 } & 0 & 0.001000 & 0.001000 & $4.89746 \times 10^{-10}$ \\
\hline & 10 & 0.002507 & 0.002607 & 0.038243 \\
\hline & 20 & 0.005788 & 0.006144 & 0.057934 \\
\hline & 30 & 0.011346 & 0.011946 & 0.050230 \\
\hline & 40 & 0.017587 & 0.018048 & 0.025525 \\
\hline & 50 & 0.021929 & 0.022087 & 0.007169 \\
\hline & 60 & 0.023999 & 0.024011 & 0.000481 \\
\hline & 70 & 0.024803 & 0.024784 & 0.000757 \\
\hline & 80 & 0.025088 & 0.025073 & 0.000610 \\
\hline & 90 & 0.025186 & 0.025178 & 0.000335 \\
\hline & 100 & 0.025220 & 0.025216 & 0.000160 \\
\hline \multirow{11}{*}{$\begin{array}{c}n \\
1 \\
0 \\
\| \\
\sim \\
\sim\end{array}$} & 0 & 0.001000 & 0.001000 & $4.89746 \times 10^{-10}$ \\
\hline & 10 & 0.002454 & 0.002536 & 0.032295 \\
\hline & 20 & 0.005167 & 0.005369 & 0.037476 \\
\hline & 30 & 0.008529 & 0.008704 & 0.020110 \\
\hline & 40 & 0.011015 & 0.011063 & 0.004275 \\
\hline & 50 & 0.012210 & 0.012197 & 0.001036 \\
\hline & 60 & 0.012660 & 0.012642 & 0.001411 \\
\hline & 70 & 0.012813 & 0.012802 & 0.000849 \\
\hline & 80 & 0.012864 & 0.012858 & 0.000411 \\
\hline & 90 & 0.012880 & 0.012878 & 0.000180 \\
\hline & 100 & 0.012885 & 0.012884 & 0.000074 \\
\hline \multirow{11}{*}{$\begin{array}{c}\underset{1}{1} \\
\underset{n}{0} \\
\sim\end{array}$} & 0 & 0.001000 & 0.001000 & $4.89746 \times 10^{-10}$ \\
\hline & 10 & 0.002052 & 0.002050 & 0.000924 \\
\hline & 20 & 0.002704 & 0.002685 & 0.006899 \\
\hline & 30 & 0.002897 & 0.002886 & 0.003790 \\
\hline & 40 & 0.002939 & 0.002935 & 0.001334 \\
\hline & 50 & 0.002948 & 0.002947 & 0.000396 \\
\hline & 60 & 0.002950 & 0.002949 & 0.000108 \\
\hline & 70 & 0.002950 & 0.002950 & $2.8110^{-5}$ \\
\hline & 80 & 0.002950 & 0.002950 & $7.06748 \times 10^{-6}$ \\
\hline & 90 & 0.002950 & 0.002950 & $1.73844 \times 10^{-6}$ \\
\hline & 100 & 0.002950 & 0.002950 & $4.20476 \times 10^{-7}$ \\
\hline
\end{tabular}




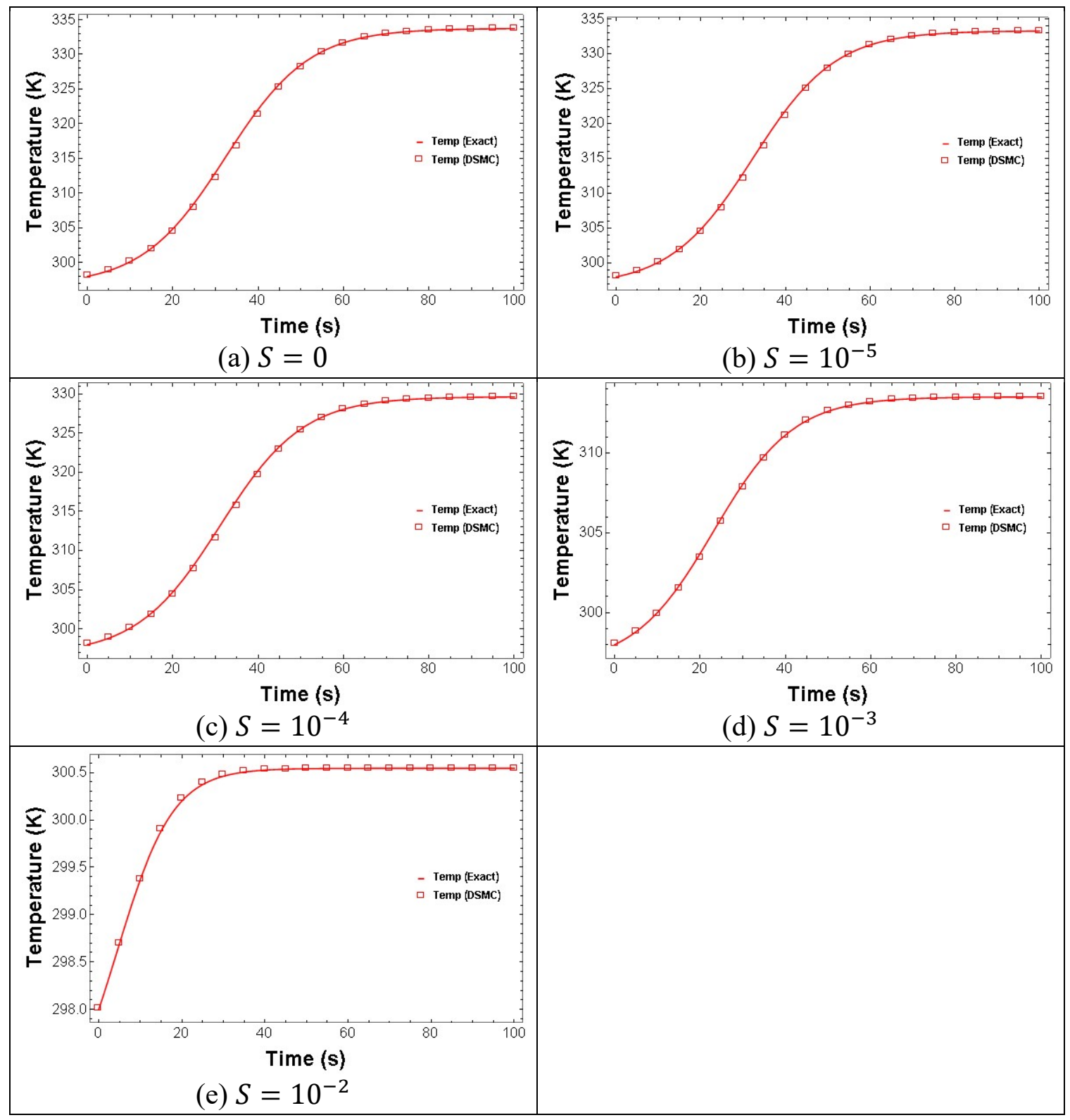

Figure 36: Plots (a)-(d) compare the exact and DSMC temperature curves using various values for $S$.

\subsection{Coupled Problem with Coagulation and Deposition}

Due to the non-linear complexity of the GDE, an exact analytical solution may not always exist. Numerical schemes like the DSMC technique, however, are robust, accurate, and quite simple to implement. In the previous section, we demonstrated that 
the exact solution of Gelbard's problem is well modeled by the DSMC technique. We now extend of the work by Gelbard to include aerosol coagulation and deposition processes. For this work, we assumed Brownian coagulation as well as diffusional and gravitational deposition. Considering coagulation, condensation, and deposition, the GDE reduces to:

$$
\begin{array}{r}
\frac{\partial n(v, t)}{\partial t}=-\frac{\partial}{\partial v}[I(v, t) n(v, t)]+\frac{1}{2} \int_{0}^{v} K\left(v^{\prime}, v\right) n\left(v-v^{\prime}, t\right) n\left(v^{\prime}, t\right) \mathrm{d} v^{\prime} \\
-n(v, t) \int_{0}^{\infty} K\left(v^{\prime}, v\right) n\left(v^{\prime}, t\right) \mathrm{d} v^{\prime}-R(v, t) n(v, t)
\end{array}
$$

which is coupled to equations (6.3-2) and (6.3-3).

To solve the system of equations by the DSMC technique, the GDE used the following aerosol models:

$$
\begin{gathered}
I(v, t)=A\left(M_{\text {vap }}(t)-M_{\text {vap }, \text { } q}(T(t))\right) v \\
K\left(v^{\prime}, v\right)=\beta_{\text {Brownian }}=\frac{2 \pi\left(D_{i}+D_{j}\right)\left(\gamma_{i} d_{i}+\gamma_{j} d_{j}\right)}{\left(\frac{d_{i}+d_{j}}{d_{i}+d_{j}+2 \sqrt{g_{i}^{2}+D_{j}^{2}}}+\frac{8\left(D_{i}+D_{j}\right)}{\sqrt{V_{i}^{2}+V_{j}^{2}}\left(d_{i}+d_{j}\right)}\right)} \\
R(v, t)=R_{\text {gravity }}+R_{\text {diffusional }}=\left(\frac{A_{\text {floor }} V_{T}}{V_{\text {chamber }}}\right)+\left(-\frac{D}{\Delta}\left(\frac{A_{\text {wall }}}{V_{\text {chamber }}}+\frac{A_{\text {floor }}}{V_{\text {chamber }}}+\frac{A_{\text {ceiling }}}{V_{\text {chamber }}}\right)\right)
\end{gathered}
$$

where $A_{\text {wall }}$ is the wall area, $A_{\text {ceiling }}$ is the area of the ceiling, $A_{\text {floor }}$ is the floor area, $V_{\text {chamber }}$ is the volume of the chamber, $V_{T}$ is the particle settling velocity, $D$ is the particle diffusivity (or diffusion coefficient), and $\Delta$ is the diffusion boundary layer thickness. 
It is important to note here that this problem is not isothermal, regardless of the chosen value for $S$. Since water vapor in the atmosphere condenses onto the surface of the aerosol particles, heat is released when the vapor changes state from gas to liquid. Mass is conserved for coagulating and deposited mass by modifying $M_{v a p}(t)$ and $T(t)$ to:

$$
\begin{gathered}
M_{\text {vap }}(t)=M_{\text {Tot }}-M_{\text {aero }}(t)-M_{\text {aero,coag }}(t)-M_{\text {dep }}(t) \\
T(t)=\frac{L}{M_{g} C_{V}}\left[M_{\text {vap }}(0)-M_{\text {Tot }}+M_{\text {aero }}(t)+M_{d e p}(t)\right]+T_{0}
\end{gathered}
$$

where $M_{\text {aero,coag }}(t)$ is a variable found only in the condensation module and accounts for particles (and thus mass) which underwent coagulation only. The particles (or mass) in $M_{\text {aero }}(t)$ go through the condensation process with all mass accounted for by $M_{v a p}(t)$. Finally, the particles (or mass) entries in $M_{\text {aero,coag }}(t)$ are added back into $M_{\text {aero }}(t)$ after the condensation process is complete. In addition to the list of values used in the prior section, the diffusion boundary layer was taken as $\Delta=10^{-5} m$ (as prescribed by the MAEROS User Manual) in the proceeding calculations.

Figure 37 summarizes the time-dependent vapor and aerosol mass concentrations that were calculated by the DSMC technique for the set of values $S=\left\{0,10^{-5}, 10^{-4}, 10^{-3}, 10^{-2}\right\}$. Applying the same logarithmically spaced bin sizes from the previous section, Figure 38 shows the suspended aerosol mass concentration per diameter bin. Lastly, Figure 39 shows the change in temperature due to heat released from condensation in the chamber. The average 
aerosol sizes for $t=0 \mathrm{~s}, t=20 \mathrm{~s}$, and $t=100 \mathrm{~s}$ were also calculated and the results are summarized in Table 22. From these simulations, the total mass deposited at $t=100 \mathrm{~s}$ was found to be $7.97 \mathrm{mg}, 0.6861 \mathrm{mg}, 0.4434 \mathrm{mg}$, $0.7557 \mathrm{mg}$, and $2.9058 \mathrm{mg}$ for $S=0, S=10^{-5}, S=10^{-4}, S=10^{-3}$, and $S=10^{-2}$, respectively.

In each simulation, coagulation played an important role because approximately $1 \%$ of the total number of particles remained at the end of the simulation. On the other hand, deposition did not play an important role in aerosol evolution because most of the particles remained too small to deposit by their own weight, leaving most particles to deposit primarily by diffusional deposition, which relies heavily on the diffusional boundary layer $\Delta$. To show this effect, we have also examined the sensitivity of the diffusion boundary layer to cumulative mass deposited for $S=0$ and $S=10^{-3}$. Previously, we had used a value for $\Delta$ as prescribed by the MAEROS User Manual as $\Delta=10^{-5} \mathrm{~m}$. For our analysis we will use $\Delta=\left\{10^{-4} m, 10^{-5} m, 10^{-6} m, 10^{-7} m\right\}$. These results are summarized in Figure 40 and Figure 41. As expected, the diffusional deposition increased (and thus an increase in the total mass deposited) when the value for $\Delta$ was decreased. 


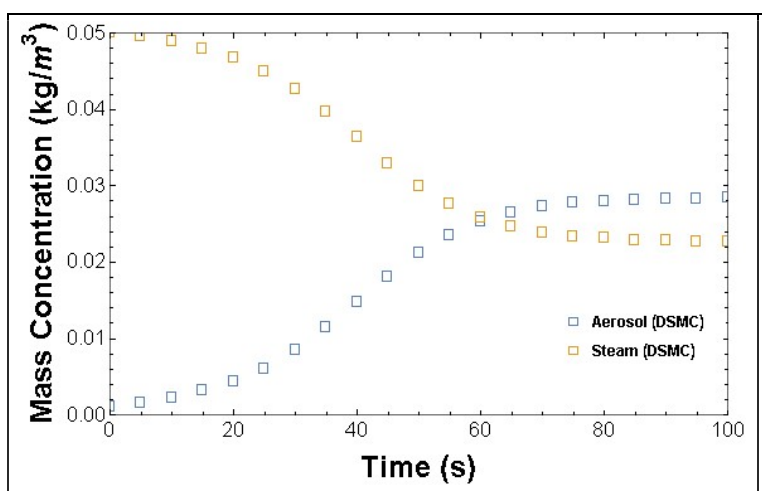

(a) $S=0$

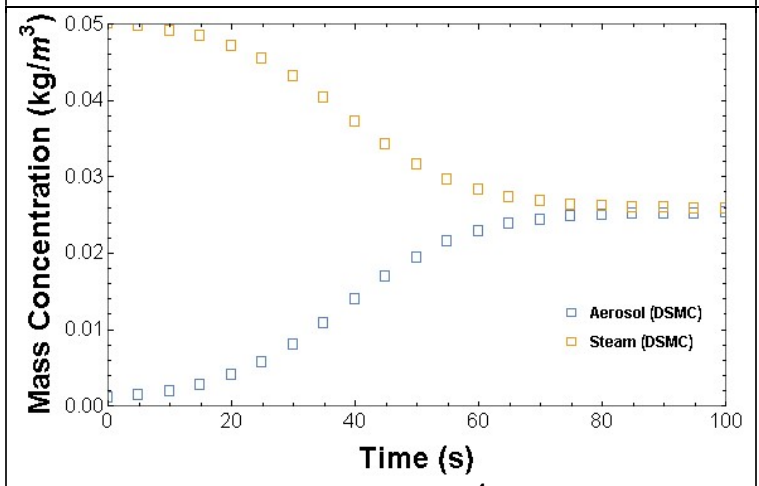

(c) $S=10^{-4}$

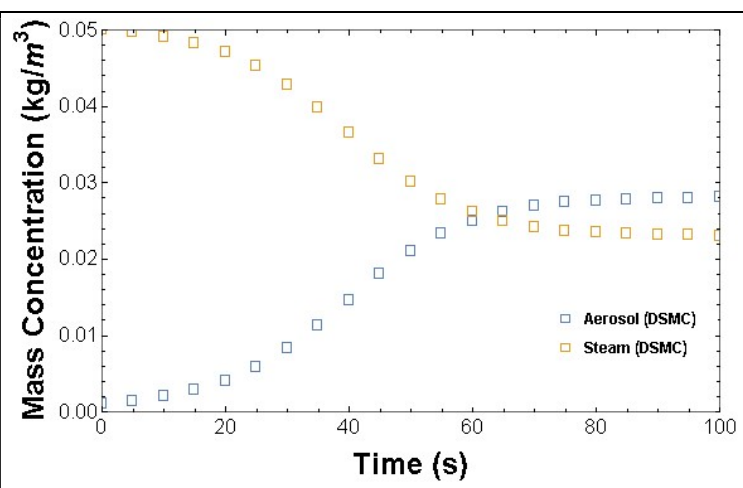

(b) $S=10^{-5}$

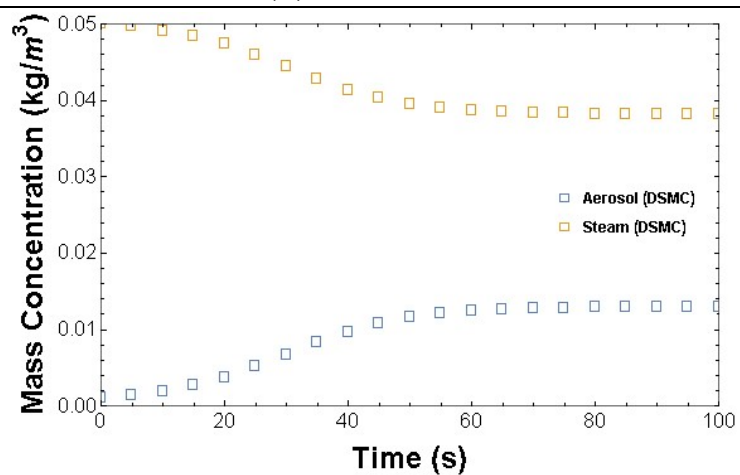

(d) $S=10^{-3}$

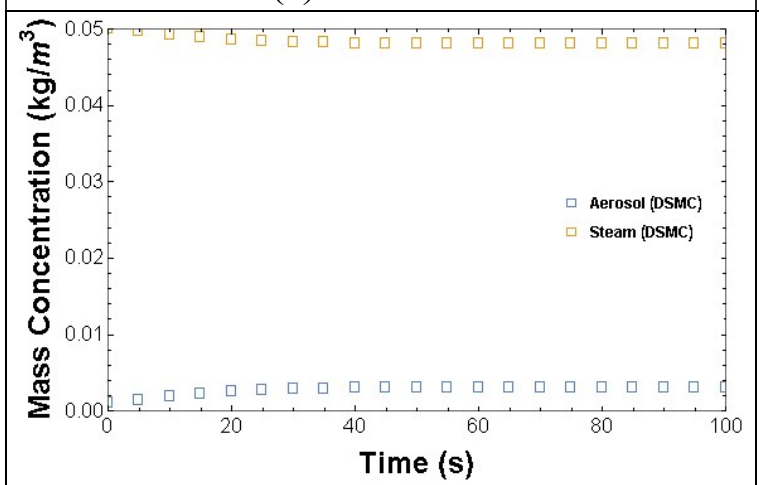

(e) $S=10^{-2}$

Figure 37: Plots (a)-(e) show the steam and aerosol concentrations for condensation, coagulation, and deposition using the DSMC technique for varying $S$. 


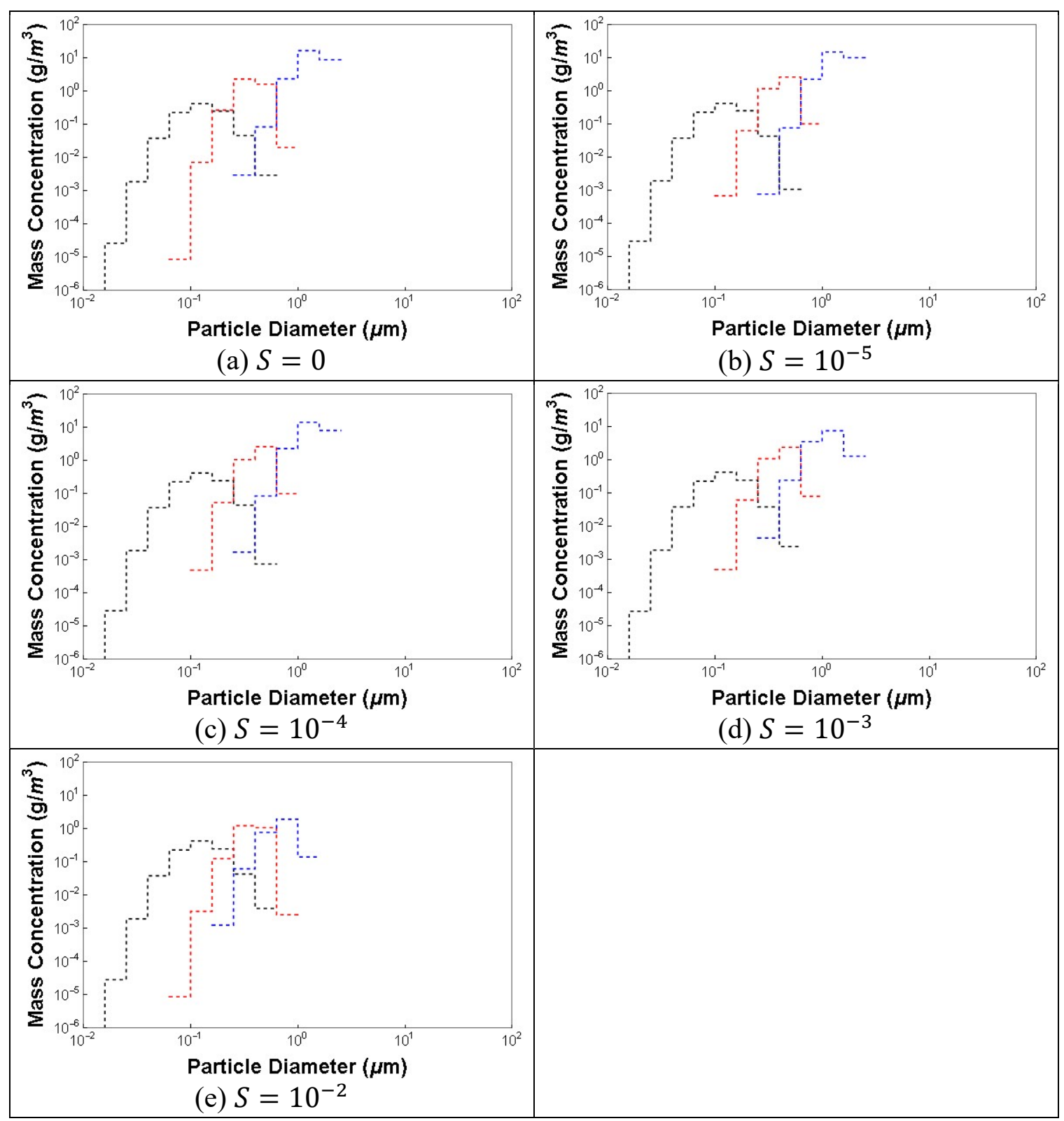

Figure 38: Plots (a)-(e) show the mass concentration per diameter bin from the DSMC solution for coagulation, condensation, and deposition with varying $S$. The dashed black, red, and blue lines represent the mass concentration per bin for times $t=0 \mathrm{~s}, t=20 \mathrm{~s}$, and $t=100 \mathrm{~s}$, respectively. 


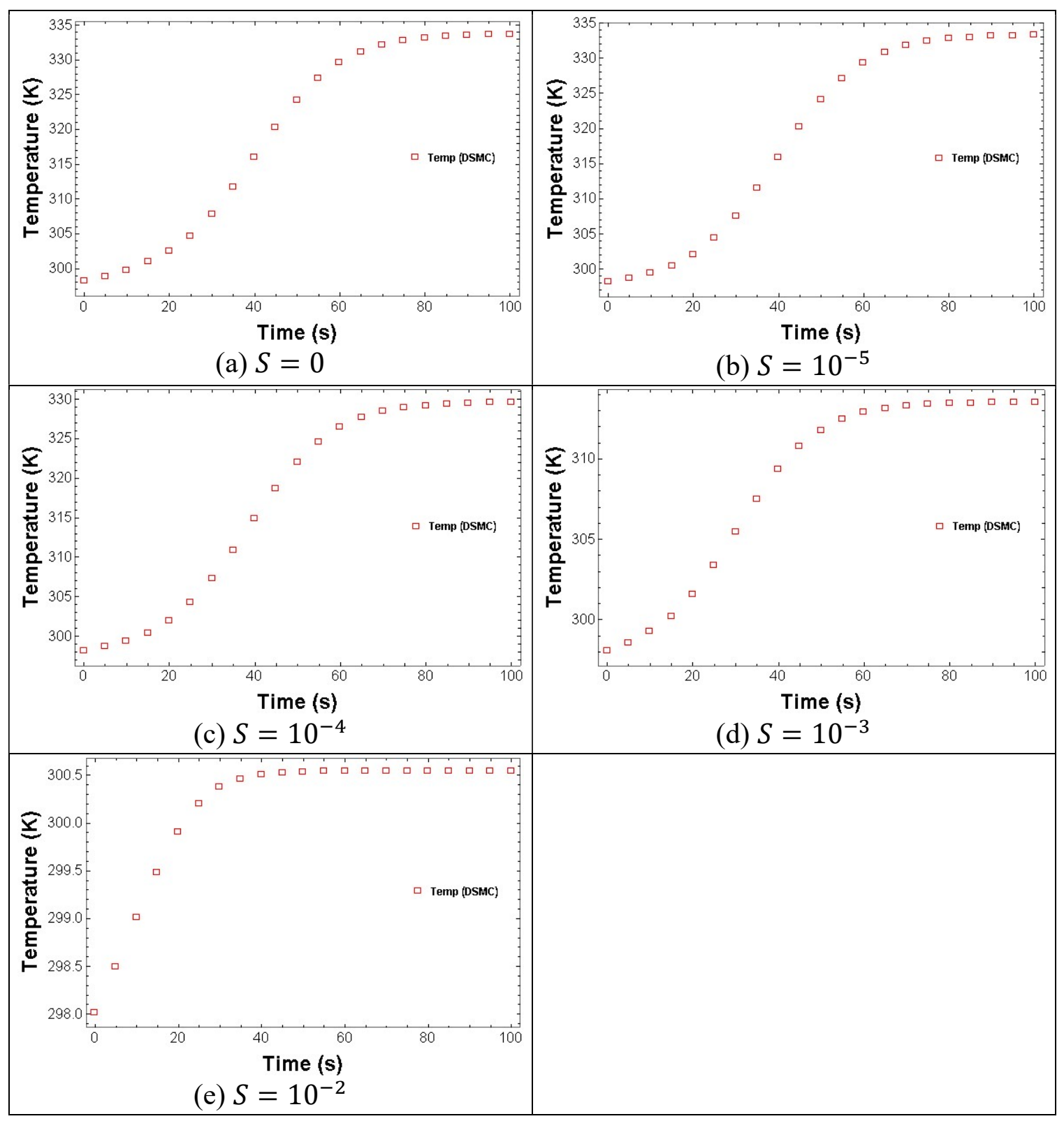

Figure 39: Plots (a)-(e) show the temperature as a function of time from the DSMC solution for coagulation, condensation, and deposition processes with varying $S$. 
Table 22: Average particle diameters as a function of time for varying values of $S$

\begin{tabular}{|c|c|c|c|c|c|}
\hline & $S=0$ & $S=10^{-5}$ & $S=10^{-4}$ & $S=10^{-3}$ & $S=10^{-2}$ \\
\hline $\begin{array}{c}\text { Time } \\
(s)\end{array}$ & $\begin{array}{c}\text { Avg. Dia } \\
(\mu m)\end{array}$ & $\begin{array}{c}\text { Avg. Dia } \\
(\mu m)\end{array}$ & $\begin{array}{c}\text { Avg. Dia } \\
(\mu m)\end{array}$ & $\begin{array}{c}\text { Avg. Dia } \\
(\mu m)\end{array}$ & $\begin{array}{c}\text { Avg. Dia } \\
(\mu m)\end{array}$ \\
\hline 0 & 0.1 & 0.1 & 0.1 & 0.1 & 0.1 \\
\hline 20 & 0.3339 & 0.3996 & 0.4066 & 0.3977 & 0.3434 \\
\hline 100 & 1.263 & 1.288 & 1.256 & 1.009 & 0.6361 \\
\hline
\end{tabular}

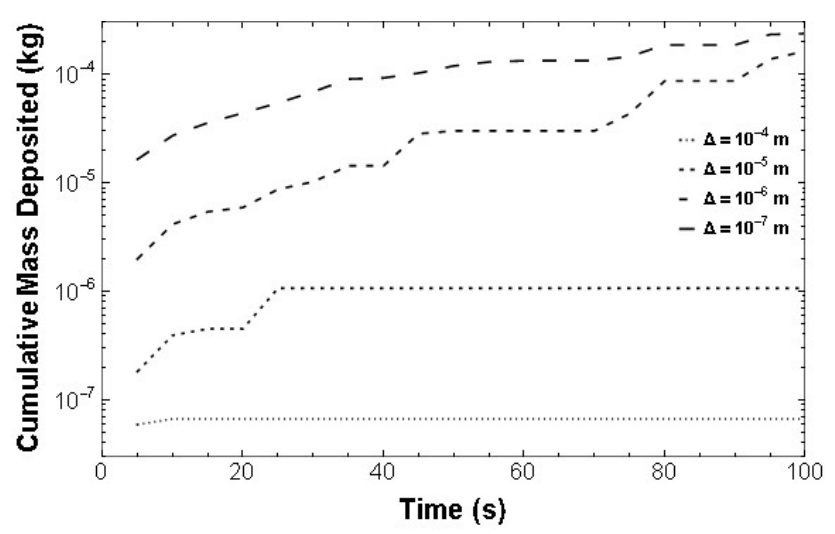

Figure 40: Sensitivity analysis for cumulative mass deposited for $S=0$

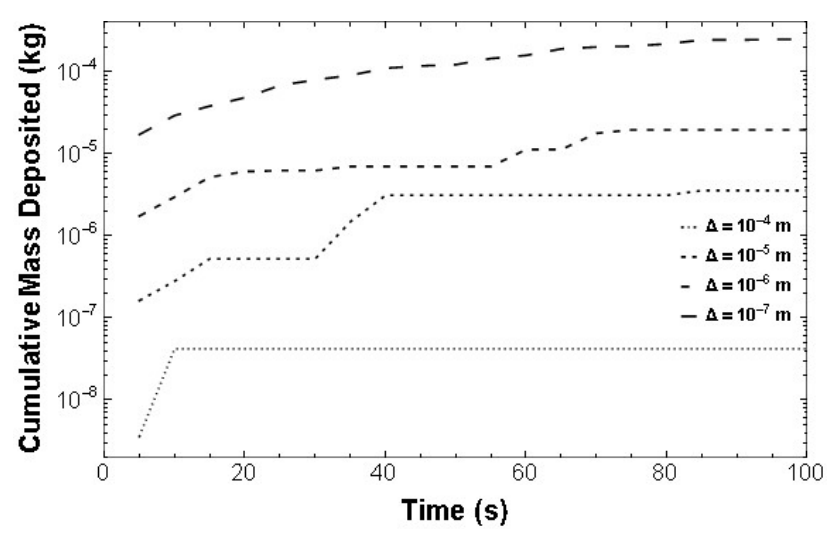

Figure 41: Sensitivity analysis for cumulative mass deposited for $S=10^{-3}$ 


\section{CONCLUSION}

This research focused on the creation of a computational source term code for modeling the behavior of aerosolized fission products using the DSMC technique. The DSMC code was built from the ground up and tested in several stages with the final objective of simulating the LA4 experiment.

Generalization for an $n$-component aerosol under any combination of aerosol processes demonstrated the DSMC technique to be effective in modeling aerosol dynamics through a series of benchmark problems.

Attention was also focused into generalizing Mason's condensation model to include the Kelvin, Knudsen, and solute effects. This new model gave strong insights into quantifying the role of the condensation process for single and multi-component aerosols with hygroscopic and non-hygroscopic properties.

Through successful implementation of simulation scaling theory, we have drastically reduced computation time by orders of magnitude. These improvements in the DSMC code have been benchmarked against exact solutions. Though not reported here, other efforts to reduce simulation time were made with positive results.

Accurate and robust, the DSMC technique was shown to be effective for simulating coupled aerosol transport and thermal-hydraulics. The condensation studies reported here show a strong interdependence between aerosol transport and thermalhydraulics; and hence, successful coupling would drastically increase the accuracy of any LA4 simulation. 
While these endeavors have proven fruitful, the simulation the LA4 experiment by the DSMC technique has not been feasible due to memory and computational restrictions. Moreover, it is the belief of the author that reducing the runtime through scaling alone would risk simulation accuracy and resolution. CUDA and other highperformance computing techniques could help remedy this issue, but these efforts lie outside the scope of this project. 


\section{REFERENCES}

Barrett, J. C., and C. F. Clement. 1988. “Growth Rates for Liquid Drops.” Journal of Aerosol Science 19 (2): 223-242.

Bieder, Ulrich, Felice de Rosa, Peter Fynbo, Jorma Jokiniemi, Andreas Paller, and Alfred Schatz. 1995. Nuclear Science and Technology: Coupling Aerosol Behavior and Thermal-Hydraulics State of the Art Review Final Report. Contract No. FI3SCT92-0006. EUR 16504 EN. Luxembourg: European Commission, DirectorateGeneral XII, Science, Research and Development.

Bird, G. A. 1994. Molecular Gas Dynamics and Direct Simulation of Gas Flows. New York: Oxford University Press.

Bloom, G. R., D. R. Dickinson, R. K. Hilliard, J. D. McCormack, L. D. Muhlestein, and Frank J. Rahn. 1986. “LWR Aerosol Containment Experiments (LACE) Program.” In Proceedings of an International Symposium on Source Term Evaluation for Accident Conditions Held in Columbus, Ohio October 28November 1, 1985. Vienna, Austria: International Atomic Energy Agency.

Bowsher, B. R., and A. L. Nichols. 1988. "The Formation of Heterogeneous Aerosols in Severe Reactor Accidents." In Nuclear Science and Technology Proceedings Of CSNI-OECD Workshop on Water-Cooled Reactor Aerosol Code Evaluation and Uncertainty Assessment From 9 to 11 September 1987, edited by E. della Loggia and J. Royen, 170-184. EUR 11351 EN. Luxemburg: Commission of the European Communities. 
Brock, J. R. 1993. "New Aspects of Aerosol Growth Processes.” Aerosol Science and Technology 2 (2): 109-120.

Campbell, Shawn A., and Sudarshan K. Loyalka. 2015. "Computation of Aerosol Evolution under Coagulation.” Nuclear Science and Engineering 181 (2): 137-59.

Friedlander, Sheldon K. 2000. Smoke, Dust, and Haze: Fundamentals of Aerosol Dynamics. New York: Oxford University Press.

Fuchs, N. A. 1964. The Mechanics of Aerosols. New York: Pergamon Press.

Fukuta, N., and L. A. Walter. 1970. "Kinetics of Hydrometeor Growth from a VaporSpherical Model.” Journal of the Atmospheric Sciences 27 (8): 1160-1172.

Fynbo, P., Hans Häggblom, and J. Jokiniemi. 1990. Aerosol Transport in Severe Reactor Accidents: Final Report of the NKA Project AKTI-160. Copenhagen: Nordic Liaison Committee for Atomic Energy.

Gelbard, Fred. 1982. “MAEROS User Manual.” Report\# NUREG/CR-1391, SAND800822. Albuquerque, New Mexico: Sandia National Laboratories.

Gelbard, Fred. 1990. “Modeling Multicomponent Aerosol Particle Growth By Vapor Condensation.” Aerosol Science and Technology 12 (2): 399-412.

Gelbard, Fred, and John H. Seinfeld. 1978. "Coagulation and Growth of a Multicomponent Aerosol.” Journal of Colloid and Interface Science. 63 (3): 472479.

Gelbard, Fred, and John H. Seinfeld. 1980. "Simulation of Multicomponent Aerosol Dynamics." Journal of Colloid and Interface Science. 78 (2): 485-501. 
Hatch, Theodore and Sarah P. Choate. 1929. "Statistical description of the size properties of non-uniform particulate substance.” Journal of the Franklin Institute 207 (3): 369-87.

Humrickhouse, Paul W. 2011. HTGR Dust Safety Issues and Needs for Research and Development. Report\# INL/EXT-11-21097. Idaho Falls, ID: Idaho National Laboratory. DOI:10.2172/1023483.

Jokiniemi, J. 1990. "Effect of Selected Binary and Mixed Solutions on Steam Condensation and Aerosol Behavior in Containment." Aerosol Science and Technology 12 (4): 891-902.

Kljenak, I., and B. Mavko. 2006b. "Simulation of LACE LA4 Experiment on Aerosol Behavior in a Nuclear Power Plant Containment with the ASTEC CPA V1.2 Code.” Report\# IJS-DP-9291. Ljubljana, Slovenia: Jozef Stefan Institute.

Kljenak, Ivo, Maik Dapper, Jiří Dienstbier, Luis E. Herranz, Marco K. Koch, and Joan Fontanet. 2010. "Thermal-hydraulic and Aerosol Containment Phenomena Modelling in ASTEC Severe Accident Computer Code." Nuclear Engineering and Design 240 (3): 656-67.

Kmetyk, L. N. 1991. "MELCOR 1.8.1 Assessment: LACE Aerosol Experiment LA4.” Report\# SAND91-1532. Albuquerque, NM: Sandia National Laboratories. Kulmala, M. 1993. "Condensational Growth and Evaporation in the Transition Regime: An Analytical Expression.” Aerosol Science and Technology 19 (3): 381-388.

Laaksonen, A., T. Vesala, M. Kulmala, P. M. Winkler, and P. E. Wagner. 2005. “Commentary on Cloud Modelling and the Mass Accommodation Coefficient of Water." Atmospheric Chemistry and Physics 5 (2): 461-464. 
Loyalka, S. K., and J. W. Park. 1988. “Aerosol Growth by Condensation: A Generalization of Mason's Formula." Journal of Colloid and Interface Science 125 (2): 712-716.

Maiello, Mark L., and Mark D. Hoover. 2011. Radioactive Air Sampling Methods. Boca Raton: Taylor \& Francis.

Mason, Basil J. 1971. The Physics of Clouds. Oxford: Clarendon Press.

McDonald, B. H. 1988. “Assessing Numerical Models Used in Nuclear Aerosol Transport Models.” In Nuclear Science and Technology Proceedings Of CSNIOECD Workshop on Water-Cooled Reactor Aerosol Code Evaluation and Uncertainty Assessment From 9 to 11 September 1987, edited by E. della Loggia and J. Royen, 185-204. EUR 11351 EN. Luxemburg: Commission of the European Communities.

Palaniswaamy, Geethpriya, and Sudarshan K. Loyalka. 2006. "Direct Simulation Monte Carlo Aerosol Dynamics: Coagulation and Collisional Sampling." Nuclear Technology 156 (1): 29-38.

Palaniswaamy, Geethpriya, and Sudarshan K. Loyalka. 2008. "Direct Simulation, Monte Carlo, Aerosol Dynamics: Coagulation and Condensation." Annals of Nuclear Energy 35 (3): 485-94.

Palsmeier, John F., and Sudarshan K. Loyalka. 2013. "Evolution of Charged Aerosols: Role of Charge on Coagulation." Nuclear Technology 184 (1): 78-95.

Passalacqua, Roberto, Claude Renault, and Didier Tarabelli. 1995. "Two Compartment Thermal-Hydraulics Experiment Analyzed By ESCADRE Code.” Energia Nucleare (Rome), 12(1), 21-30. 
Passalacqua, Roberto, Didier Tarabelli, and Claude Renault. 1996. "Light Water Reactor Aerosol Containment Experiment LA4 Simulated by JERICHO and AEROSOLSB2 Codes." Nuclear Technology 116 (3): 283-92.

Rahn, Frank.1988. “The LWR Aerosol Containment Experiments (LACE) Project Summary Report.” Report\# LACE TR-012, NP-6094-D. Palo Alto, California: Electric Power Research Institute

Rahn, Frank. 2010. Technical Foundation of Reactor Safety, Revision 1: Knowledge Base for Resolving Severe Accident Issues. Final Report No. 1022186. Palo Alto, California: Electric Power Research Institute.

Ramabhadran, T. E., T. W. Peterson, and J. H. Seinfeld. 1976. "Dynamics of Aerosol Coagulation and Condensation." AlChe Journal 22 (5): 840-851.

Ross, Kyle, Jesse Phillips, Randal O. Gauntt, and Kenneth C. Wagner. 2014. "MELCOR Best Practices as Applied in the State-of-the-Art Reactor Consequence Analyses (SOARCA) Project.” NUREG/CR-7008. Washington, District of Columbia: U.S. Nuclear Regulatory Commission, Office of Nuclear Regulatory Research.

Sehgal, Bal Raj. 2012. Nuclear Safety in Light Water Reactors: Severe Accident Phenomenology. Amsterdam: Elsevier/Academic Press.

Seinfeld, John H., and Spyros N. Pandis. 2006. Atmospheric Chemistry and Physics of Air Pollution. New York: Wiley.

Sher, Rudolph, and Richard R. Hobbins. 2011. Transport and Removal of Aerosols in Nuclear Power Plants Following Severe Accidents. La Grange Park, IL: American Nuclear Society. 
Stempniewics, M. M., L. Winters, and S. A. Caspersson. 2012. “Analysis of Dust and Fission Products in a Pebble Bed NGNP." Nuclear Engineering and Design 251, $5^{\text {th }}$ International Topical Meeting on High Temperature Reactor Technology (HTR 2010): 433-442.

US Atomic Energy Commission. 1950. "Summary Report of the Reactor Safeguard Committee.” Report\# WASH-3.

US Atomic Energy Commission. 1957. "Theoretical Possibilities and Consequences of Major Accidents in Large Nuclear Power Plants.” Report\# WASH-740.

US Atomic Energy Commission. 1962. "Calculation of Distance Factors for Power and Test Reactor Sites.” Report\# TID-14844.

US Nuclear Regulatory Commission. 1975. "Reactor Safety Study: An Assessment of Accident Risks in US Commercial Nuclear Power Plants.” Report\# WASH-1400, NUREG-75/014.

Weber, G. 1989. "Verification des Containment Rechenprogramms FIPLOC an DEMONA und LACE Experimenten. Ges. für Reaktorsicherh.” GRS-A-1641.

Williams, M. M. R. 1983. "The Time-Dependent Behavior of Aerosols with Growth and Deposition. I. Without Coagulation.” Journal of Colloid and Interface Science 93 (1): 252-263.

Williams, M. M. R., and Sudarshan K. Loyalka. 1991. Aerosol Science: Theory and Practice: With Special Applications to the Nuclear Industry. Oxford; New York: Pergamon Press. 
Wilson, J. H., and P. C. Arwood. 1990. "Comparison of (Posttest) Predictions of Aerosol Codes with Measurements in LWR Aerosol Containment Experiment (LACE) LA4.” Report\# LACE TR-084, ORNL/M-991. Oak Ridge, TN: Oak Ridge National Laboratory. 


\section{APPENDIX}

\section{A. Gas Relations Required for Mason's Model of Condensation}

\section{A.1 Saturation Pressure}

At saturation, the ideal gas law is:

$$
\begin{gathered}
P_{s} V=n_{s} R T=\frac{m}{M} R T \\
P_{s}=\left(\frac{m}{V}\right)_{s} \frac{R T}{M}=\rho_{s} \frac{R T}{M}
\end{gathered}
$$

where $P_{s}$ is the saturation pressure in $\frac{N}{m^{2}}, V$ is the volume in $m^{3}, n_{s}$ is the number saturation density in $m o l, R$ is the universal gas constant in $\frac{J}{\mathrm{~mol} \cdot K}, T$ is the temperature in $K, m$ is the mass in $k g, M$ is the molar mass in $\frac{k g}{m o l}$, and $\rho_{s}$ is the saturation density in $\frac{\mathrm{kg}}{\mathrm{m}^{3}}$. Thus, the saturation pressure is:

$$
P_{s}=\rho_{s} \frac{R T}{M}
$$

\section{A.2 Clausius-Clapeyron Equation}

The Clausius-Clapeyron equation is:

$$
\frac{d P}{d T}=\frac{\Delta s}{\Delta V}=\frac{L}{T \Delta V}
$$

where $\Delta V=V_{\text {vapor phase }}-V_{\text {liquid phase }} \approx V_{\text {vapor phase }}$. Using the ideal gas law, and solving for volume, we get: 


$$
\begin{gathered}
P V=n R T=\frac{m}{M} R T \\
V=\frac{m R T}{M P}
\end{gathered}
$$

Inserting this equation for volume into the Clausius-Clapeyron equation, we get:

$$
\begin{gathered}
\frac{d P}{d T}=\frac{L}{T \Delta V}=\frac{L}{T \frac{m R T}{M P}}=\frac{L M P}{m R T^{2}} \\
\frac{1}{P} \frac{d P}{d T}=\frac{L M}{m R T^{2}}
\end{gathered}
$$

For a unit mass $(m=1)$, and:

$$
\frac{1}{P} \frac{d P}{d T}=\frac{L M}{R T^{2}}
$$

\section{A.3 Combination of Saturation Pressure and Clausius-Clapeyron Equation}

From A.1, we find that:

$$
\begin{gathered}
P_{s}=\rho_{s} \frac{R T}{M} \\
d P=\frac{R}{M}\left(\rho_{s} d T+T d \rho_{s}\right) \\
\frac{d P}{d T}=\frac{R}{M}\left(\rho_{s}+T \frac{d \rho_{s}}{d T}\right)
\end{gathered}
$$

Dividing this result by $P$ and setting this equal to the right-hand side of the ClausiusClapeyron equation from A.2, this gives:

$$
\frac{1}{P} \frac{d P}{d T}=\frac{1}{\rho_{s} R T / M} \frac{d P}{d T}=\frac{1}{\rho_{s} T}\left(\rho_{s}+T \frac{d \rho_{s}}{d T}\right)=\frac{1}{T}+\frac{1}{\rho_{s}} \frac{d \rho_{s}}{d T}=\frac{L M}{R T^{2}}
$$

and thus: 


$$
\frac{d \rho_{s}}{\rho_{s}}=\frac{L M}{R} \frac{d T}{T^{2}}-\frac{d T}{T}
$$

\section{B. Derivation of Mason's Equation}

The condensational growth rate equation is found by solving the coupled mass and heat rate equations. These equations are:

$$
\begin{gathered}
\frac{d m}{d t}=4 \pi r D m_{v}\left(n_{\infty}-n_{r}\right) \\
L \frac{d m}{d t}=4 \pi r K\left(T_{r}-T_{\infty}\right)
\end{gathered}
$$

where $m_{v}$ is the vapor molecular mass and $n$ is the number saturation density. Using the ideal gas law, we may rewrite the mass rate equation as:

$$
\frac{d m}{d t}=4 \pi r D\left(\rho_{\infty}-\rho_{r}\right)
$$

where $\rho$ represents the mass saturation density. Integrating the result from $\mathbf{A . 3}$ from the particle surface to infinity:

$$
\begin{gathered}
\int_{\rho_{s}\left(T_{r}\right)}^{\rho_{s}\left(T_{\infty}\right)} \frac{\mathrm{d} \rho_{s}}{\rho_{s}}=\int_{T_{r}}^{T_{\infty}} \frac{L M}{R} \frac{\mathrm{d} T}{T^{2}}-\int_{T_{r}}^{T_{\infty}} \frac{\mathrm{d} T}{T} \\
\ln \left(\frac{\rho_{s}\left(T_{r}\right)}{\rho_{s}\left(T_{\infty}\right)}\right)=\frac{L M}{R} \frac{\left(T_{r}-T_{\infty}\right)}{T_{r} T_{\infty}}-\ln \left(\frac{T_{r}}{T_{\infty}}\right)
\end{gathered}
$$

Assuming that $T_{r} \approx T_{\infty}$,

$$
\ln \left(\frac{\rho_{s}\left(T_{r}\right)}{\rho_{s}\left(T_{\infty}\right)}\right)=\frac{L M}{R} \frac{\left(T_{r}-T_{\infty}\right)}{T_{r} T_{\infty}}-\ln \left(1+\frac{T_{r}}{T_{\infty}}\right)
$$


The Mercator Series for $|x|<1$ is given as:

$$
\ln (1+x)=x-\frac{x^{2}}{2}+\frac{x^{3}}{3}-\cdots=\sum_{n=0}^{\infty} \frac{(-1)^{n+1}}{n} x^{n}
$$

Using the Mercator Series above, we may approximate the last term as $\ln (1+x) \approx x$ by neglecting higher order terms. Applying this approximation and simplifying, this gives

$$
\begin{aligned}
\ln \left(\frac{\rho_{s}\left(T_{r}\right)}{\rho_{s}\left(T_{\infty}\right)}\right) & =\frac{L M}{R} \frac{\left(T_{r}-T_{\infty}\right)}{T_{r} T_{\infty}}-\left(\frac{T_{r}-T_{\infty}}{T_{\infty}}\right)=\left(\frac{L M-R T_{r}}{R T_{r}}\right)\left(\frac{T_{r}-T_{\infty}}{T_{\infty}}\right) \\
& =\left(\frac{L M-R T_{\infty}}{R T_{\infty}^{2}}\right)\left(T_{r}-T_{\infty}\right)
\end{aligned}
$$

where we approximate that $T_{r} \approx T_{\infty}$ in the last line. Exponentiating gives:

$$
\frac{\rho_{s}\left(T_{r}\right)}{\rho_{s}\left(T_{\infty}\right)}=\operatorname{Exp}\left[\left(\frac{L M-R T_{\infty}}{R T_{\infty}^{2}}\right)\left(T_{r}-T_{\infty}\right)\right]
$$

The Taylor series expansion for exponentials is given by:

$$
e^{x}=1+x+\frac{x^{2}}{2 !}+\cdots=\sum_{n=0}^{\infty} \frac{x^{n}}{n !}
$$

Taylor expansion of the exponential gives:

$$
\frac{\rho_{s}\left(T_{r}\right)}{\rho_{s}\left(T_{\infty}\right)}=1+\left(\frac{L M-R T_{\infty}}{R T_{\infty}^{2}}\right)\left(T_{r}-T_{\infty}\right)+\frac{1}{2}\left(\frac{L M-R T_{\infty}}{R T_{\infty}^{2}}\right)^{2}\left(T_{r}-T_{\infty}\right)^{2}+\cdots
$$

Assuming that $T_{r}-T_{\infty}$ is small (i.e., $\leq 1^{\circ} C$ ):

$$
\frac{\rho_{s}\left(T_{r}\right)}{\rho_{s}\left(T_{\infty}\right)}=1+\left(\frac{L M-R T_{\infty}}{R T_{\infty}^{2}}\right)\left(T_{r}-T_{\infty}\right)=\frac{\rho_{s}}{\rho_{s}}+\left(\frac{L M-R T_{\infty}}{R T_{\infty}^{2}}\right)\left(T_{r}-T_{\infty}\right)
$$

and 


$$
\frac{\rho_{s}\left(T_{r}\right)-\rho_{s}\left(T_{\infty}\right)}{\rho_{s}\left(T_{\infty}\right)}=\left(\frac{L M-R T_{\infty}}{R T_{\infty}^{2}}\right)\left(T_{r}-T_{\infty}\right)
$$

Solving for $T_{r}-T_{\infty}$ in the heat rate equation, we get:

$$
T_{r}-T_{\infty}=\frac{L}{4 \pi r K} \frac{d m}{d t}
$$

Substituting this result, we get:

$$
\frac{\rho_{s}\left(T_{r}\right)-\rho_{s}\left(T_{\infty}\right)}{\rho_{s}\left(T_{\infty}\right)}=\left(\frac{L M-R T_{\infty}}{R T_{\infty}^{2}}\right)\left(\frac{L}{4 \pi r K}\right) \frac{d m}{d t}
$$

Assuming that $\rho_{r}=\rho_{s}\left(T_{r}\right)$ in the mass rate equation and dividing by $\rho_{s}\left(T_{\infty}\right)$, the mass rate equation becomes:

$$
\frac{1}{\rho_{s}\left(T_{\infty}\right)} \frac{d m}{d t}=4 \pi r D \frac{\left(\rho_{\infty}-\rho_{r}\right)}{\rho_{s}\left(T_{\infty}\right)}=4 \pi r D \frac{\rho_{s}\left(T_{\infty}\right)-\rho_{s}\left(T_{r}\right)}{\rho_{s}\left(T_{\infty}\right)}
$$

so that:

$$
\frac{\rho_{s}\left(T_{\infty}\right)-\rho_{s}\left(T_{r}\right)}{\rho_{s}\left(T_{\infty}\right)}=\frac{1}{4 \pi r D \rho_{s}\left(T_{\infty}\right)} \frac{d m}{d t}
$$

Adding together the modified mass rate equations, we get:

$$
\frac{\rho_{s}\left(T_{r}\right)-\rho_{s}\left(T_{\infty}\right)}{\rho_{s}\left(T_{\infty}\right)}=\frac{d m}{d t}\left[\left(\frac{L}{4 \pi r K}\right)\left(\frac{L M-R T_{\infty}}{R T_{\infty}^{2}}\right)+\frac{1}{4 \pi r D \rho_{s}\left(T_{\infty}\right)}\right]
$$

Solving for the mass rate gives: 


$$
\begin{aligned}
\frac{d m}{d t} & =\frac{\rho_{s}\left(T_{r}\right)-\rho_{s}\left(T_{\infty}\right)}{\rho_{s}\left(T_{\infty}\right)}\left[\left(\frac{L}{4 \pi r K}\right)\left(\frac{L M-R T_{\infty}}{R T_{\infty}^{2}}\right)+\frac{1}{4 \pi r D \rho_{s}\left(T_{\infty}\right)}\right]^{-1} \\
& =4 \pi r(\underbrace{\frac{\rho_{s}\left(T_{r}\right)}{\rho_{s}\left(T_{\infty}\right)}}_{=S}-\underbrace{\frac{\rho_{s}\left(T_{\infty}\right)}{\rho_{s}\left(T_{\infty}\right)}}_{=1})\left[\left(\frac{L}{K}\right)\left(\frac{L M-R T_{\infty}}{R T_{\infty}^{2}}\right)+\frac{1}{D \rho_{s}\left(T_{\infty}\right)}\right]^{-1} \\
& =4 \pi r(S-1)\left[\frac{L}{K T_{\infty}}\left(\frac{L M}{R T_{\infty}}-1\right)+\frac{1}{D \rho_{s}\left(T_{\infty}\right)}\right]^{-1}
\end{aligned}
$$

Assuming spherical particles, we find the particle's radial growth in terms of mass rate by:

$$
m=\rho_{L} V=\frac{4}{3} \pi \rho_{L} r^{3}
$$

By the chain rule, this is:

$$
\begin{gathered}
\frac{d m}{d t}=\frac{d m}{d r} \frac{d r}{d t}=4 \pi \rho_{L} r^{2} \frac{d r}{d t} \\
\frac{d r}{d t}=\frac{1}{4 \pi \rho_{L} r^{2}} \frac{d m}{d t}
\end{gathered}
$$

Applying the radial growth rate to our result gives:

$$
\begin{aligned}
r \frac{d r}{d t} & =\frac{r}{4 \pi \rho_{L} r^{2}} \frac{d m}{d t}=\frac{4 \pi r(S-1) r}{4 \pi \rho_{L} r^{2}}\left[\frac{L}{K T_{\infty}}\left(\frac{L M}{R T_{\infty}}-1\right)+\frac{1}{D \rho_{s}\left(T_{\infty}\right)}\right]^{-1} \\
& =\frac{(S-1)}{\rho_{L}}\left[\frac{L}{K T_{\infty}}\left(\frac{L M}{R T_{\infty}}-1\right)+\frac{1}{D \rho_{s}\left(T_{\infty}\right)}\right]^{-1}
\end{aligned}
$$

Using $\rho_{s}=\frac{P_{s} M}{R T}$ from A.1, we get the Mason Equation for radial condensation growth:

$$
r \frac{d r}{d t}=\frac{(S-1)}{\left[\frac{L \rho_{L}}{K T_{\infty}}\left(\frac{L M}{R T_{\infty}}-1\right)+\frac{R T \rho_{L}}{D M P_{s}\left(T_{\infty}\right)}\right]}
$$




\section{Equilibrium Vapor Mass Concentration Approximation}

Saturation density is a function of temperature. From A.3, the combination of the saturation density and Clausius-Clapeyron equations is:

$$
\frac{d \rho_{s}}{\rho_{s}}=\frac{L M}{R} \frac{d T}{T^{2}}-\frac{d T}{T}
$$

Integrating both sides for a temperature change from $T_{0}$ to $T$ gives:

$$
\begin{gathered}
\int_{\rho_{s}\left(T_{0}\right)}^{\rho_{s}(T)} \frac{\mathrm{d} \rho_{s}}{\rho_{s}}=\frac{L M}{R} \int_{T_{0}}^{T} \frac{\mathrm{d} T}{T^{2}}-\int_{T_{0}}^{T} \frac{\mathrm{d} T}{T} \\
\ln \left(\rho_{s}(T)\right)-\ln \left(\rho_{s}\left(T_{0}\right)\right)=\frac{L M}{R}\left(-\frac{1}{T}+\frac{1}{T_{0}}\right)-\left(\ln (T)-\ln \left(T_{0}\right)\right) \\
\ln \left(\frac{\rho_{s}(T)}{\rho_{s}\left(T_{0}\right)}\right)=\frac{L M}{R T T_{0}}\left(T-T_{0}\right)-\ln \left(\frac{T}{T_{0}}\right)
\end{gathered}
$$

Assuming a small temperature variation, (i.e., $T \approx T_{0}$ ),

$$
\ln \left(\frac{\rho_{s}(T)}{\rho_{s}\left(T_{0}\right)}\right)=\frac{L M}{R T T_{0}}\left(T-T_{0}\right)-\ln \left(1+\frac{T-T_{0}}{T_{0}}\right)
$$

By the Mercator Series for $|x|<1$, we can approximate $\ln (1+x)=x-\frac{x^{2}}{2}+\cdots \approx x$.

This approximation gives:

$$
\begin{gathered}
\ln \left(\frac{\rho_{s}(T)}{\rho_{s}\left(T_{0}\right)}\right)=\frac{L M}{R T T_{0}}\left(T-T_{0}\right)-\frac{T-T_{0}}{T_{0}}=\cdots=\frac{L M-R T_{0}}{R T_{0}^{2}}\left(T-T_{0}\right) \\
\frac{\rho_{s}(T)}{\rho_{s}\left(T_{0}\right)}=\operatorname{Exp}\left[\frac{L M-R T_{0}}{R T_{0}^{2}}\left(T-T_{0}\right)\right] \approx 1+\frac{L M-R T_{0}}{R T_{0}^{2}}\left(T-T_{0}\right)
\end{gathered}
$$

Thus, 


$$
\rho_{s}(T)=\rho_{s}\left(T_{0}\right)+\underbrace{\rho_{s}\left(T_{0}\right)\left(\frac{L M-R T_{0}}{R T_{0}^{2}}\right)}_{\equiv S}\left(T-T_{0}\right)=\rho_{s}\left(T_{0}\right)+S\left(T-T_{0}\right)
$$

\section{General Solution for Single Species Aerosol Growth by Condensation}

The evolution of an aerosol growing purely by condensation processes may be expressed by:

$$
\frac{\partial}{\partial t} n(v, t)=\frac{\partial}{\partial v}[I(v, t) n(v, t)]
$$

where $n(v, t)$ is the number density function of particles of mass $v$ at time $t, I(v, t)$ is the mass condensation rate, and with initial condition:

$$
n(v, 0)=n_{0}(v)
$$

For a mass condensation rate of the form:

$$
I(v, t)=h(t) f(v)
$$

where $h(t)$ and $f(v)$ are some prescribed functions, exact analytical solutions may be obtained by the moment of characteristics (see Williams (1983), Brock (1983), Williams and Loyalka (1991)). Substitution of the condensation rate into the reduced GDE, multiplying, and rearranging, one gets:

$$
\frac{\partial}{\partial t}[f(v) n(v, t)]+h(t) f(v) \frac{\partial}{\partial v}[f(v) n(v, t)]=0
$$

where:

$$
I(v, t)=h(t) f(v)=\frac{d v}{d t}
$$


defines the characteristic. After separation of variables, one can integrate along the characteristic. This process yields:

$$
\begin{gathered}
\int_{v(0)}^{v} \frac{\mathrm{d} v^{\prime}}{f\left(v^{\prime}\right)}=\int_{0}^{t} h(t) \mathrm{d} t \\
F(v(0))=F(v)-H(t)+H(0) \\
v(0)=F^{-1}[F(v)-H(t)+H(0)]
\end{gathered}
$$

where $F$ and $H$ are the antiderivatives of the functions $f$ and $h$, respectively; and $F^{-1}$ is the inverse of the function $F$. Along the characteristic curve, we also have:

$$
\frac{d}{d t}[f(v) n(v, t)]=0
$$

Integration along the curve, we get:

$$
\begin{gathered}
\int_{v(0)}^{v} \mathrm{~d}\left(f\left(v^{\prime}\right) n\left(v^{\prime}, t\right)\right)=f(v) n(v, t)-f(v(0)) n(v(0), t)=0 \\
n(v, t)=\frac{f(v(0)) n(v(0), t)}{f(v)}=\frac{f(v(0)) n_{0}(v)}{f(v)}
\end{gathered}
$$




\section{VITA}

Isaac Saldivar was born in Caborca, Sonora, in 1989, but calls Arizona home. He received his Bachelors of Science degree in Physics with a minor in Mathematics from Arizona State University and Barrett, The Honors College in May of 2012. He went on to receive his Masters in Nuclear Engineering from the Nuclear Science and Engineering Institute at the University of Missouri-Columbia in December 2013 and graduated with a $\mathrm{PhD}$ in Nuclear Engineering from the Nuclear Science and Engineering Institute at the University of Missouri-Columbia in May 2018. Upon completion of his doctorate, Isaac will begin employment at Arizona Public Service as a Legacy Engineer in the Nuclear Fuels Management group at Palo Verde Nuclear Generating Station. 